\title{
MODELOS DE POPULAÇÖES FINITAS E MÁXIMA VEROSSIMILHANÇA RESTRITA NO PROBLEMA DE ESTIMATIVAS NEGATIVAS PARA COMPONENTES DE VARIANNCIA
}

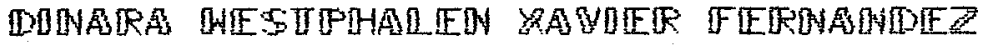

Orientador: Prof. Dr. Dëcio Barbin

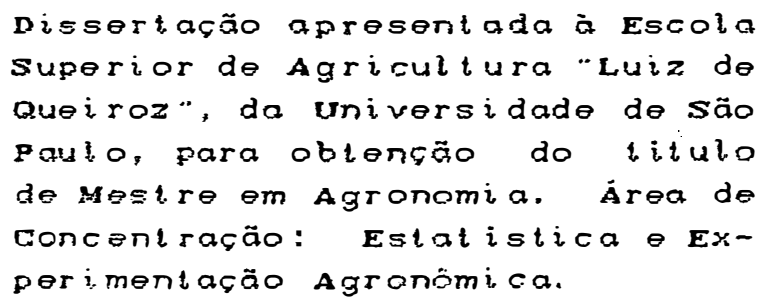

$P$ I R A C I C A B A

Estado de Săo Paulo - Brasil

Maio - 1931 
Ficha catalográfica preparada pela Seção de Livros da Divisão de Biblioteca e Documentação - PCAP/USP

Fernandez, Dinara Westphalen Xavier

F363m Modelos de populações finitas e mâxima verossimi lhança restrita no problema de estimativas negativas para componentes de variância, Piracicaba, 1991, 118P, ilus,

Diss, (Mestre) - ESALQ

Bibliografia,

1. Anâlise de variância - Componente 2, Estatística mațemática aplicada 3. Estimativa negativa 4. Método da máxima verossimilhança restrita 5, Modelo matemático 6. População finita - Modelo matemático I, Escola Supe rior de Agricultura "Luiz de Queiroz", Piracicaba

CDD $\quad 519,535$ 


\section{MODELOS DE POPULACOES FINITAS E MAXIMA VEROSSIMILHANGA RESTRITA NO PROBLEMA DE ESTIMATIVAS NEGATIVAS PARA COMPONENTES DE VARIANCIA}

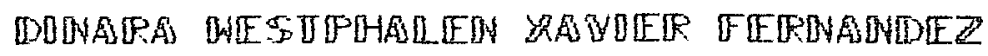

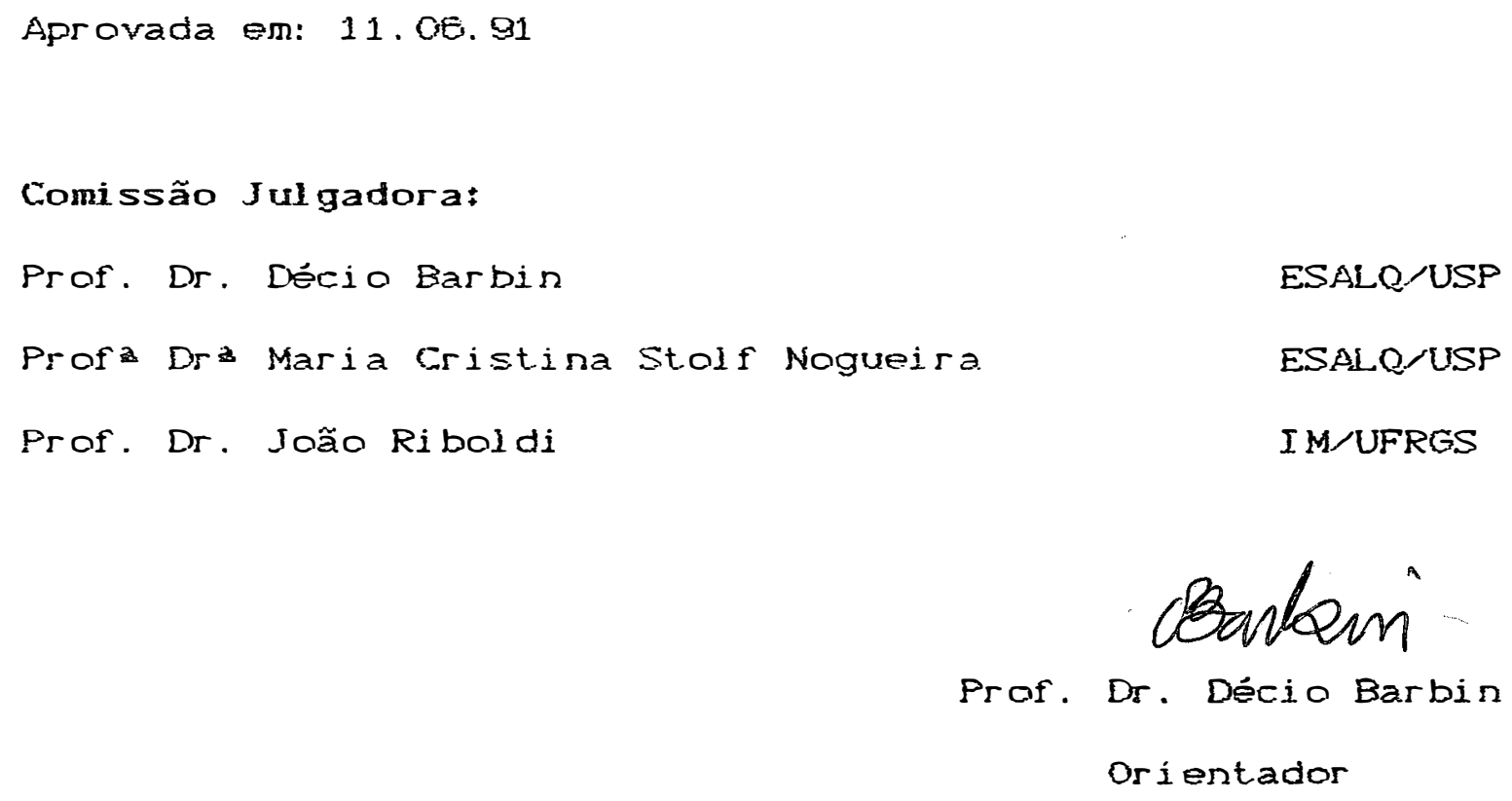

Prof. Dr. Décio Barbin Orientador 
Ao Prof. Dr. Décio Barbin, Chefe do Departamento de Matemática e Estatística da ESALQ/USP, mestre amigo, pela dedicacăo, permanente estimulo, e valiosa orientacào.

Aos docentes do Gurso de Pós-Graduacão em Estatistica e Experimentacão Agronomica da ESALQ USP, pelo conhecimento experiência transmitidos, especialmente, ao Prof. Dr. Humberto de Campos, pela receptividade.

As Professoras Dra Clarice Garcia Borges Demér trio e Dra Maria Cristina Stolf Nogueira, pelas sugestôes.

Ao Prof. Dr. Antonio Francisco Iomma, pela atencลัด.

Ao Prof. Dr. Joäo Riboldi, Chefe do Departamento de Estatistica da UFRGS, pelo constante incentivo, eficiente colaboração e amizade.

A Direcão do Instituto de Matemática da UFRGS - aos colegas do Departamento de Estatística, pela confianca depositada e, em especial, aos Professores Luiz Glock e Silvio Possoli, pelo apoio amizade.

A CAPES, pela concessão da bolsa de estudos através do PICD.

Aos funcionários do Departamento de Matemática e Estatistica da ESALQ USP e do Instituto de Matemática da UFRGS, pel a cooperacão e manifestacão de solidariedade. 
Aos colegas do Curso de Pós-Graduacão, pela convi vència saudável, particularmente à Liciana Vaz de Arruda Silveira, El vira Maria Alves de Freitas Barbosa e Silvio Sandoval, pela amizade e companheirismo que me ajudaram a crescer com a experiência de nossas interacóos, e ao João Maurício Motta, pelos ensinamentas o contrituicão no desenvolvimento do mádulo de MVR para o programa SoC.

A Rejane Alves, pela paciência na correcâo da digitacăo deste trabal ho.

A Maria Izalina Ferreira Alves, pela excelente revisão da redacão, despreendimento, e presenca amiga.

A Rosa Maria Alves, pelo compartilhar espacos - multiplicar amizade, pela cooperacăo apoio irrestritos.

A Diva Ferreira Alves, pelo calor humano enriqueci mento pessoal.

A todos os amigos que sabom a importancia de uma palava, um sorriso, um gesto de carinho.

A Deus por ter me dado perseveranca, vontade e fe. 


\section{SUMARIO}

Página

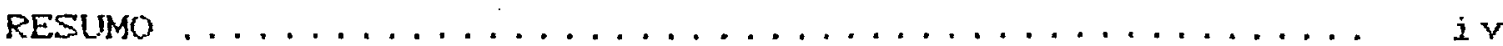

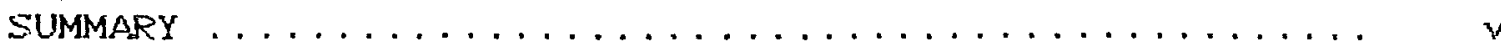

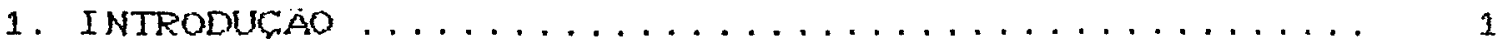

2. REVISAO DE LITERATURA ..................

2.1. Métodos de Estimaräo Para Componentes de Variància $\ldots \ldots \ldots \ldots \ldots \ldots \ldots \ldots \ldots \ldots \ldots \ldots \ldots \ldots \ldots \ldots \ldots$

2.1.1. Método da análise de variància ...... 5

2.1.2. Métodos 1, 2 e de Henderson ........ B

2.1.3. Método da máxima verossimilhanqa CMV . 7

2.1.4. Método da máxima verossimilhança restrita $(M V R) \ldots \ldots \ldots \ldots \ldots$

2. 1.5. MINQUE MI VQUE ............... 19

2.2. Alguns Estudos Comparativos Entre os Métodos. 20

2.3. OProblema de Estimativas Negativas ........ 23

3. METODO .......................... 28

3.1. Estimaçăo do Componentes de Variância em Modelos Com Populacăo Finita ............. 28

3.1.1. Introducăo ................ 28

3.1.2. Modelo Geral ................ 30

3. 1. 3. Modelos Hierárquicos ............ 34

3.1.4. Modelo de classificacäo cruzada ...... 45

3.1.4.1. Glassificaqäo cruzada dupla .. 45

3.1.4.2. Classificacăo cruzada geral .. 48 
Página

3.1.5. Combinacăo de classificacões hierárquica e cruzada ................ so

3.1.6. Modelos mistos .............. 54

3.2. Estimaçăo de Máxima Verossimilhanca Restrita Para Componentes de Variância em Modelos Mis-

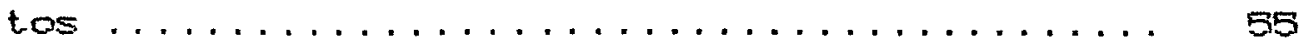

3.2.1. Introducăo ................. 55

3. 2. 2. o Modelo ................... 57

3.2. 3. os Estimadores ............... 65

3. 2. 4. Procedi mento de Călculo ............ 74

3.2. 4.1. A transformacăo $W \ldots \ldots \ldots 75$

3.2. 4.2. Algoritmos ............ so

3.2. 4. 3. Estimą̧ăo dos Efeitos Fixos .. 85

4. ILUSTRACAO DOS METODOS E DISCUSSAO . . . . . . . . . .

4.1. Exemplo $1 \ldots \ldots \ldots \ldots \ldots$. . . . . . . . .

4.2. Exemplo z ..................... 89

4.3. Exemplo $3 \ldots \ldots \ldots \ldots \ldots \ldots$

4.4. Discussăo ......................

5. CONCLUSOES .......................... 98

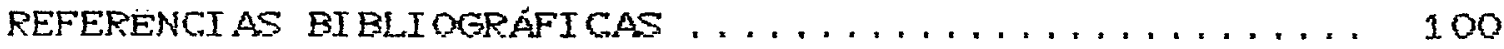

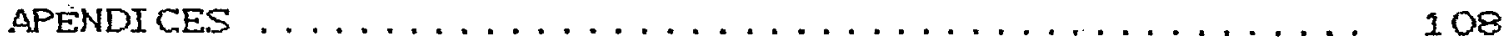


vii.

\title{
MODELOS DE POPULAÇÖES FINITAS E MAXIMA VEROSSIMILHANCA RESTRITA NO PROBLEMA DE ESTIMATIVAS NEGATIVAS PARA COMPONENTES DE VARIANCIA
}

\author{
Autora: DINARA WESTPHALEN XAVTER FERNANDEZ \\ Orientador: PROF. DR. DÉCIO BARBTN
}

RESUMO

Discutiram-se dois procedimentos com o intuito de contornar o problema de estimativas negativas para componentes de variància.

Constatou-se que o procedimento de adotar o modelo supondo Populacous Finitas funciona satisfatoriamente para al gumas situacôes. Já o procedimento da Máxima Verossimilhanca Restrita exige que sejam desenvolvidos novos algoritmos que răo apresentem dificuldades de oálculo. 


\title{
FINITE POPULATION MODEL AND RESTRICTED MAXIMUM \\ LIKELIHOOD PROCEDURE ON PROBLEM OF THE NEGATIVES \\ ESTIMATES IN VARIANCE COMPONENTES
}

\author{
Author: DINARA WESTPHALEN XAVIER FERNANDEZ \\ Adviser: DÉCIO BARBIN
}

\section{SUMMARY}

Two statistical procedures were discussed in order to solve the problem of negative estimates in variance components.

When finite population model is adopted it worked out fine for some special situations. However the Restricted Maximum Likeli hood Procedure showed the necessity of new algorithms developments free of calculations difficulties. 


\title{
1. INTRODUCAOA
}

\begin{abstract}
A Análise de Variância, comumente utilizada para testar a significància de efeitos de tratamentos, é uma ferramenta que também permite estimar os componentes de variäncia, isto é, as variâncias associadas aos efeitos aleatórios do modelo. Esse método é conhecido como Método da Análise de Variância para estimar componentes de variância ou Método 1 de Henderson e consiste em igualar os quadrados médios pbservados COM com seus valores esperados $[E C O M]$
\end{abstract}

Os estimadores dos componentes de variância obtidas pelo Método da Análise de Variảncia não raramente nos conduzem a estimativas negativas. Isto pode ocorrer em qualquer modelo (misto ou aleatório) e em qualquer classificaçăo chierárquica ou cruzada), o que é uma situacão bastante constrangedora, uma vez que os paràmetros considerados são essencial mente näo negati vos.

O objetivo do presento trabalho é discutir dois procedimentas que, conforme a literatura, visan remover as estimativas negativas dos componentes de variância e, assim, contribuir para a solucăo deste problema. 
- primeiro procedimento foi sugerido por SEARLE 8* FAWCET (1970) E consiste em supor o modelo em termos de populaçóes finitas, em vez de populacóes infinitas.

O segundo procedi mento é da Máxima Verassimilhanca Restrita. 


\section{REVISAO DE LITERATURA}

Ao se realizar uma Análise de Variância, além de testar a existência de diferencas entre médias de tratamentos, pode-se também estimar os componentes de variância.

Ds componentes de variância são as variâncias associadas aos éeitos aleatários de um modelo matemático.

Num experimento, quando são considerados todos as niveis de um fator (tratamentos, temos um efeito fixo. Se apenas uma amostra de níveis do fator é considerada, temos um efeito aleatório.

No modelo

$$
y_{i j}=\mu+\alpha_{i}+e_{i j}
$$

onde:

$y_{i j}$ é a j-ésima observacâo do i-ésimo tratamento, $\mu$ é a média geral,

$\alpha_{i}$ é o efeito aleatório do i-ésimo tratamento,

$e_{i j}$ é o erro correspondente a Cij-ésima observacão com

$$
\begin{array}{ll}
E\left(\alpha_{i}\right)=0 & \operatorname{var}\left(\alpha_{i}\right)=\alpha_{\alpha}^{2} \\
E\left(\varepsilon_{i j}\right)=0 & \operatorname{var}\left(\theta_{i j}\right)=\sigma_{\theta}^{2}
\end{array}
$$

$E\left(\alpha_{i} \alpha_{k}\right)=0, i \neq k, \quad E\left(\alpha_{i} \theta_{i-j}\right)=0, E\left(\theta_{i j} \theta_{i \cdot j}\right)=0$,

$\forall i, i, j$, temos

$$
\operatorname{Var}\left(y_{i j}\right)=\alpha_{\alpha}^{2}+\alpha_{\theta}^{2}
$$

que säo os componentes de variância. 
Os componentes de variancia têm grande aplicacăo em experimentos de melhoramento animal e vegetal para a obtencâo dos índices de repetibilidade, coeficiente de herdabilidade, etc. Uma outra aplicacão dos componentes de variância no campo da genética é quando estamos interessados om decompor a variância de um caráter, medida rum ser vivo, em componentes de variància genética e ambiental. Dada a importancia dos componentes de variància, existe crescente preocupacăo no sentido de melhor estimá-los, obtendo, desta forma, estimativas mais precisas.

\subsection{Métodos de Estimacăo Para Componentes de Variância}

Na literatura, encontram-se descritos vários mëtodos de estimacão para comporentes de variância. Meste capitulo, é apresentada uma revisão dos principais métodos.

CÍl (1982) compilou os seguintes métodos de estimacăo de componentes de variância: momentos ou Análise de Variância; MINQUE CMinimum Norm Quadratic Unbiased Estimator?, MI VQUE CMinimum Variance Quadratic Unbiased Estimators, MV CMáxima Verossimilhanca) e MVR CMáxima VerossimiIhanca Restrital, acompanhados de algoritmos para a resolução numérica de problemas de estimaçăo.

VALERIO FILHO (1983) descreveu os métodos de HENDERSON (1953) para determinacăo dos componentes de variància de dados năo balanceados, visando facilitar suas aplicacöes práticas. Foram estudados o Método da Análise de Yariância CMétodo 1 de Henderson, o Método do Ajuste para o 
vício nos modelos mistos (Método 2 de Henderson) o Método de ajustar constantes (Método 3 de Henderson).

\subsubsection{Método da análise de variância}

Dentre os métodos disponiveis para estimar componentes de variància, talvez o mais utilizado e estudado seja o da Análise de Variância.

Como as esperancas dos quadrados médios são funcöes lineares dos componentes de variância, podemos encontrar estimadores para esses componentes a partir do sistema de equaçós formado i gual ando-se os quadrados médios COMD com seus valores esperados [ECOM]].

Quando empregado em dados balanceados (modelo aleatório ou misto) e em dados não-balanceados cmodelo aleatório) o método da ANOVA nos fornece estimadores năo tendenciosos, de variância minima entre uma classe de estimadores quadráticos näo tendenciosos. No entanto, podem resultar estimativas negativas para os componentes de variância, ainda que, por definicâo, estes sejam positivos. Isto pode ocorrer em qualquer modelo (misto ou aleatáriol e em qualquer classificacăo (nierárquica ou cruzada).

Este método, quando aplicado a dados năo balanceados, é equivalente ao Método 1 de Henderson. Se os dados säo năo balanceados e o modelo é misto, os esti madores obtidos pelo método da ANOVA săo tendenciosos CSEARLE, $1971 \mathrm{a} ; 1971 \mathrm{bs}$. 


\subsubsection{Métodos $1,2 \ominus 3$ de Henderson}

HENDERSON (1953) desenval veu très métodos que basicamente são o método dos momentos com pequenas modificacòes impostas pela estrutura dos dados, isto é, pelo seu não bal anceamento.

o Método 1 de Henderson deve ser utilizado apenas para modelos aleatórios é praticamente uma generalizaçăo do método usual da Análise de Variancia para dados bal anceados.

- Método 2 de Henderson é usado para modelos mistos desde que năo existam interacõos e qualquer tipo de hierarquizacăo entre efeitos fixos e aleatórios. Em sintese, este método consiste em inicialmente estimarmos os efeitos fixos do modelo; os dados são então ajustados por esses estimadores e os componentes de variância são estimados dos dados assim ajustados. Usando esse procedimento, realmente produziremos estimadores năo viciados, mas em contrapartida, o procedimento năo é definido de maneira única, pois envol ve uma inversa generalizada.

O Método 3 de Henderson, baseado no método de ajustamento de constantes Cdenominacão moti vada pelo fato de que algumas vezes os efeitos fixos, em modelos de efeitos fixos, săo chamados de constantesl, é apropriado para modelos mistos e produz estimativas que säo näo tendenciosas, solucionando, portanto, o problema de tendenciosidado encontrado no método da ANovA, quando o modelo é misto e os dados não 
balanceados. Além disso, supre a limitacão do Método a de Henderson para modelos que contèm interacão entre efeito fixo aleatório. Para dados balanceados, é identico ao Método da ANOVA, SEARLE (1968), possuindo como inconveniente o fato de não ser unicamente definido e envolver, na maioria das vezes, matrizes de grandes dimensöes.

\subsubsection{Método da máxima verossimilhanca CMV}

Os estimadores de Máxima Verossimilhança usados, talvez pela primeira vez, por HERBACH (1959), para modelos aleatórios simples em dados balanceados, säo rão negati vos, embora sejam truncados. Não levam em consideracăo a perda dos graus de liberdade devido à estimacão dos efeitos fixos e, na maior parte das vezes, são não tendenciosos. Se os dados săo bal anceados, as soluçóes das equacões de MY, nos modelos mistos e aleatórios, para componentes de variầcia, são quase as mesmas dos estimadores obtidos pelo método da ANOVA, diferindo nos divisores de certos quadrados médios, resultantes de algumas solucöes serem tendenciosas CSEARLE, 1971 a).

o procedimento de MV para estimacão dos componentes de variància tem algumas caracteristicas atraentes. Os estimadores de MV säo funcöes de cada estatística suficiente, săo consistentes, assintoticamente normais e eficientes [no sentido descrito por MILLER (1973)]. Certas deficièncias de vários outros métodos näo ocorrem na MV. Em 
particular, o procedimento de MV é "sempre" bem definido, exatamente para muitas generalizacöes usuais dos modelos ordinários de ANOVA e, com MV, restriçöes de não negati vidade de componentes de variància ou outras restricôes do espaco dos paràmetros não causam dificuldades conceituais. Além disso, os estimadores de MV e a matriz de informacăo para uma dada parametrizacão do modelo podem ser prontamente obtidas delas para qualguer outra parametrizacăo.

HAYMAN (1960) compara a estimacão de MV para componentes de variància em experimentos genéticos com a análise de minimos quadrados de MATHER (1949). o primeiro é um método iterativo exige dois ciclos de cálculo, enquanto que o segundo só faz um ciclo. Este trabal ho extra compensado pela capacidade do primeiro método em tratar uma ampla elasse de magnitude de variancias. O segundo método super-estima os erros derivados dos componentes de variancia pequenos e fornece correspondentemente estimativas incorretas desses componentes. Uma situacăo inversa é considerada para estimativas de componentes de variancia grandes. O método de NELDER (1953) fornece as mesmas estimatives dos componentes de variância que o método dos minimos quadrados, mas suas estimativas dos erros concordam com as estimativas da MV, quando as obser vacões são normalmente distribuidas.

HARTLEY \& RAO (1967) desenvalvem um procedimento de MV para estimacăo de constantes desconhecidas e variàncias, inoluindo o modelo geral misto de análise variância, envolvendo fatores fixos e aleatórios e interaçóes. 0 
método se aplica a todos os casos onde a matriz do delineamento satisfaz certas condicóes de estimabilidade dos paràmetros. Săo discutidas a consistência e a fífiência assintótica dos estimadores deduzidos as testes de hipótese regióos de confiança.

$$
\text { KLOTZ \& PUTTER (1989) definem } \theta \text { deduzem os }
$$

estimadores de MV para o caso geral p-variado. Apresentam os métodos de cálculo e as fórmulas explicitas para o caso bi-vari ado.

SEARLE (1970) apresenta uma expressão geral para os elementos da matriz de informacão dos estimadores de MV dos componentes de variância, deduzida para dados não balanceados de qual quer model o misto. Esta expressão geral é utilizada para obter resultados explicitos em modelo aleatório de classificacão hierárquica dupla.

Existem muitos algoritmos iterativos que podem ser utilizados para calcular os estimadores de MV. os cálculos para cada iteracão desses algoritmos estão associados com cálculos para estimacão de efeitos fixos a aleatórios para valores dados dos componentes de variância.

SAHAI \& THOMPSON (1973) apresentaram um método analítico simples para obter os estimadores de MV de um modelo aleatório balanceado num espaço restrito de parâmetros.

HEMMERLE \& HARTLEY (1973) desenvolveram a transformaçäo $W$, matriz de transformacão, aplicada para o modelo misto de análise de variância para calcular estimadores de MV dos componentes de variância e paràmetros fixos. 
10.

Esta transformaçăo năo somente elimina a necessidade de explicitar o cálculo da inversa da matriz $H^{-1}, \Omega \times n$, mas permite manipular os cálculos iterativos de modo que não dependam de $n$ Cnúmero de observacão) em nenhum passo. Embora nầo pertenca a um método numérico particular, a transformaçăo w E implementada com o algoritmo de Newton-Raphson modificado, no qual os componentes de variância säo restritos a serem não-negati vos.

MILLER (1973) desenvolveu uma teoria assintotica satisfatória para estimadores de MV para componentes de variància.

JENNRICH \& SAMPSON (1976) discutem três algoritmos gerais para estimar a média componentes de variância pelo método da MV em modelos mistos de análise de variância. os algoritmos em discussão são o algoritmo de Newton-Raphson, o algoritmo dos escores de Fisher e o algoritmo de Hemmerle Hartley. São dadas deducôes dos dois primeiros - uma apresentacão unificada para os trôs, fazendo algumas comparacŏes teóricas e práticas possiveis. Para enriquecer os resultados de aplicacão, os très algoritmos são apresentados numa sequência de cinco problemas. A transformacão de Hemmerle Hartley e utilizada do comero ao fim para reduzir os trabalhosos cálculos associados com algoritmos de MV para componentes de variància. Os algoritmos fornecem um procedimento unificado para estimacão e teste no modelo geral de análise de variância. 
HARVILLE (1977) apresenta uma excelente revisăo sobre procedimentos de MV para estimacăo de componentes de variància e problemas relacionados, enfatizando aspectos de călculo. Os tópicos abordados incluem a situacão corrente da teoria da MV aplicada na est-imarào de componentes de variância; a relaçăo entre a estimacão de MV para componentes de variância e a estimacăo de efeitos aleatórios e fixos nos modelos; a exploracão dessa relacão para propósitos de cálculo e aproximacăo; o uso' de algoritmos numéricos para cálculo dos estimadores de MY para componentes de variància; o uso de MV como um veiculo para relacionar os vărios métodos que têm sido propostos para estimar componentes de variância; e uma discussăo da direcão para pesquisas futuras.

Todo esforco feito para incentivar o ponto de vista de que o problema para estimacăo dos componentes de yariantia pode ser visto romo um caso especial do problema do modelo linear geral, no qual os elementos da matriz de covariâncias săo funcões conhecidas de un vetor de parâmetros a ser estimado.

Recentes desenvol vimentos prometem incrementar grandemente a popularidade da MV como técnica para estimar componentes de variancia. $O$ interese por estimadores de MV pode ser exaltado pela recente descoberta de OLSEN, SEELY \& BIRKES (1976) de que, pelo menos para delineamentos năo balanceados, existem estimadores na classe dos estimadores quadráticos năo-viesados localmente melhores e de translacão invariante que tèm variância uniformemente menor que os es- 
timadores de Henderson. Esses estimadores localmente melhores estão proximamente relacionados aos estimadores de MV CHOCKING \& KUTNER, 1975.

Apesar dessas propriedades, os estimadores de MV näo eram muito utilizados na prática. Existiam algumas razôes para sua negligencia; a mais importante delas $\bar{e}$ que, exceto para conjuntos relati vamente simples, o cálculo dos estimadores de MV exigem solucôes numéricas de problemas restritos de otimizacão não-lineares. Antes do advento dos computadores eletrónicos, essa exigência apresentava uma barreira virtualmente intransponivel para uma ampla divulgacâo e utilizacão. Mesmo depois que os computadores se tornaram de uso comum, a MV năo passou a ser muito utilizada para estimar componentes de variância, porque os algoritmos efetivos para cálculo năo estavam prontamente disponiveis para utilizacăo. Recentemente, vărios trabalhos têm contribuido no sentido de oferecer procedimentos práticos para a estimafăo de componentes de variância por MV em mujtas situacôes onde antes era impossivel.

Dois outros problemas que têm impedido que os estimadores de MV para componentes de variancia se tornem populares săo os seguintes: 13 os estimadores de MV para. componentes de variância não consideram a perda dos graus de liberdade resultantes da estimacão dos efeitos fixos do modelo; (2) os estimadores de MV săo deduzidos sob a suposicăo de uma particular forma paramétrica, geralmente Normal, para a distribuicăo do vetor de dados. 
O primeiro desses problemas pode de fato ser eliminado por PATIERSON \& THOMPSON $(1971)$ através do procedimento de Máxima Verossimilhanca Restrita (MVR). Com respeito ao segundo problema, HARVILLE (1977b) most.ra que os estimadores de $M V$ deduzidos com base na normalidade podem ser justamente adequados quando a forma da distribuicão não é especificada.

SHALLOW \& MONAHAN (1984), utilizando simulacão por Monte Carlo, comparam os estimadores de componentes de variància obtidos pelos métodos de ANOVA, MIVQUE, MV O MVR, para um modelo aleatório de classificacăo simples com dados năo balanceados. Os estimadores săo comparados através do "viés" e erro quadrático médio. Os resultados indicam que os estimadores de ANOVA sä́ bons, exceto para dados seriamente năo bal anceados, quando $\alpha_{a}^{2} \alpha^{2}<0.5$, onde $\sigma_{a}^{2}$ o $\sigma_{0}^{2}$ săo componentes de variância entre dentro, respectivamente.

\subsubsection{Método da máxima verossimilhanca restrita (MVR)}

Com a intencão de eliminar as deficiências apresentadas pelo método da MV, foram desenvolvidos os estimadores de MVR, cuja idéia básica é obter os estimadores de MV para os componentes de variância eliminando os efeitos fixos. Uma comparacão muito simples dos dois métodos é a seguinte: 
Dado o modelo

$$
\begin{aligned}
y_{\mathrm{i}} & =\mu+{ }_{\mathrm{i}}, \\
\mathrm{i} & =1, \ldots, \mathrm{n}
\end{aligned}
$$

$\odot$

$$
\operatorname{var}(e)=1 \sigma_{e}^{2}
$$

o estimador de MV para $o_{\theta}^{2}$

$$
\left.\sum_{i} c_{i}-\bar{y}\right)^{2} r_{n}
$$

e de MVR é

$$
\left.\Sigma c y_{i}-\bar{y} \cdot\right)^{2} / n-1
$$

com esperancas $(n-1) \alpha_{\theta}^{2}, e d_{\theta}^{2}$, respecti vament.

Historicamente, a estimacăo do componentes de variância e covariànoia por MVR iniciou sendo desenvolvida por muitos pesquisadores para especificos modelos de ANOVA balanceados, inclundo ANDERSON \& BANGROFT C19SE) O RUSSEL \& BRADLEY (19B8) foi estendida para todo modelo balanceado de ANOVA por THOMPSON (1962). Mais tarde foi colocado em sua forma geral para modelos näo halanceados por PATIERSON \& THOMPSOM (1971). Uma extensăo para modelos multivariados para casos especiais de matriz de delineamento igual para todos os tratamentos o todos os tratamentos medidos em todos os individuos foi feita por THOMPSON (1973). Esta restricấo foi removida por SGHAEFFER et alii (1978) para o caso de covariảncia residual nula entre tratamentos, como seria a situacăo para medidas de diferentes tratamentos em diferentes animais.

PATIERSON \& THOMPSON (1971) dividiram a funcão de verossimilhanca, sob condicão de normalidade, em duas 
partes, de modo que a maximizacäo da parte livre dos efeitos fixos fornecesse os estimadores de MV para os componentes de variància e a outra fornecesse os estimadores para os efeitos $f i x o s$.

Um desenvolvimento para dados não bal anceados considerando dados balanceados como caso especial, é dado por CORBEIL \& SEARLE (1976b). Para dados balanceados, os estimadores de MVR são identicos aos estimadores de ANOVA, mas se os dados sâo näo balanceados, estes não sâo os mesmos, conforme CORBEIL \& SEARLE (1976a, $1976 \mathrm{~b})$.

GIANOLA \& FERNANDO (1986) salientam que tanto os estimadores de MV como os de MVR năo são afetados pela selecão dos dados. HENDERSON (1986) acrescenta que esses estimadores são capazes de produzir variancias amostrais e erros quadraticos médios menores que outros métodos que fornecem estimadores não tendenciosos. Estas últimas propriedades também são apresentadas pelos estimadores de MIVQUE.

Embora apresente ainda outras propriedades altamente desejáveis, tais como produzir estimadores únicos que näo dependem dos primeiros utilizados, logo que surgiu, - método da MVR era pouco utilizado na prática, devido a suas exigências de cálculo. Mais recentemente, vários algoritmos têm sido desenvolvidos e podem ser vistos como candidatos para calcular estimadores de MV ou de MVR.

HARVILLE (1977) revisou o desenvolvimento e muitos dos problemas associados com MV a MVR. Ele apresenta um algoritmo que consiste na iteracăo das equacóos de MIVQUE 
até sua convergencia, desde que a convergencia ocorra dentro do espaco dos parâmetros.

MEYER (1983) apresentou un algoritmo para estrimacão simultânea dos componentes de variância e covariància, baseado no Método dos escores de FISHER CMSCD. Este procedimento adapta a covariância ambiental entre tratamentos o também permite que diferentes números de tratamentos sejam medidos em diferentes individuos.

HENDERSON (1984a, 1984b e 1986) tem defendido um algoritmo de maximizacão da esperanra CEM pela sua comparativa simplicidade de cálculo cpor iteracãol o por sua propriedade de forcar estimativas que caiam dentro do espaco de paràmetros permitido. Utilizando pequenos exemplos, HENDERSON (1984a) ilustra algoritmos de MVR para uma variedade de situacões, incluindo modelos com efeitos genéticos aditivos e dominantes, efeitos diretos e maternais, e um modelo de classificação tríplice.

MEYER (1985) desenval veu a MVR de forma análoga ao algoritmo de ANDERSON (1973). O procedimento envol ve uma transformacâo numa escala canônica reduzindo uma análise a q-variáveis para q correspondentes análises univariadas. A convergência foi rápida, mas não existe garantia de que as estimativas da matriz de variâncias e covariâncias irấo cair no espaco dos parâmetros. O autor aponta que na análise de tratamentos altamente corelacionados existe uma grande chance que, devido a amostragem, a estimativa para os pais Cem experimentos genéticos) da matriz de variâncias e co- 
variăncias seja definida não-positiva. A probabilidade de que isso ocorra cresce com o número de variáveis CHILL \& THOMPSON, 1978 .

Um algoritmo foi desenvol vido por MEYER (1986) para acelerar a razão de convergência quando comparada com EM, bem como decrescer o tempo por iteracăo, quando comparado com MSC. Este algoritmo foi denominado Shor Cut CSHCO combina aspectos do algoritmo EM para estimar os "componentes de efeitos aleatórios dentro" com o MSC para estimar os "componentes de efeitos aleatórios entre". O procedimento pode ser utilizado para estimar componentes de; variancia e covarancia num modelo misto multivariado, quando registros são perdidos para alguns tratamentos. Uma desvantagem do SHC é que nâo há garantia de que as estimati vas caiam dentró do espaco dos parâmetros, embora o autor considerasse o processo razoavel mente robusto diante de estimativas fora do espaso dos parâmetros.

Muitos algoritmos tôm sido utilizados para obter estimativas de MVR para os componentes de variância. Exceto para delineamentos balanceados, a iteracão é exigida para solucionar a maximizacão das equacõos, então, dependendo da matriz de incidência, dos valores básicos dos parâmetros e do algoritmo utilizado, a convergôncia pode ou năo estar no espaco dos parâmetros [HENDERSON (1986)].

Enquanto esses algoritmos foram testados para tratamentos simples CHARVILLE, 1977b; DEMPSTER et alii, 19773 e para tratamentos múltiplos com igual informacão em 
18.

todos os tratamentos [THOAPSON (1973), SCHAEFFER et ali (1978), MEYER (1983) ), temos poucos elementos para considerar o procedimento desses algoritmos para tratamentos com informacöes perdidas. Raramente foram testados mais do que dois tratamentos, isto é, MEYER (1986) só apresentou resultados para dois tratamentos.

VALENTE (1988) utilizou a MVR para estimar componentes de variância covariância em tratamentos múltiplos com informacốes perdidas para alguns tratamentos.

HENDERSON (1986) apresentow um algoritmo EM para múltiplos tratamentos e afirmou que ele garante que estimativas de variâncias serão positivas definidas e matrizes de covariâncias serâo definidas positivas. Para isso ser verdadeiro, os valores iniciais devem definir matrizes de variâncias-covariâncias definida positiva e assim permanecer depois de cada iteracão. SCHAEFFER et alii (1986) encontraram este principio quando aplicaram transformacão canônica para conduzir a análise de múltiplos tratamentos.

Alguns autores propuseram o uso de restriços para garantir que todas as estimativas caiam dentro do espaso dos parämetros. Como apontou HARVILLE (1977): "O algoritmo iterativo de Henderson para calcular estimadores de MV para componentes de variância e seus análogos MVR nâo são afetados pelas restricóes no espaço dos parâmetros, com isso, componentes negativos simplesmente nurca são encontrados. Infelizmente, nenhum dos algoritmos modificados discutidos tem esta propriedade." Visto que MSC e reparametriza- 
cöes tais como SHC săo algoritmos modificados, näo garantem estimativas dentro do espaco dos parâmetros. Portanto, precisamos ter o cuidado de fazer ajustes em suas estimativas. A seguis, de HARVILLE (1977): "Quando uma iteracão foi obtida com valores negativos ou próximos de negativo para um ou mais elementos, fazem-se estes elementos iguais a zero e com efeito restringem-na a serem zero nas subsequentes iteracồes. Esta aproximação para o problema não é satisfatória porque pode causar a convergencia para um ponto que não é sempre um máximo global restrito."

\subsubsection{MINQUE $\odot$ MVQUE}

Os estimadores MINQUE CMinimum Norm Quadratio Unbiased Estimator são os estimadores quadráticos não tendenciosos de minima norma os estimadores MIVouE CMinimum Variance Quadratic Unbiased Estimator sầ os estimadoros quadráticos não tendenciosos de minima variância.

Estes métodos de estimacão desenvolvidos por RAO (1970, 1971a, 1971b, 1972) satisfazem a algumas propriedades, tais como: invariância quanto à translacão de efeitos fixos, não tendenciosidade, mínima norma da diferença entre um estimador e seu verdadeiro valor, e minima variancia do estimador, sendo estas duas últimas propriedades que os tornam distintos.

Tanto o MINQUE como o MIVQUE também podem produzir estimativas negativas para os componentes de variância 
20 .

e, em certas situaböes săo equivalentes, de acordo com RAo (1970) e com HARVILLE (1977), quando aplicados a dados normalmente distribuidos, uma vez que estes têm coeficiente de curtose zero. HARVILLE (1977), ainda argumenta que o método MINQUE, considerando-se certos aspectos, é idéntico aos estimadores de MVR.

\subsection{Alguns Estudos Comparativos Entre os Métodos}

Para comparar os vários estimadores de componentes de variância tem sido utilizado o erro quadrático médio CEOM como principal medida de eficácia.

KLOTZ et ali (1989) estudaram o erro quadrático médio de vários estimadores no modelo inteiramente ao acaso, bal anceado.

Low (1969), utilizando o modelo de blocos incompletos balanceados, estudou o problema da falta de segurança para os estimadores não tendenciosos de variância minima obtidos pelos mótodos usuais, quando a distribuicão näo é completa e mostrou que as estatisticas suficientes são alcancadas através de tabelas de análise de variancia comuns. Também apresentou a transformação de três estatisticas suficientes para estimadores näo tendenciosos de quatro parâmetros a mais dois estimadores näo tendenciosos para zero, e construiu outros estimadores, obtendo e comparando variâncias e estudando a admissibilidade inadmissibilidade dos estimadores. 
BASSON (1970) descreveu um método para obtencão de variâncias das estimativas dos Métodos 1,2 e de Henderson num modelo em blocos incompletos balanceados com efeitos aleatorios, admitindo normalidade, e concluiu gue nenhum desses métodos é uniformemente melhor que os outros, devendo cada um ser escolhido em funcão da relação existente entre as variâncias.

HOCKING \& KUTNER (1975), estabeleceram comparacões numéricas entre as seguintes métodos de estimacão para componentes de variáncia: MV, MVR, MINQUE e Método 1 de Henderson, no modelo de blocos incompletos balanceados, aleatório. Concluiram que os estimadores de MV apesar de sua tendenciosidade bastante evidente, possuem menores variâncias e erro quadrático médio, e que se a tendenciosidade não for de importancia fundamental, esse procedimento é melior do que os outros.

COREEIL \& SEARLE (1976a) apresentaram comparacões entre os estimadores de MV e MVR para quatro modelos balanceados Cinteiramente ao acaso, aleatório; classificarão hierárquica, aleatório; 'classificacâo cruzada sem interacão, misto; classificacão cruzada com interacão, misto e entre os estimadores de MVR, Métodos 2 e 3 de Henderson e um método iterativo, no modelo misto de classificarăo oruzada sem interacão com dados não balanceados. Utilizando como crit.Ério de comparacăo o erro quadrático médio, os resultados mostraram ser mais eficientes para os estimadores de MV, tanto para dados balanceados como não balanceados. Quando a 
razắ $\sigma_{\beta}^{2} \sigma^{2}$ ou o rumero de repeticóes era muito pequeno, em dados balanceados, os estimadores de MVR mostraram-se mais eficientes.

\section{SERAPHIN (1984) compara numericamente três} estimadores para componentes de variância em dois modelos lineares genético estatisticos de cruzamento, para dados balanceados e nầo balanceados, utilizando como medida de eficiència de cada estimador, o erro quadrático médio, além do tempo gasto em Unidade Central de Processamento cCPUD outras características, tais como: estimativas médias para cada componente de variância, valor mínimo e máximo encontrado, número de estimativas negativas e experimentos cujo processo de estimacão não convergiu. os estimadores estudados foram: ajuste de constantes ou Método 3 de Henderson, estimadores de MY MIVQUE; considerados para o Modelo I (classificacão hierárquica, aleatório) e Modelo II (fatorial, misto, com interacãos. O autor concluiu que, uniformemente, nenhum dos métodos, ajuste de constantes e MIVQUE, é melhor do que o outro para os modelos estudados, embora o método MIVQUE tenha apresentado maior rapidez e eficiência como estimador. Já o método da MV, baseado somente nos dados de eficiencia, apresentou resultado melhor apenas no Modelo II, podendo, portanto, ser empregado para esse modelo, desde que năo se considere de fundamental importância a tendenciosidade e os problemas de convergência e tempo.

GONCALVES (1984), utilizando simulação, compara quatro métodos de estimacão para componentes de variân- 
cia: Método 3 de Menderson, MV, MVR e MIVQUEd Cque é o MVQUE com valores a priori $\sigma_{G}^{2}=0 \& \sigma_{\sigma}^{2}=1$, onde $\sigma_{G}^{2}$ a variáncia genética e $\sigma_{\sigma}^{2}$ é a variancia do erros, no caso particular de blocos aumentados em que os tratamentos comuns a todos os blocos são de éfeitos fixas o os restantes aleatórios. O desempenho dos estimadores é avaliado através de sua tendenciosidade, coeficiente de variacão e erro quadrático da análise realizada, a autora concluiu, para o caso onde $\sigma_{G}^{2} / \sigma_{\theta}^{2} \geq 1$, que o desempenho dos estimadores depende do tamanho do experimento: para experimentos grandes, o método da MV foi superior aos outros; para experimentos de tamanho médio, o MIVQUE申 e o MV tiveram desempenho similar; para experimentos pequenos, todos os métodos, exceto o Método 3 de Henderson, tiveram o mesmo desempenho. Para o caso onde $\alpha_{G}^{2} \alpha_{e}^{2}<1$, o Método 3 de Henderson o MV tiveram desempenho melhor que o método MIVQUE申, para todos os tamanhos de experimentos considerados.

\subsection{O Problema de Estimativas Negativas}

Um fato desagradável que acompanha a estimacão de componentes de variancia é o de encontrarmos, en certas ocasiões, estimativas negativas desses componentes. Este problema tem merecido tratamento especial por parte dos estatísticos e vem se mostrando responsável, recentemente, por inumeras contribuiçóes na área de componentes de variância. 
24.

A titulo de ilustracăo, considerem-se os seguintes dados apresentados por MCHUGH \& MIELKE (1968):

\begin{tabular}{ccccc}
\hline$I W$ & 1 & 2 & 3 & $\Sigma$ \\
\hline 1 & 1059 & 1237 & 949 & 3245 \\
2 & 1245 & 1341 & 1332 & 3918 \\
3 & 1283 & 1078 & 1129 & 3490 \\
4 & 1101 & 988 & 1262 & 3351 \\
\hline$\Sigma$ & 4688 & 4644 & 4672 & 14004 \\
\hline
\end{tabular}

que, analisados através do modelo:

$$
y_{i, j}=\mu+\alpha_{i}+e_{i j}
$$

para

$$
i=1,2,3,4 \quad j=1,2,3
$$

resultou no quadro de análise de variancia a seguir:

ANALISE DE VARI ANCIA

\begin{tabular}{lcccc}
\hline C.V. & G.L. & SQ & OM & ECOM \\
\hline Trat. & 2 & 248 & 124 & $\sigma_{\theta}^{2}+4 \sigma_{C}^{2}$ \\
Res. & 9 & 198068 & 21740,89 & $\sigma^{2}$ \\
\hline Total & 11 & 195916 & & \\
\hline
\end{tabular}

A estimativa dos componentes de variância pelo método da ANOVA é

$$
\begin{gathered}
\hat{\alpha}_{\sigma}^{2}=Q M E=2 i 740,89 \\
Q M A=\hat{\sigma}_{\theta}^{2}+4 \hat{\sigma}_{\alpha}^{2} \Rightarrow \hat{\alpha}_{\alpha}^{2}=\frac{Q M A-Q M E}{4}=-5404,2 Z
\end{gathered}
$$


25.

Ou seja, o métcodo de estimacão escolhido forneceu uma estimati va negativa para $\alpha_{\alpha}^{2}$.

SEARLE (1971a) enumera alguns procedimentos alternativos para contornar o problema de estimativas negativas para componentes de variância:

i) Aceitar a estimativa negativa, admitindo que o verdadeiro valor do componente zero cos. Embora possa parecer lógico, isto afeta as propriedades dos estimadores, tendo em vista que a estimacăo foi truncada.

i i) Eliminar o parâmetro correspondente no modelo e reestruturar a análise de variância, obtendo uma ponderacão dos quadrados médios restantes e, com isso, obter novas estimativas dos componentes de variância restantes.

ii uma indicacão da utilização de um modelo errôneo.

$\mathrm{Na}$ tentativa de contornar este problema, HERBACH (1959) usa estimadores de MV que são nâo negativos, mas apresentam a desvantagem de serem truncados e viciados.

THOMPSON (196e) desenvol veu um algoritmo que resulta da maximizacão da funcão de verossimi lhanca dos quadrados médios, sujeita a um conjunto de restricões, que recebe a denominacão de Princípio da Máxima Verossimilhanca Restrita. Esse procedimento também provoca um truncamento e o estimador resultanté viciado. 
EE.

RAO C1972) estendeu o método MINQUE para estimacăo de componentes de variância e de covariância. As estimativas obtidas, após uma modificacão introduzida pelo autor, săo säo negati vas.

LAMOTTE (1973) desenvolveu, dentro da classe dos estimadores quadráticos não viciados, as condicôes para obtermos estimativas não negativas de combinacốes lineares dos componentes de variância. Complementando essa idéia, BEZERRA (1975) discutiu as condicổes de estimabilidade näo negativa dos estimadores quadráticos năo viciados para componentes de variância e most.rou que, se conhecermos a relasão entre $\sigma_{a}^{2} \Rightarrow \sigma_{e}^{2}$ num modelo aleatório simples com dados balanceados, podemos calcular a probabilidade de obtermos uma estimativa negativa para o componente $\alpha_{\alpha}^{2}$

PEREIRA (1983) apresentou novas estimativas dos componentes de variância através do método dos momentos, quando determinamos uma estimativa negativa dos componentes de variância em modelos aleatórios, mistos e fixos de classificacão hierárquica, bem como a expressão da estimativa da correlacăo negativa entre as variáveis, já que a presença de correlação negativa entre os elementos de uma mesma parcela (correlacăo intra-classe) pode ocasionar estimativas negativas de componentes de variância.

No aspecto da reconsideracầo do modelo, SEARLE \& FAWGETT (1970) discutem o procedimento de adotar o modelo em termos de populacóes finitas, em vez de populações infinitas, o que nos leva a encontrar estimativas não negativas 
onde, anteriormente, sob a suposicăo de populacóos infinitas, eram negativas.

Em todos esses trabalhos até aqui citados, a estimaçăo de componentes de variância foi vista sob a luz dos métodos que produzem estimativas negativas e apresentados vários procedimentos que tentam contornar a situacão.

Uma outra abor dagem para o problema de estimativas negativas, considerada mais fundamentada, é sugerir métodos alternati vos de esti macăo que não produzam estimativas negativas para os componentes de variância. Neste sentido, podemos estudar a estimacão dos componentes de variância dentro do aspecto bayesiano e através do método da MVR.

Com HILL (1965) IIAO \& TAN (1965) surgiram os primeiros trabalhos utilizando a inferencia bayesiana para obtencão de componentes de variância, num modelo aleatório em dados balanceados @ não balanovados. Tambóm BEZERRA (1976) estudou o problema da estimarão dos eomponentes de variancia dentro do contexto bayesiano, tendo por base o modelo aleatório em classificacão simples balanceado. A grande vantagem pratica do uso dos métodos bayesianos é que as estimativas dos componentes de variância são sempre não negativas.

PATTERSON 8: THOMPSON (1971) desenvalveram o método da Máxima Verossimilhanca Restrita que tem sido aceito, segundo MEYER (1986), como o método preferido para estimar paràmetros genéticos, isto é, componentes de variancia e covariancia para experimentos de melhoramento animal. 


\section{METODO}

\subsection{Estimacâo de Componentes de Variancia em Modelos com Populacão Finita}

\subsubsection{Introducăo}

Em modelos de componentes de variância, as efeitos aleatórios são usualmente assumidos como provenientes de uma populacão infinita. Fopulacós finitas têm também sido consideradas: BENNETT \& FRANKLIN (1954), CORNFIELD \& TUKEY (1956) \& WILK \& KEMPTHORNE (1956), discutem vắios casos para dados balanceados. Entretanto, para dados năo balanceados, a não ser o tratamento dado por Tukey para classificacâo simples, a única discussăo sobre modelos de popu1 acăo finita surgiu com GAYLOR \& HARTWELL (1969), que apresentaram com detalhes somente a classificaça hierárquica triplice.

SEARLE \& FAWCET (1970) sugerem o procedimento de adotar o modelo em termos de populacöes finitas, em lugar de populacões infinitas, a fim de encontrar estimativas não negativas para os componentes de variànoia, onde, sob a suposicão de populacóes infinitas, resultavam em estimativas negativas. 
A razäo da utilização do modelo para população Iinita origina-se na seguinte situacão envolvida no delineamento:

$$
\text { Quando se trabal ha com uma classificacão hie- }
$$
rárquica com dois fatores $A \odot B$, o modelo é dado por:

$$
y_{i j k}=\mu+c_{i}+\beta_{i j}+e_{i j k},
$$

onde:

$$
\begin{aligned}
& y_{i j k} \text { é a observacão da variável aleatória } c_{i}=1, \ldots, n_{a} \\
& \text { classes com } i=1, \ldots, n_{b} \text { observacốes por classes; } \\
& \mu \text { é a média populacional; } \\
& A_{i} \text { é o efeito (aleatório) do fator } A \text {; } \\
& B_{i j} \text { o efeito Caleatório) do fator } B \text { dentro de A; } \\
& e_{i j k} \text { é o erro associado à observacâo } y_{i j k} \text {, e supondo gue: } \\
& a_{i} \text { tem média zero, variância } \alpha_{a}^{z} \text { e săo independentes; } \\
& \beta_{i j} \text { tem média zero, variäncia } \sigma_{b}^{2} \text { săo independentes; } \\
& \alpha_{i} \text { e } \beta_{i, j} \text { são mutuamente independentes; } \\
& \text { trata-se de um "modelo infinito". }
\end{aligned}
$$

Neste modelo, tem-se dois estágios de amostragem envolvidos: o primeiro, correspondente ao fator $A$, onde uma amostra aleatória de tamanho $n_{a} G i=1, \ldots, n_{a}$ é considerada; o segundo, correspondente ao fator $B$, onde uma amostra aleatória de tamanho $n_{b} C_{j}=1, \ldots, n_{b}$ é associada a cada i.

E claro que a independência estatística entre as variáveis aleatórias está baseada numa suposicão de populacăo infinita. Entretanto, se de fato, a amostragem 
está sendo realizada sob um universo existente, então a populacấo necessariamente finita. Como, na prática, a amostragem é sem reposicão, surge uma dependencia estatística de $\alpha_{i} \in \beta_{i j}$

MCHUGH \& MELKE (1968) mostra que a estimativa de um componente de variáncia negativo ocorre em situaçôes em que a suposicâo de independência estatística entre as variáveis é falsa, ou seja, não podemos considerar que as populacôes săo infinitas.

SEARLE \& FAWCEIT (1970) apresentam uma regra para converter as esperancas dos quadrados médios na análise de variância dos modelos infinitos, em esperancas para modelos finitos, que se aplica a dados balanceados 0 não balanceados, em olassificacão hierárquica e cruzada, bem como na mistura delas. Desde que as esperancas dos quadrados médios sob populacôes infinitas encontram-se disponiveis na literatura, a regra aqui desenvolvida permite a substituicão de modelos de populacão infinitra para finita.

\subsubsection{Modelo Geral}

$$
\text { Considere-se um modelo com os fatores } A \text {, }
$$
B,..,$K$, representando $N_{e}$ o tamanho da populacão do e-ésimo fator. os efeitos são $\Theta_{i}$, para $i=1, \ldots$ N $N_{\theta}$, com $\theta$ tomando os valores A, B, ..., K. Como e costume CGAYLOR \& HARTHELL, 1969), assume-se que a média de cada populasão é zero $\cos$, assim: 


$$
\sum_{i=1}^{N} \theta_{i}=0 \quad \theta \quad \sigma_{\theta}^{z}=\frac{\sum_{i=1}^{N} \theta_{i}^{2}}{N_{\theta}-1}
$$

é definida como variância populacional.

Consequentemente,

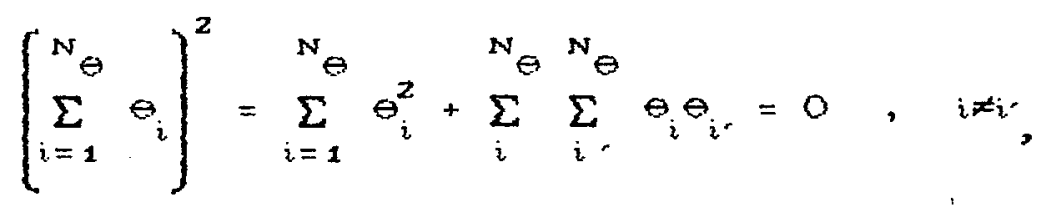

isto é,

$$
\begin{aligned}
& \sum_{i}^{N} \sum_{i}^{N} \theta_{i} \theta_{i,}^{N}=-\sum_{i=1}^{N} \theta_{i}^{2} \\
\therefore \quad & \sum_{i}^{N} \sum_{i}^{N} \theta_{i} \theta_{i}=-C N \theta-1 D \theta_{\theta}^{2}, i \neq i .
\end{aligned}
$$

Ao se obterem dados amostrais, admite-se que os efeitos das populacöes finitas (e erros do modelo são obtidos aleatoriamente e sem reposicão. Desta forma, a suposicăo de independência estatística entre os efeitos $\varphi_{i} \ominus$ $\theta_{i,}, i \neq i$, fica prejudicada.

Se $\theta_{T}$ o um valor amostral do efeito $\ominus$, então, por [1]:

$$
\text { Media }\left(\theta_{r}\right)=E\left(\theta_{2}\right)=\frac{\sum_{i=1}^{N_{\theta}} \theta_{i}}{N_{\theta}}=0
$$

e 


$$
\begin{aligned}
& \operatorname{Var}\left(\Theta_{r}\right)=E\left(\theta_{r}^{2}\right)=\frac{\sum_{i=1}^{N} \Theta_{i}^{2}}{N_{\Theta}}=\frac{1}{N_{\theta}}\left(N_{\theta}-1\right) c_{\theta}^{2}=\left(1-\frac{1}{N_{\Theta}}\right) \alpha_{\theta}^{z} \\
& \therefore \quad \operatorname{Var}\left(\theta_{r}\right)=\left(1-N_{\theta}^{-1} \alpha_{\theta}^{2}\right.
\end{aligned}
$$

e, para dois valores amostrais, $\theta_{r} \theta_{s}$ :

$$
\begin{aligned}
& \operatorname{cov}\left(\theta_{r}, \theta_{S}\right)=\operatorname{Ec} \theta_{r} \theta_{S}=\frac{1}{N_{\theta} \operatorname{CN}-12} \sum_{i}^{N_{\theta}} \sum_{i}^{N_{\theta}} \theta_{i} \theta_{i}, i \neq i \\
& \left.=\frac{1}{N_{\theta}\left(N_{\theta}-1\right)}-C N_{\theta}-1\right) \sigma_{\theta}^{2} \\
& \therefore \quad \operatorname{cov} \cos _{x}, \theta_{s}=-\frac{\alpha_{\theta}^{2}}{N_{\theta}}
\end{aligned}
$$

Desde que os valores correspondentes a $[3]$ a

[4] para populacóes infinitas são $\alpha_{\theta}^{2}$ o, respectivamente, as esperancas dos quadrados médios em modelos de populacão finita năo são as mesmas que as de populacão infinita.

Em cada caso, os valores esperados são funcões lineares dos componentes de variância, cujos coeficientes dos componentes são determinados para modelos de populacóes finitas, de acordo com $\{3\}$ e $\{4\}$.

Suporiha que y representa o vetor de observacöes, com vetor de médias $\mu$ e matriz de covariâncias $v$. Entå̆o, qualquer soma de quadrados é uma forma quadrática em y, ou seja, y'oy, e seu valor esperado é

$$
E\left(Y^{\prime} D Y\right)=t r(Q Y)+\mu^{\prime} Q H
$$


Assim, os quadrados médios da análise de variância com dados balanceados e seus análogos pará dados deshalanceados são formas quadráticas das observacões. Além disso, a soma das linhas de $\mathbf{Q}$ é zero, isto é, $\mathbf{Q} 1=0$, onde 1 é o vetor de uns; em modelos aleatórios, $\mu=\mu .1$ e, também, em [5] $\mu^{\prime} Q \mu=\mu^{\circ} \mathrm{Q} \mu=0$. Portanto, considerando somente a expressão original, denotando por M, I5] pode ser escrita como:

$$
E(M) E\left(y^{*} Q y\right)=\operatorname{tr}(Q D)
$$

Este resultado independe se o modelo é de populacão finita ou infinita. Aplica-se a ambos podemos escrever

$$
E_{\infty} C D=\operatorname{tr}\left(Q_{\infty}\right) \quad \Leftrightarrow \quad E_{F}\left(M=\operatorname{tr}\left(Q_{F}\right)\right.
$$

para modelos de populacão infinita e finita, respectivamente. Como $Q$ é a mesma em anbos os casos, a única diferenca entre as duas esperancas dos quadrados médios é o uso de $V_{F}$ em 1 ugar de $V_{\infty}$. A natureza exata dessa diferenca pode ser verificada ao ol har o modo como $V_{\text {o }}$ será alterado para $V_{F}$ quando se trocar populacão infinita para finita. A alteracão depende dos resultados [3] e [4]. Quaisquer que sejam eles, é indiferente para [6] se $Q$ é proveniente de dados balanceados ou desbal anceados. Em cada caso, [0] permanece, e assim a troca a ser feita para derivar $V_{F}$ de $V_{\infty}$ produzira $E_{F} C M$ de $E_{\infty} C M$. tanto para dados balanceados como desbalanceados. A discussăo e os resultados a seguir, portanto, aplicam-se igualmente para ambos os tipos de dados. 


\subsubsection{Modelos Hierárquicos}

$$
\text { É oportuno, no desenvalvimento do resultado }
$$

geral, considerar trés casos separadamente: modelos hierárquicas consistindo unicamente de classificacão hierárquica); modelos de classificacào cruzada csem classificacão hierárquisal; e modelos envolvendo combinacóes de classificacăo hierárquica e cruzada.

Para se discutir modelos hierárquicos, considera-se inicialmente um modelo hierárquico duplo com os fatores $A=B$ dentro de $A$ :

$$
y_{i j k}=\mu+\alpha_{i}+\beta_{j(i)}+\theta_{i j k}
$$

A obtencão de $Y_{F}$ a partir de $Y_{\infty}$ leva en consideracăo o efeito de $[3]$ e $[4]$ nos vários elementos de $V_{\infty}$

os elementos diagonais de $v_{\text {w }}$ são:

$$
y y_{i, j k}=\sigma_{A}^{2}+\sigma_{B}^{2}+\sigma_{\theta}^{2}
$$

- por 13.1 passam a ser elementos diagonais em $V_{F}$ :

$$
\left.\left(1-N_{A}^{-1}\right) \sigma_{A}^{2}+\left(1-N_{B}^{-1}\right) \sigma_{B}^{2}+C 1-N_{\theta}^{-1}\right) \sigma_{\theta}^{2}
$$

[8]

onde $\mathrm{N}_{\text {é }}$ o tamanho da popul acão de erros.

$$
\begin{aligned}
& \text { São também elementos de } v_{\infty} \text { : } \\
& \operatorname{COV} C y_{i j k}, y_{i j k} \supset=\alpha_{A}^{2}+\alpha_{B}^{2},
\end{aligned}
$$

que é a covariancia entre observacóse que estão na mesma sub-casela dos dados, mas tôm diferentes termos de erro. No caso de populaçăo finita, esses erros terão covariância $-\mathrm{Co}_{\theta}^{2} \mathrm{H}_{0}$, de acordo com [4]. Então, na correspondencia de I9] para um modelo de populacăo finita, as $\sigma_{5}^{2}$ podem ser 
35.

trocadas exatamente como foi feito em [7] e [8], mas surgirá

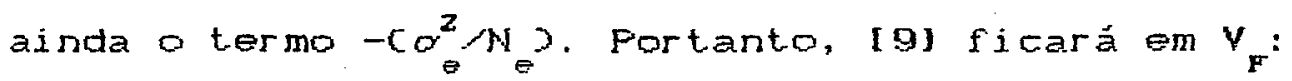

$$
c 1-N_{A}^{-1} \sigma_{A}^{2}+c 1-N_{B}^{-1} \sigma_{B}^{2}-\frac{\sigma_{\theta}^{2}}{H_{\theta}}
$$

Similarmente, em $Y_{\infty}$, a

$$
\operatorname{cov} y_{i, j k}, y_{i j k}{ }^{2}=\alpha_{A}^{2}
$$

- a covariância entre observaçäes que estão no mesmo nível de A, mas em diferentes niveis de B. Portanto, no caso de populacöes finitas, essas covariàncias envolvem $-\cos _{B}^{2} \mathrm{~N}_{\mathbf{B}}$, como em [4]. Logo, em $Y_{F}[11]$ fica:

$$
\left(1-N_{A}^{-1} \alpha_{A}^{2}-N_{B}^{-1} \alpha_{B}^{2}\right.
$$

Também, pela mesma razão, os elementos de $Y_{\infty}$ que săo zero, isto é,

$$
\operatorname{cov}\left(y_{i, j k}, y_{i-j k}\right)=0 \quad i x_{i}
$$

tornam-se, em $\mathbf{V}_{\mathbf{F}}$ :

$$
-\mathrm{N}^{-1} \mathrm{~d}_{\mathrm{A}}^{\mathrm{Z}}
$$

Em [8], [10], [12] [14], pode-se ver que $\mathbf{Y}_{\mathbf{y}}$ tem - $N_{A}^{-1} \alpha_{A}^{2}$ em cada elemento. Fortanto, $Y_{F}$ pode ser expressa por

$$
V_{F}=C-N_{A}^{-1} \alpha_{A}^{2} \supset 11,+V_{F}^{*}
$$

Como já foi discutido, $Q 1=0$; então,

$$
Q V_{F}=Q V_{F}^{*} \text {. }
$$

Assim, $[6]$ torna-se

$$
E_{F}(M)=\operatorname{tr}\left(\mathrm{QV}_{\mathbf{F}}^{*}\right.
$$

Por [15], $V_{F}^{*} \doteq$ obtida adicionando-se $\mathrm{N}_{A}^{-1} \alpha_{A}^{2} a$ cada elemento de $V_{F}$. Portanto, os elementos de $V_{F}^{*}$ são: 


$$
\begin{aligned}
& \int \sigma_{A}^{2}-\frac{\sigma_{B}^{2}}{N_{B}}+c \sigma_{B}^{2}-\frac{\sigma_{\theta}^{2}}{N_{\theta}}+\sigma_{\theta}^{2}, 1171 \\
& i=i \cdot, j=j^{\prime}, k=k^{\prime} \\
& \left(\alpha_{A}^{2}-\frac{\alpha_{B}^{2}}{N_{B}}\right)+\left(\alpha_{B}^{2}-\frac{\alpha_{\theta}^{2}}{N_{\theta}}, \quad[18]\right. \\
& \operatorname{cov}\left(y_{i j k}, y_{i \cdot j \cdot k}\right)= \\
& i=i, \quad j=j \\
& \left(\sigma_{A}^{2}-\frac{\sigma_{B}^{2}}{N_{B}}, \quad i=i^{\prime} \cdot[19]\right. \\
& \text { zero, } \quad i \neq i *[20]
\end{aligned}
$$

Os elementos correspondentes para $V_{\infty}$ são dados em [7], [9], [11] [13]. Comparando os dois conjuntos de elementos, observa-se que $v_{F}^{*}$ pode ser obtida de $v_{\infty}$ se

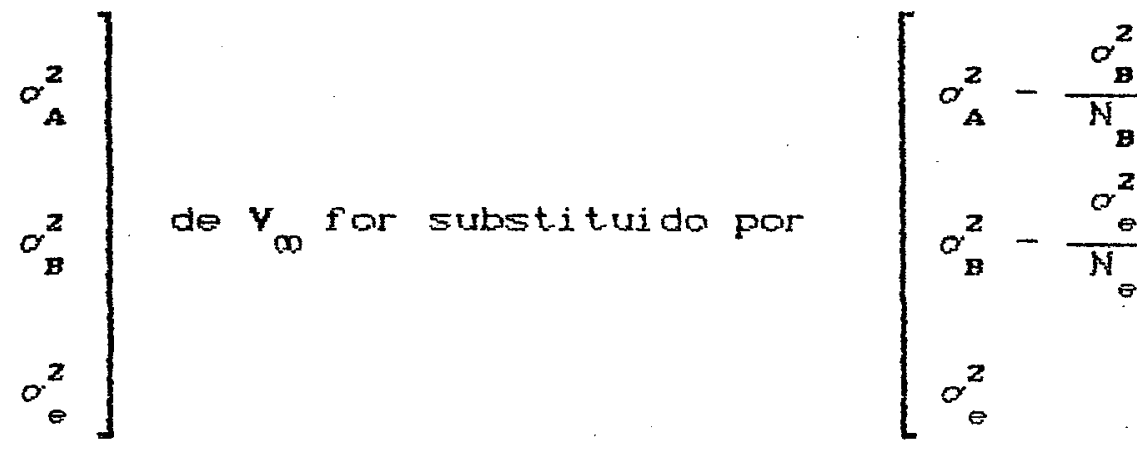

$[21]$

Portanto, como $E_{\infty}(M)=\operatorname{tr}\left(Q_{\infty}{ }_{\infty}\right.$ e $E_{F}\left(N=\operatorname{tr}\left(Q_{F}^{*}\right)\right.$ como em [6] [16], respectivamente, substituindo-se [21] em $E_{\infty} C M$ obtém-se $E_{F} C M$; isto é, colocando a substituicão de I21 I nas esperancas dos quadrados médios num modelo de popu- 
lacăo infinita, produziremos as correspondentes esperancas dos quadrados médios de um modelo de populaqão finita.

Essa discussăo, em termos de classificacão hierárquica dupla, se estende a qualquer modelo hierárquico. Em geral, cada elemento diagonal de $v_{\infty}$ é a soma de todos os componentes de variância do modelo

$$
\sum_{\theta=A}^{x} \alpha_{\theta}^{2}
$$

e, por [3] torna-se

$$
\sum_{\theta=A}^{\kappa}\left(1-\mu_{\theta}^{-1}\right) \alpha_{\theta}^{2}
$$

em $V_{F} ;[7]$ [ [8] ilustram isso. Similarmente, em cada elemento diferente de zero da diagonal de $v_{\infty}$, está a soma de certas $\alpha_{\theta}^{2}, s$ do modelo, que por 131 torna-se $\left(1-N_{\theta}^{-1}\right) \sigma_{\theta}^{2}$ em $v_{F}$. Também os elementos que em $v_{w}$ têm covariancia zero, por $[4]$ săo diferentes de zero em $v_{F}$ sob a forma $-6 o_{y}^{2}-N_{p}$, chamada de covariancia ontre os dois niveis do fator hierarquizado dentro de cada sub-fator, cujas variâncias são os elementos de $v_{\omega}$. Exemplos disso sâo vistos nas equacões $[10]$ e 1121. Finalmente, os elementos zero de $v_{\infty}$ são covariâncias entre observaçós de diferentes niveis do fator A e assim, em ' $\mathbf{V}_{\mathbf{F}}$, devido a dependencia, essas covariâncias săo $\left.-\operatorname{coc}_{A}^{2} N_{A}\right)$, como exemplificado em [13] $[141$. É claro que observaçes em diferentes niveis do fator A estäo também em diferentes niveis de todos os outros fatores, mas desde que as populacŏes são definidas somente dentro de fatores dentro dos quais são hierárquicos $C e$ em particular dentro de $A$, somente $-\left(\alpha_{A}^{2}-N_{A}\right)$ entra nessa covariância. Esta também $\dot{e}$ a 
38.

razäo pela qual o termo $-6 \alpha^{2} y_{y}=$ surge em cada um dos outros elementos de $V_{F}$.

A substituicão indicada em lal para classificacão dupla hierárquica estende-se prontamente a cada classificacão hierárquica de ordem $k$. Além disso, como visto, na substituição de

$$
\sigma_{A}^{2} \text { por } \sigma_{A}^{z}-\frac{\sigma_{B}^{2}}{N_{B}}
$$

em [21], B o f ator hierárquico dentro de A. 'Similarmente, na substitui ६ăo de

$$
\alpha_{\theta}^{2} \text { por } \alpha_{B}^{2}-\frac{\alpha_{\theta}^{2}}{N_{\theta}} \text {, }
$$

onde $\alpha_{\theta}^{2}$ é variáncia do erro, o termo erro pode ser pensado como um "fator" hierárquico dentro de B, a sub-classificação máxima do modelo. Desta maneira, a trora la1 pode ser generalizada.

Seja $y: \theta$ denotando o fator $\gamma$ imediatamente hierárquico dentro de $\theta$, e seja $\mathrm{N}_{\gamma}$ o tamanho da populacão $\gamma$ dentro de cada nivel do fator e Cpara cada nivel, o mesmo tamanho populacional). Por exemplo: numa classificarão hierárquica dupla, onde $\mathrm{B}$ é hierárquico dentro de A e o "fator" erro é hierárquico dentro de B; o fator hierárquico imediatamente dentro de A é B Cisto é, para $\gamma: A$, o fator $\gamma$ E $B$ não o fator errol. Então temos a seguinte regra.

Regra: As esperanças dos quadrados médios em modelos de classificacão hierárquica são obtidas a partir dos valores das populacóes infinitas pela substituicăo de $\sigma_{\theta}^{z}$ por 


$$
\alpha_{\theta}^{2}-\frac{\alpha^{2}}{N_{\gamma}}
$$

[2e]

onde $\sigma_{\gamma}^{2}$ é o componente de variancia do fator $\gamma: \theta$ cr imediatamente hierárquico dentro de $\theta$.

Tres exemplos da Regra [22] estäo mostrados na

Tabela 1.

Tabela 1 - Classificacão hierárquica: substituiçôes necessárias para obtencão das esperancas dos quadrados médios em modelos com populacões finitas, a partir de populacôes infinitas.

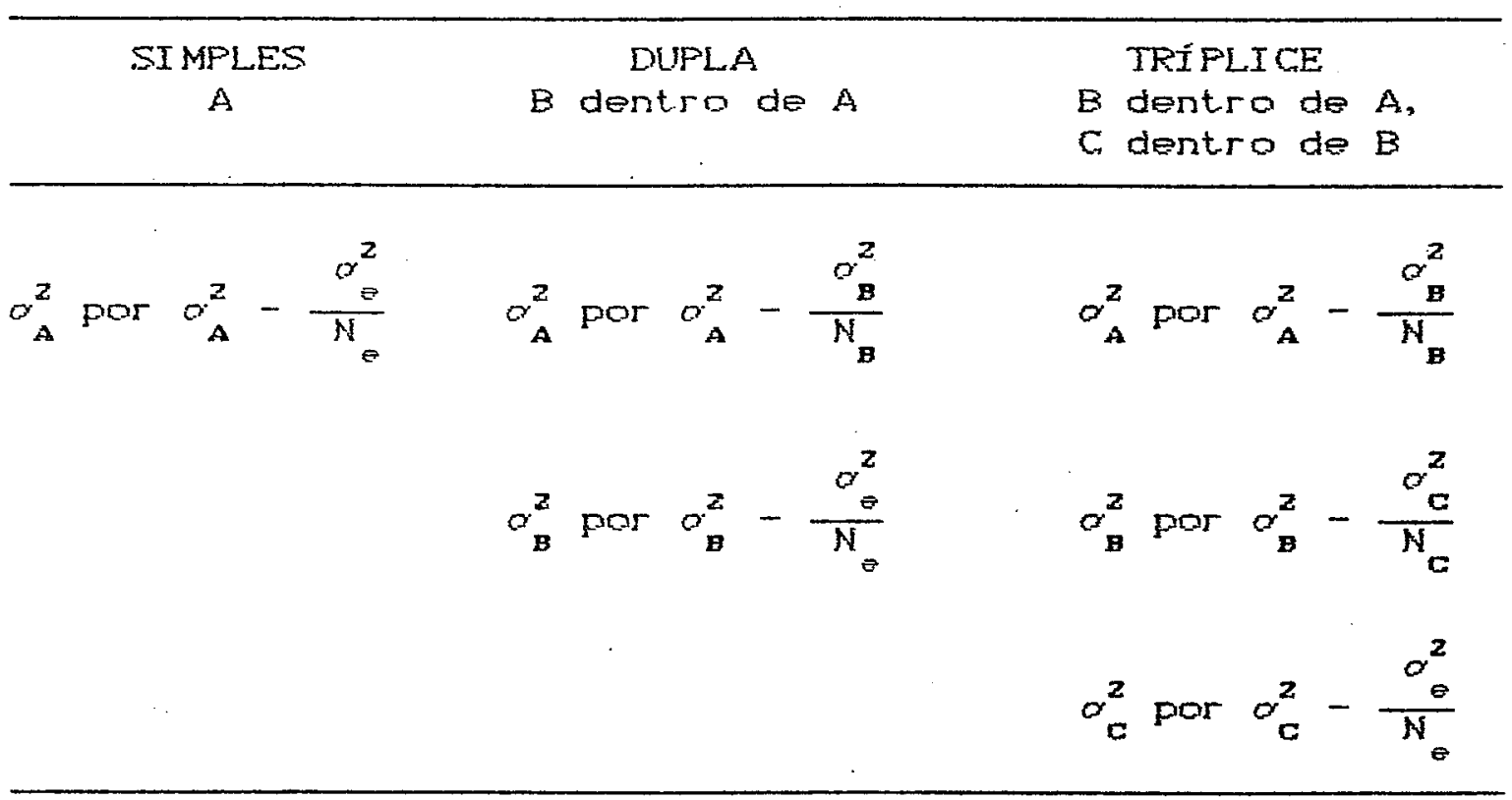

Para ilustrar seu uso, apresenta-se, na Tabela 2, o quadro da análise de variancia usual de uma classificacão simples para modelos de populacão infinita, e os seus correspondentes resultados para população finita. 
Tabela 2 - Análise de variäneia.

$$
\text { Modelo: } \begin{aligned}
y_{i j}=\mu+a_{i}+e_{i j}, i & =1, \ldots, a ; \\
j & =1, \ldots, n .
\end{aligned}
$$

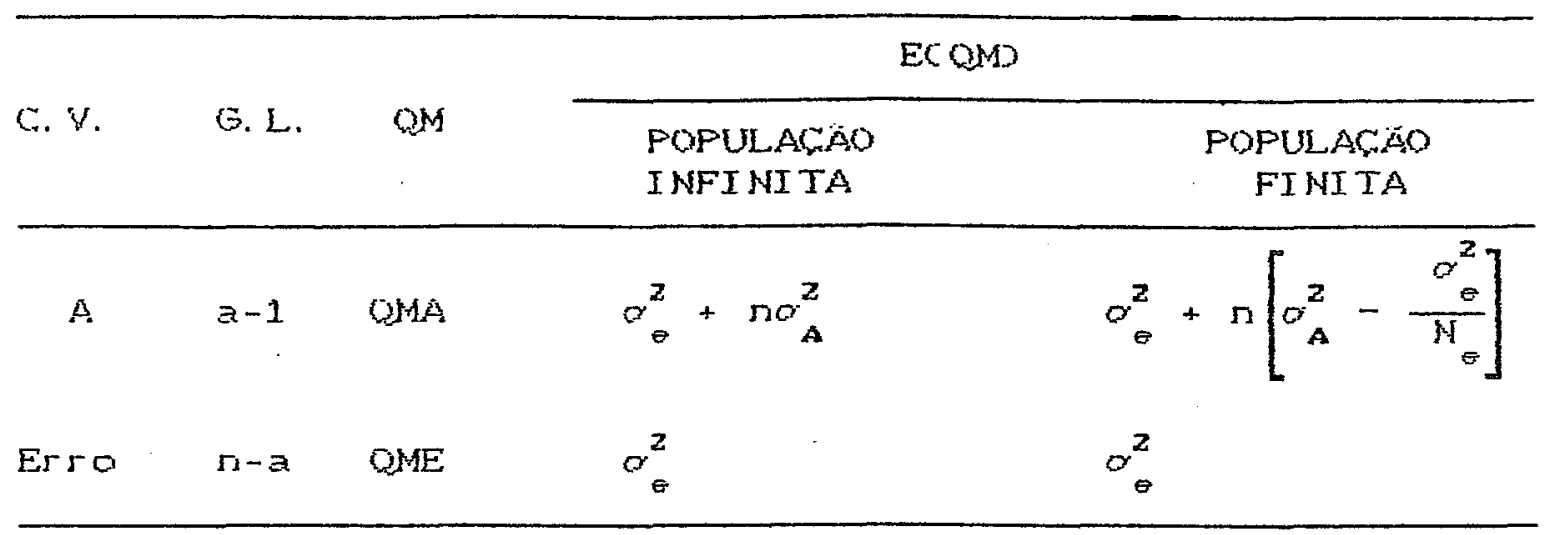

Este caso de classificacăo simples nos transporta à discussâo para modelas de populacâo finita como alternativa de modelos de populacâo infinita enfocada por MCHUGH \& MILE (1968).

No caso de populacão infinita, o estimador não viesado usual para componentes de variancia entre classes é - familiar

$$
\left.\hat{a}_{A ; \infty}^{i}=C Q M A-Q M E\right) / n
$$

onde QMA e OME são os quadrados médios entre e dentro das classes, respectivamente, com $\mathbf{n}$ observacốs em cada classe. Para populacóes finitas, esses quadrados médios têm esperancas

$$
E_{F} \operatorname{COMA}=r\left[\sigma_{A}^{2}-\frac{\sigma^{2}}{N_{\theta}}\right]+\sigma_{\theta}^{2} \quad \theta \quad E_{F} \operatorname{CQME}=\sigma_{\theta}^{2}
$$

e entăo: 


$$
\begin{aligned}
E_{F}\left[\hat{\sigma}_{A ; \infty}^{2}\right] & \left.=E_{F}\left[\frac{Q M A-\alpha M E}{n}\right]=\frac{1}{n} E_{F} \operatorname{coMA}-\frac{1}{n} E_{F} \operatorname{coME}\right] \\
& =\frac{1}{n}\left[\sigma_{\theta}^{2}+n\left[\sigma_{A ; F}^{2}-\frac{\sigma_{\theta}^{2}}{N_{\theta}}\right]-\frac{1}{n} \sigma_{\theta}^{2}=\right. \\
& =\frac{1}{n} \sigma_{\theta}^{2}+\sigma_{A}^{2}-\frac{\sigma_{\theta}^{2}}{N_{\theta}}-\frac{1}{n} \sigma_{\theta}^{2}=\sigma_{A ; F}^{2}-\frac{\sigma_{\theta}^{2}}{N},
\end{aligned}
$$

ande $\alpha_{A ; F}^{2}$ é o componente de variancia entre classes para popul arăo finita; e, portanto, $E_{F}\left[\begin{array}{c}2 \\ a ; \infty\end{array}\right]$ pode ser negativa. Além disso, se $\hat{\alpha}_{A ; \infty}^{2}$ é negativa, o estimador não viciado sugerido por [23] para o caso de populacão finit.a é:

$$
\begin{aligned}
& \hat{\sigma}_{A ; F}^{Z}=\left[O M A-\left[1-\frac{n}{N}\right) O M E\right] / n=O M E\left[\frac{O M A}{O M E}\left(1-\frac{n}{N}\right)\right] / n= \\
& =\operatorname{QME}\left[F-\left(1-\frac{n}{N}\right)\right] n
\end{aligned}
$$

e será positivo se $N_{e}\langle\Gamma(1-F)$, com $1-F$ sendo positivo pois $F<1$ quando $\hat{o}_{A ; \infty}^{2}$ de [23] é negativo. Assim, quando um estimador para populacão infinita é negativo, o estimador para populacão finita será positivo desde que consideremos que a populacăo é finita quando $N_{e}<\frac{n}{1-F}$ Como $n / C 1-F>$ é próximo de $n$ quando $F(<1)$ é próximo de zero, usando $\hat{o}_{A ; F}^{2}$ em 1 ugar de $\hat{\sigma}_{a ; \infty}^{2}$ é pouco provável que se tenha muito ganho sempre que $F$ está próximo de zero, especialmente se $n$ é pequeno. Por outro lado, quando $F$ é ligeiramente menor do que $1, n /(1-F)$ é então apreciavelmente maior do que $n$, e a postulacão sobre populacão finita para o termo aleatório 
42.

precisa ser considerada a fin de se obter uma estimativa positiva para o componente de variäncia $\hat{\sigma}_{A ; F}^{z}$ en vez de usar a negativa $\hat{\sigma}_{A ; \omega^{\prime}}$. Neste sentido, pode-se notar por I23I $\theta$ [25] gue:

$$
\begin{aligned}
& \hat{\sigma}_{A ; \mathbf{F}}^{2}=\left[O M A-\left[1-\frac{n}{N_{\theta}}\right] O M E\right] / n=\left[O M A-\left(\frac{N_{\theta}^{-n}}{N_{\theta}}\right] O M E\right] n= \\
& =\left[O M A-\frac{N_{E} \cdot Q M E-n \cdot Q M E}{N_{\theta}}\right], n=\frac{Q M A}{n}-\frac{N_{\theta} \cdot Q M E-n \cdot Q M E}{n \cdot N_{\theta}}= \\
& =\frac{Q M A}{n}-\frac{Q M E}{\Omega}+\frac{Q M E}{N}=\left[\frac{Q M A-Q M E}{n}\right]+\frac{Q M E}{N_{\theta}}= \\
& =\hat{\sigma}_{A ; \infty}^{Z}+\frac{Q M E}{N_{\theta}}
\end{aligned}
$$

Para ilustrar, retomemos o exemplo de McHUGH MIELKE (1968) apresentado em 2.3, cuja análise de variância, acompanhada das esperancas dos quadrados médios nos casos de populacão infinita e finita é a seguinte:

ANALISE DE VARI BNCIA

C.V. G.L. Q.M.

ECQ. M. $)$

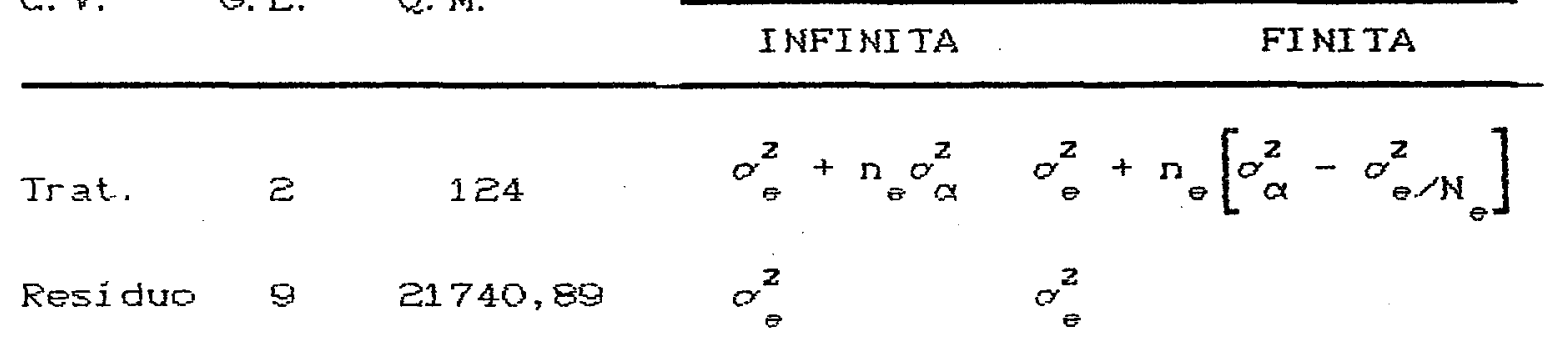

Total 


$$
\begin{aligned}
& \text { Assumindo popul açăo finita com } n_{e}=N_{e} \text {, tem-se: }
\end{aligned}
$$

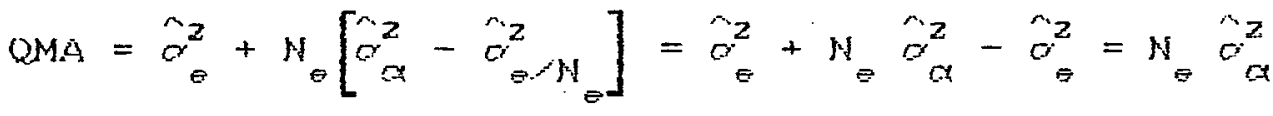

$$
\begin{aligned}
& \therefore \quad \hat{\sigma}_{a}^{2}=O M A N=124 / 4=31 \text {, }
\end{aligned}
$$

obtendo, desta forma, uma estimativa positiva para ${ }_{\alpha}^{2}$.

Também observa-se que

$$
\hat{\sigma}_{\alpha ; F}^{2}=\hat{\sigma}_{\alpha ; \infty}^{2}+Q H E \alpha N_{\theta}=-5404,22+21740,89 / 4=31 \text {, }
$$

onde:

$\hat{\alpha}_{\alpha ; F}^{2}$ é a estimativa de $\alpha_{\alpha}^{2}$ no caso de populacáo finita, e $\hat{\sigma}_{\alpha ; \infty}^{2}$ é a estimativa de $\alpha_{\alpha}^{2}$ no caso de populacăo infinita.

A importância de [22] é que ela se aplica tanto a dados balanceados como a dados não balanceados. For exemplo, numa classificacăo hierárquica com três niveis para dados deshalanceados, as esperancas dos quadrados médios são apresentadas por GAYLOR e HARTWELL (1989) e aqui reproduzidas na Tabela 3 . Considere-se a popularäo constituida por A classes, B sub-elasses dentro de cada classe A, e C sub-sub-classes dentro de cada sub-classe B. O modelo é:

$$
y_{i j k l}=\mu+\alpha_{i}+\beta_{j\{i\rangle}+\gamma_{k(i j)}+e_{k i j k},
$$

com

$$
\begin{aligned}
& i=1, \ldots, a, j=1, \ldots, b_{i} ; k=1, \ldots, c_{i j} \\
& \text { e } \\
& \imath=1, \ldots, n_{i j k} \text { on } \infty \\
& \text { e }
\end{aligned}
$$

$$
\sum_{i=1}^{A} \alpha \alpha_{i}=\sum_{j=1}^{B} \beta_{j+i}=\sum_{k=1}^{C} \gamma_{k+i j}=0 .
$$


44.

Note que $E$ e $G$ aparecem nas esperancas dos quadrados médios e tanto podem ser finitos como infinitos. No último caso, a tabela se reduz aos resultados apresentados por ANDERSON \& BANCROFT (1952). Ainda, se os dados forem balanceados, isto é, $b_{i}=b, c_{i j}=c e n_{i j k}=n$, obtemos resultados fornecidos por BENNETT \& FRANKLIN (1954).

Tabela 3 - Esperanca dos quadrados médios para modelos hierárquicos com dados desbalanceados en populacõos finitas ou infinitas.

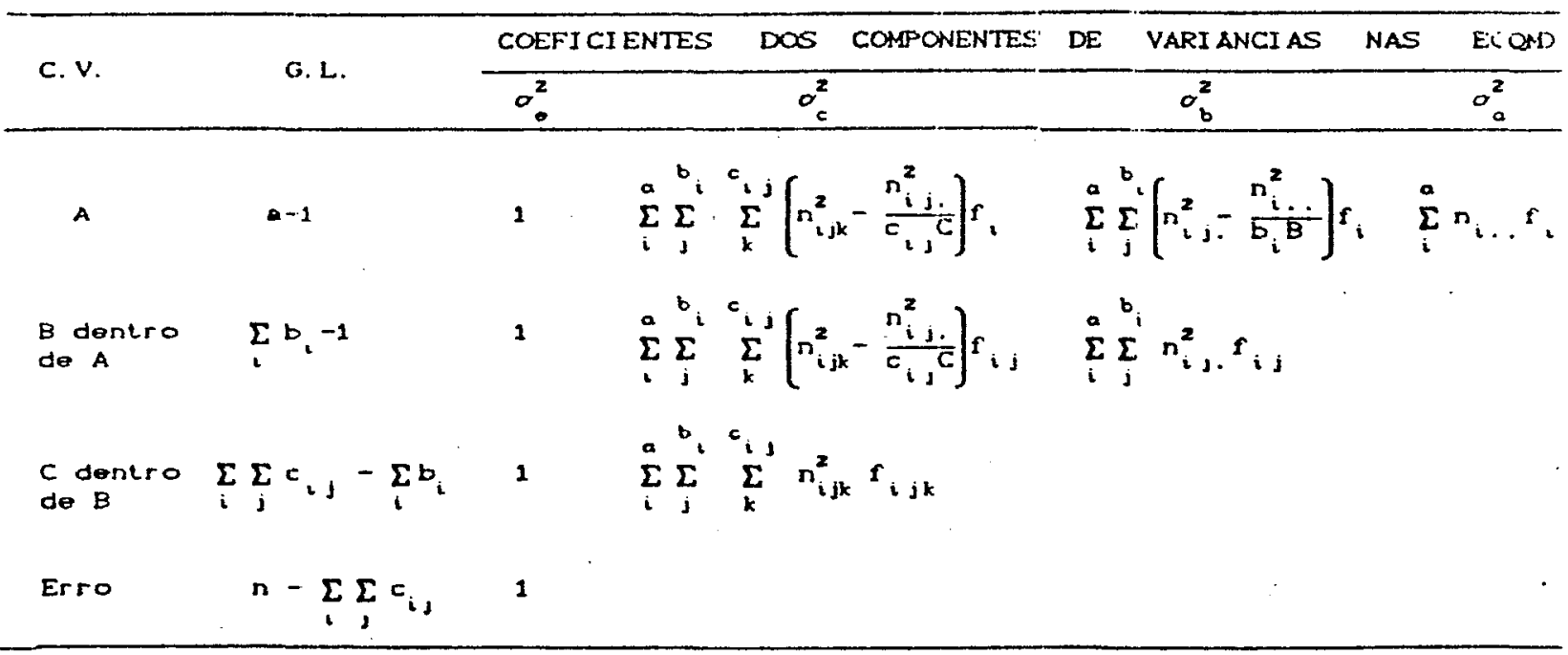

onde:

$$
\begin{gathered}
f_{i}=\left[\frac{\left.\frac{1}{n_{i}}-\frac{1}{n}\right]}{a-1}\right] ; f_{i j}=\frac{\left(\frac{1}{n_{i j}}-\frac{1}{n_{i}}\right]}{\left[\sum_{i}^{a} b_{i}-a\right]} \\
f_{i j k}=\frac{\left[\frac{1}{n_{i j k}}-\frac{1}{n_{i j}}\right]}{\left[\sum_{i}^{a} \sum_{i} c_{i j}-\sum_{i}^{a} b_{i}\right]}
\end{gathered}
$$


45.

Em geral, a regra lezl se aplica a qualquer classificasäo hierắquica com dados halanceados ou näo. Na prática, $\sigma_{e}^{2}$ é conservado e em modelos nos quais somente algumas populacöes säo finitas, tem infinitos $N^{\prime} s$ para as outras populaçöes.

\subsubsection{Modelo de classificação cruzada}

\subsubsection{Classificaçăo cruzada dupla}

Na classificacão cruzada dupla com fatores A E B, os valores amostrados das populacóes dos dois efeitos principais, $A_{i}$ e $B_{j}$, terăo ambos propriedades similares a [3] e [4]. Além disso, definindo os efeitos da interacăo das populacöes de modo que:

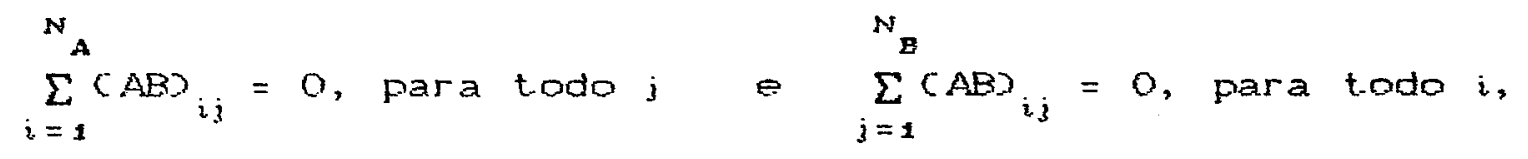

nos leva a definir:

$$
\sigma_{A B}^{2}=\sum_{i=1}^{N} \sum_{j=1}^{N}(A B)_{i j}^{2}\left(C N_{A}-1\right)\left(N_{B}-1\right)
$$

Deste modo, através da extensão dos procedimentas $[3]$ e [4], obtemos: 


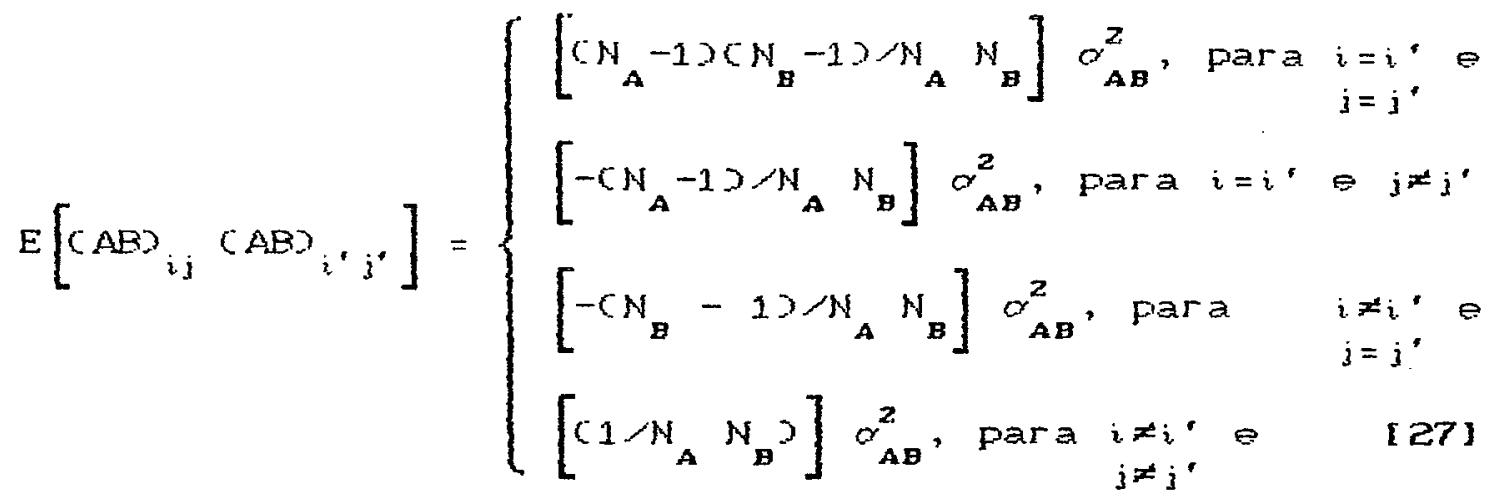

onde $(\Delta B)_{i j}$ e $(\Delta B)_{i} \cdot{ }^{\prime}$ säo dois valores amostrais do efeito da interaço.

Agora, o modelo é:

$$
y_{i j k}=\mu+A_{i}+B_{j}+(A B)_{i j}+e_{i j k} \text {, }
$$

$\operatorname{com} E\left(y_{i j k}\right)=\mu$ $A_{i}, B_{j}$ e $e_{i j k}$ sendo amostras de populacöes finitas com propriedades similares a $\mid 3\}$ e $\{4\} ;$ e $(A B)_{i j}$ com as propriedades indicadas em [27].

Para obter $V_{F}$ de $V_{\infty}$ ' consideremos inicialmente os elementos de $V_{\infty}:$

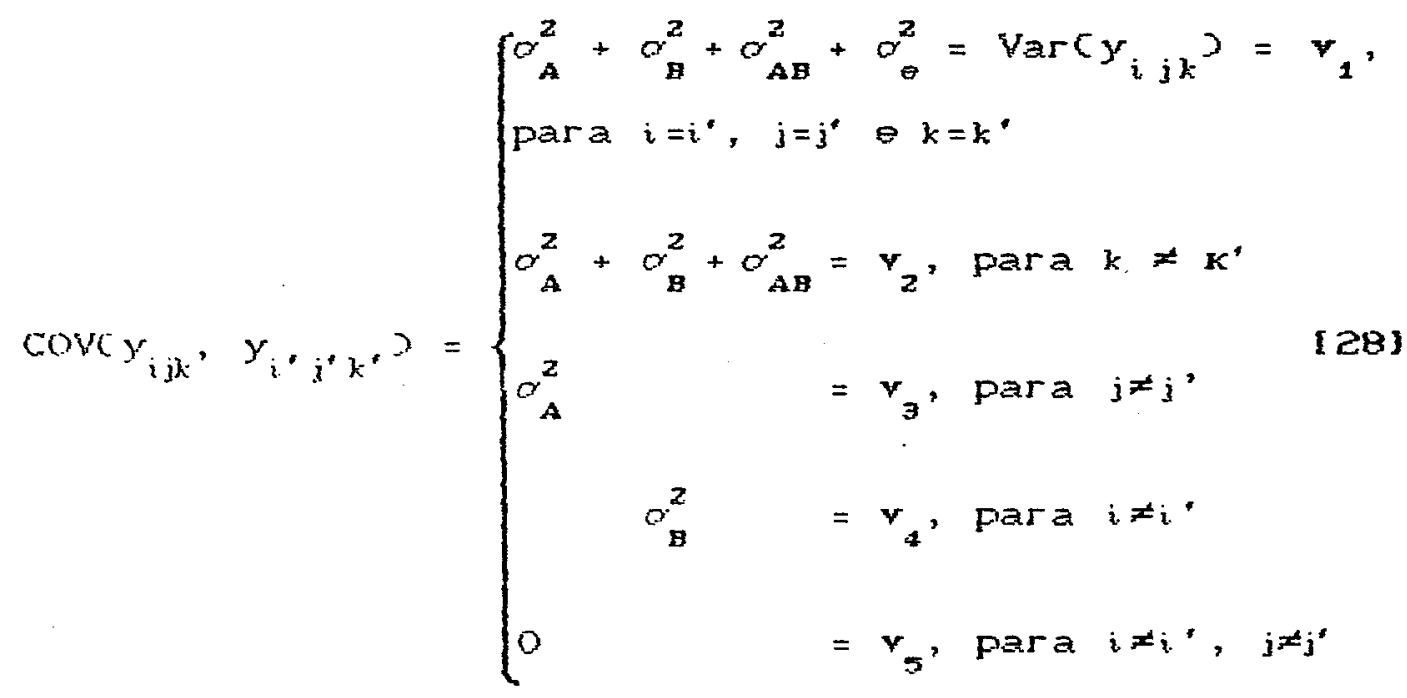


Sob a condicäo de populacōes finitas, não é dificil mostrar que os elementos de $Y_{F}$ correspondentes a $V_{\infty}$ podem ser escritas como:

$$
\begin{aligned}
& f_{2}=f_{5}+f_{1}^{*} \operatorname{com} f_{1}^{*}=C \sigma_{A}^{2}-\sigma_{A B}^{2} N_{B} \partial+C \sigma_{B}^{2}-\sigma_{A B}^{2}-N_{A} \partial+\sigma_{A B}^{2}-\sigma^{2} N_{\theta} 3+\sigma_{B}^{2}, \\
& f_{2}=f_{5}+f_{2}^{*} \operatorname{com} f_{2}^{*}=c_{A}^{2}-\sigma_{A B}^{2} N_{B} J+c \sigma_{B}^{2}-\sigma_{A B}^{2} N_{A}^{2}+C \sigma_{A B}^{2}-\sigma_{\theta}^{2} N_{\theta}{ }^{2} \\
& \left.f_{3}=f_{5}+f_{3}^{*} \operatorname{com} f_{3}^{*}=c \alpha_{A}^{2}-\alpha_{A B}^{2} N_{B}\right) \\
& f_{4}=f_{5}+f_{4}^{*} \operatorname{com} f_{4}^{*}=6 \sigma_{B}^{2}-\sigma_{A B}^{2} N_{A}^{3} \\
& f_{5}=f_{5}+f_{5}^{*} \operatorname{com} f_{5}^{*}=0
\end{aligned}
$$

onde:

$$
f_{5}=-\alpha_{A}^{2} N_{A}^{-1}-\alpha_{B}^{2} N_{B}^{-1}+\sigma_{A B}^{2} N_{A}^{-1} N_{B}^{-1}
$$

Como $f_{s}$ participa de cada elemento de $V_{F}$ este pade ser escrito como $v_{F}=f_{5} 1^{\prime}+v_{F}^{*}$ onde os $f^{*} \cdot s$ são os elementos de $V_{F}^{*}$. Portanto, como $E_{F} C M=\operatorname{trcov}>$ com $\mathbf{O}=0$, temos $E_{F} C M D=\operatorname{tr}\left(\mathrm{OV}_{\mathbf{F}}^{*}\right)$, exatamente como em modelos hierárgui$\cos$.

Além disso, comparando [29] com [2B] é evidente que os $f^{*}$ 's são os $v^{*} s$ com

$$
\begin{aligned}
& \alpha_{A}^{2} \text { substituido por } \alpha_{A}^{2}-\alpha_{A B}^{2} N_{B}, \\
& \alpha_{B}^{2} \text { substituido por } \alpha_{B}^{2}-\sigma_{A B}^{2} N_{A} \\
& \alpha_{A B}^{2} \text { substituido por } \alpha_{A B}^{2}-\alpha_{\theta}^{2} N_{\theta} \\
& \alpha_{e}^{2} \text { substituido por } \alpha_{\theta}^{2}
\end{aligned}
$$

$e \operatorname{assim} E_{F}(M) \doteq E_{\infty}(M)$ 
Esses resultados estäo mostrados na Tabela 4.

Tabela 4 - Classiticacão Cruzada: Substituicôes necessárias para obtencäo das Esperancas dos Quadrados Médios em modelas com populacóes finitas a partir de popul ações infinitas.

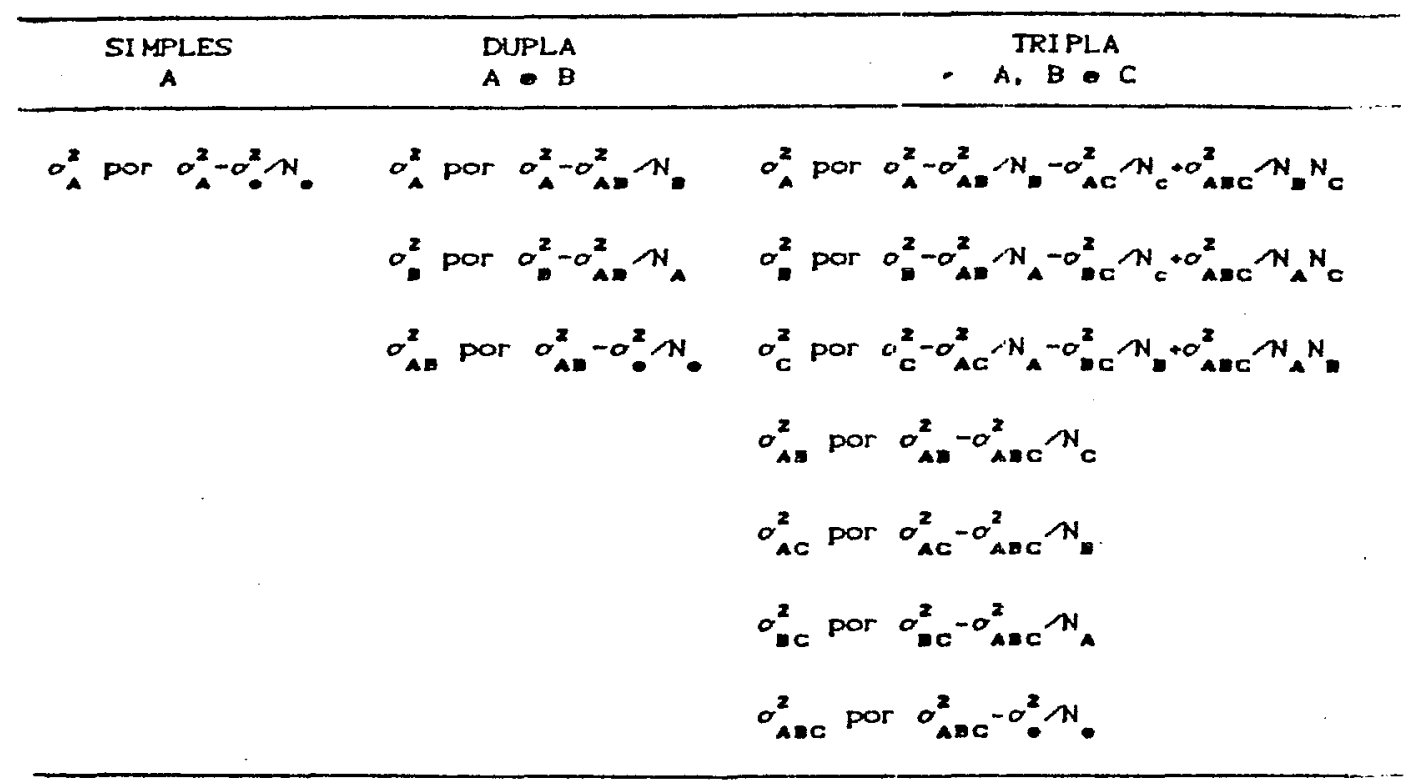

3.1.4.2. Classificação cruzada geral

O modelo de classificacão cruzada tripla é obtido por uma natural extensão dos mótodos usados nas equaCôes $[27$ a $[30]$ para o caso de classificacão dupla. os resultados estäo mostrados na Tabela 4. Para obtê-los, todas as très interacöes duplas dos fatores no modelo se comportam como [26] e o comportamento da interacâo tripla é semelhante, embora existam aito diferentes termos nas partes de [27] e năo apenas quatro como mostrou-se aqui. É claro que a complexidade algébrica dos passos é maior do que o caso de classificacäo dupla. Vejamos o resultado geral. 
49.

É Simples: numa classificacão cruzada, de ordem $r$, com efeitos principais $A, B, \ldots, R$, substitui-se o componente erro por ele mesmo, como na classificacão hierárquica; para o componente de interação de ordem mais elevada substitui-se:

$$
\sigma_{A B}^{2} \ldots R \quad \text { por } \quad \sigma_{A B}^{2} \ldots R-\frac{\sigma_{e}^{2}}{N}
$$

- para qualquer outra interacão ou componente de efeito

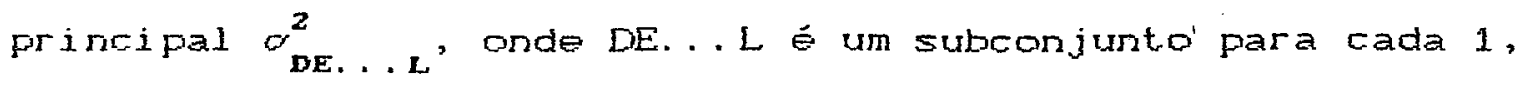
$2, \ldots, r^{-1}$ letras para $A, B, \ldots, R$, substitui-se

$$
\theta_{D E \ldots L}^{2} \quad \text { For } \quad \phi_{\text {DE. } \ldots 2}^{2} \Pi<1-g_{\theta}
$$

onde $\theta$ pertence a todo efeito principal que cruza DE..L e $g_{\ominus}$ : uma funçăo operacional tal que multiplica $\alpha^{2}$ por $g_{\ominus}$ acrescentando $\theta$ como subscrito de $\alpha^{2}$ e divide o resultado por Ne. For exemplo,

$$
\sigma_{A}^{2} g_{B}=\sigma_{A B}^{2} N_{B} \quad \theta \quad \sigma_{A B}^{2} g_{C}=\sigma_{A B C}^{2} N_{C}
$$

Além disso, a multiplicacão por $g$ é simbólica cisto $g_{A} g_{B}=g_{A B} 2$, assim

$$
\alpha_{A}^{2} g_{B} g_{C}=\alpha_{A B C}^{2} N_{B} N_{C} \otimes \alpha_{A}^{2} g_{B} g_{C} g_{D}=\sigma_{A B C D}^{2} N_{B} N_{C} N_{D} .
$$

Gom $g_{e}$ usado desta maneira, exemplos de I32l podem ser vistos na Tabela 4; isto é, numa classificacão tripla cruzada, $\alpha_{A}^{2}$ é substituido por:

$$
\begin{aligned}
\left.\sigma_{A}^{2} \prod_{B=B}^{C}\left(1-g_{Q}\right)=\alpha_{A}^{2}\left(1-g_{B}\right)\left(1-g_{C}\right)=c \sigma_{A}^{2}-\sigma_{A}^{2} g_{B}\right)\left(1-g_{C}\right)= \\
=\alpha_{A}^{2}-\alpha_{A}^{2} g_{B}-\alpha_{A}^{2} g_{C}+\alpha_{A}^{2} g_{B} g_{C}= \\
=\alpha_{A}^{2}-\alpha_{A B}^{2} N_{B}-\alpha_{A C}^{2} N_{C}+\alpha_{A B C}^{2} N_{B} N_{C}
\end{aligned}
$$


simultaneamente $\sigma_{A B}^{2} \Leftrightarrow$ sufstituido for

$$
\alpha_{A B}^{2}\left[1-g_{C}\right\rangle=\sigma_{A B}^{2}-\alpha_{A B}^{2} g_{C}=\sigma_{A B}^{2}-\alpha_{A B C}^{2} N_{C}
$$

Os resultados da tabela 4 são para modelos que tem todas as interacóes possiveis entre eles. Quando um modelo nấo tem todas as interacốs que poderiam ser incluídas as esperancas dos quadrados médios para populacão finita são obtidos inicialmente encontrando seus valores em populacóes infinitas com todas as interaroses incluidas, depois fazendo as substituiçôs acima e colocando as variâncias das interacões identicamente iguais a zero.

\subsubsection{Combinaçâo de classificacăo hierárquica e cru- zada}

Agora estender-se-á o resultado [32] de classificacôes cruzadas para modelos consistindo de qualquer combinacão de classificaçăo hierărquica e cruzada. As regras [22] e [32], respectivamente, para classificacóes puramente hierárquica e cruzada, serăo casos especiais para regras mais gerais.

$$
\text { Tomar-se-á como ponto inicial a classificacão }
$$

hierárquica.

$$
\text { Para } \gamma \text { hierárquico dentro de } \theta \text {, seja hyo uma }
$$

funcão operacional, semelhante a natureza de ge [32], mas tal que $h_{y: e}$ multiplica somente

$$
\sigma_{\theta}^{2} \quad \sigma_{\theta}^{2} \cdot h_{\gamma: \theta}=\sigma_{\gamma}^{2} \mu_{\gamma}
$$


Operacionalmente, o efeito de multiflicar $\alpha_{\theta}^{2}$ por $h_{\gamma}$ é acrescentar $\gamma: \theta$ ao subscrito de $\alpha_{\theta}^{2} \theta$ entäo "cancelar" os $\theta^{\prime} s$ porque a ocorre à direita dos "dois pontos" en h a também em $\sigma^{2}$; o resultado, $\sigma_{\gamma}^{2}$, é dividido por $N_{\gamma}$, como em [33]. A vantagem desta notacäo, hye' será evidente na aplicacão geral.

Para classificacão hierárquica, a regra l 2 zl

pode ser escrita como a substituição de

$$
\sigma_{\theta}^{2} \text { por } \quad \alpha_{\theta}^{2}\left(1-\mathrm{h}_{\gamma} \theta^{2}\right.
$$

onde $\gamma$ é fator imediatamente hierárguico dentro de $\theta$. Isto também inclui a regra de trocar $\sigma_{0}^{2}$ por ele mesmo porque $h_{y: \theta}=0$, desde que näo existe fator hierárquico dentro do fator erro.

Para classificacão cruzada, a regra [34] para a interacão de ordem mais elevada é substituir:

$$
\sigma_{A B \ldots}^{2} \text { por } \sigma_{A B \ldots R}^{2}\left(1-h_{E: A B} \ldots R^{2}=\alpha_{A B}^{2} \ldots R-\frac{\sigma_{\theta}^{2}}{N_{\theta}}\right. \text { (35) }
$$

que é a $[31]$. A partir dai, $\alpha_{e}^{2}$ vem da definicăo [33] na qual, claro, 9 não é necessariamente o efeito principal mas pode ser, como aqui, uma interacão.

Finalmente, o resultado geral [32] pode ser melhorado ao fazer o cálculo para classificacão hierárquica efetuando sua multiplicacão pela expressão 1 -h re $_{\text {DE... }}$ para qualquer fator $y$ que é o fator imediatamente hierárquico dentro de $e_{\text {DE...L }}$, onde $\Theta_{D E . . L}$ é qualquer efeito principal $D, E, \ldots$ ou $L$ ou qualquer fator interacăo desses efeitos principais. Assim, para englobar todas as combinacões das classificaròes hierárquicas ou cruzadas, incluindo o "fator" erro, generaliza-se a regra seguinte. 
SẼ.

Regra: Num modelo com tatores $A, F, \ldots$, E que tanto pode ser hierárquico quanto cruzado, substitui-se:

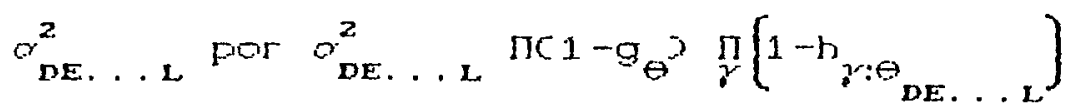

onde $\Leftrightarrow$ pertence a todo efeito principal que cruza DE. . L e r é olator hierárquico dentro de $\Theta_{\text {DE. . . L }}$.

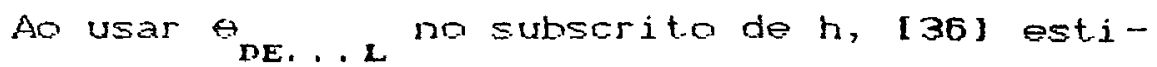

pula o termo erro como um fator hierăquico, como ilustrado em I351, e da mesma forma também prevé situacóes nas quais um fator precisa ser hierárquico dentro da interacão de dois Cou mais) outros fatores. De qualquer mado, fatores hierárquicos säo usualmente hierárquicos justamente dentro de fatores únicos e não interapões deles, em cujo caso, com excecão de \{31\}, o resultado geral [36] torna-se, substituir:

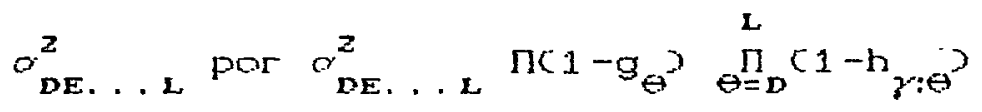

onde e pertence a todo efeito principal que cruza DE. . L.

$$
\text { Exemplos de [37] estäo mostrados na Tabela } 5 \text {, }
$$

nas tres primeiras entradas. Assim:

$\alpha_{A}^{2}$ é substituido por:

$$
\begin{aligned}
\sigma_{A}^{2}\left(1-g_{B}\right)\left(1-h_{P: A}\right) & \left.=c \alpha_{A}^{2}-\sigma_{A}^{2} g_{B}\right)\left(1-h_{P: A}\right)= \\
& =\sigma_{A}^{2}-\alpha_{A B}^{2} N_{B}-\alpha_{P}^{2} N_{P}+\sigma_{P B}^{2} N_{P}^{N} N_{B},
\end{aligned}
$$

$\alpha_{g}^{2}$ é substituido por:

e

$$
\sigma_{B}^{2}\left(1-G_{A}\right)=\sigma_{B}^{2}-\sigma_{A B}^{2} N_{A}
$$

$\sigma_{A B}^{2} \dot{e}$ substituido por:

$$
\alpha_{A B}^{2}\left(1-h_{P: A}\right)=\alpha_{A B}^{2}-\alpha_{P B}^{2} N_{P} .
$$


53

Tabela 5 - Combinacăo de Classificacóes cruzadas e hierárquicas: substituicöes necessárias para obtencão das esperangas dos quadrados médios em modelos com populacões finitas e populacóns infinitas.

\section{CRUZADOS E 1 HIERARQUICO}

$A$ A CRUZADOS, $~ P$ HIERARQUICO DENTRO DE A

$$
\begin{aligned}
& \alpha_{A}^{2} \text { por } \alpha_{A}^{2}-\alpha_{A B}^{2} N_{B}-\sigma_{P}^{2} N_{P}+\sigma_{P B}^{2} N_{P} N_{B} \\
& \sigma_{B}^{2} \text { por } \alpha_{B}^{2}-\alpha_{A B}^{2} N_{A} \\
& \alpha_{A B}^{2} \text { for } \sigma_{A B}^{2}-\alpha_{P B}^{2} N_{P} \\
& \sigma_{P}^{2} \text { por } \alpha_{P}^{2}-\sigma_{P B}^{2} N_{B} \\
& \sigma_{P B}^{2} \text { por } \sigma_{P B}^{2}-\sigma_{\theta}^{2} N_{B}
\end{aligned}
$$

Z CRUZADOS E 2 HIERARQUTCO

$A=B$ GRUZADOS, $-P$ DENTRO

$D E A \odot Q$ DENTRO DE $B$
$A \odot B$ GRUZADOS, $P P$ DENTRO DE Q DENTRO DE $P$

$\alpha_{A}^{2} p o r \sigma_{A}^{2}-\alpha_{A B}^{2} / N_{B}-\sigma_{P}^{2} N_{P}+\alpha_{P B}^{2} N_{P} N_{B} \alpha_{A}^{2} p o r \alpha_{A}^{2}-\alpha_{A B}^{2} N_{B}-\sigma_{P}^{2} N_{P}+\alpha_{P B}^{2} N_{P} N_{B}$

$\sigma_{B}^{2}$ por $\sigma_{B}^{2}-\sigma_{A B}^{2} N_{A}-\sigma_{Q}^{2}-N_{Q}+\sigma_{A Q}^{2} N_{A} N_{Q} \quad \sigma_{B}^{2}$ por $\sigma_{B}^{2}-\sigma_{A B}^{2}-N_{A}$

$\sigma_{A B}^{2}$ por $\alpha_{A B}^{2}-\sigma_{A Q}^{2} N_{Q}-\sigma_{P B}^{2} N_{P}+\sigma_{P Q}^{2} N_{P} N_{Q} \quad \sigma_{A B}^{2}$ por $\alpha_{A B}^{2}-\alpha_{P B}^{2} N_{P}$

$\alpha_{P}^{2}$ por $\alpha_{P}^{2}-\sigma_{P B}^{2} N_{B}$

$\sigma_{P}^{2}$ por $\sigma_{P}^{2}-\sigma_{P B}^{2} N_{B}-\sigma_{Q}^{2} N_{Q}+\sigma_{Q B}^{2} N_{Q} N_{B}$

$\sigma_{F B}^{2}$ por $\sigma_{P B}^{2}-\sigma_{F Q}^{2} N_{O}$

$\sigma_{P B}^{2}$ por $\sigma_{P B}^{2}-\sigma_{O B}^{2} N_{G}$

$\sigma_{Q}^{2}$ por $\sigma_{Q}^{2}-\sigma_{A Q}^{2}{ }_{A}$

$\alpha_{a}^{2}$ par $\sigma_{a}^{2}-\sigma_{a B}^{2} N$

$\sigma_{A Q}^{2}$ por $\sigma_{A O}^{2}-\sigma_{P Q}^{2} N_{P}$

$\sigma_{Q B}^{2}$ por $\alpha_{Q B}^{2}-\sigma_{\theta}^{2}-N$

$\alpha_{P Q}^{2}$ por $\alpha_{P Q}^{2}-\alpha_{e}^{2} / N$ 
54.

A deducáo dos cutoros resultados da Tabela 5. segue de modo semelhante. É claro que quando näo existem fatores hierárquicos, os termos h são zero e [36] $=[37]$ se reduzem a [32] para modelos de classificacâo cruzada. Da mesma forma, guando não existem fatores cruzados, os termos g são zero $[\{36]$ e [37 se reduzem a [34] e consequentemente a [ZZ] para modelos hierárquicos. Desta forma, [36], e sua forma simplificada [37], aplica-se a todos os modelos.

\subsubsection{Modelos mistas}

A discussão precedente refere-se a model os com efeitos aleatórios e as esperancas dos quadrados médios na anälise de variância para dados balanceados e aos "quadrados médios" usados em anälises de variância anälogas para dados desbal anceados (Método 1 de HENDERSON, 1953), como discutido em SEARLE (19B8). Nesses casos, não existem termos em $\mu$ nos quadrados médios. Similarmente, para modelos mistos o procedimento também se aplica ao quadrado médio que não contém termos de efeitos fixos.

Com dados balanceados, é sur̃iciente que isto ocorra sempre em análise de variancia para estimar componentes de variância, e assim essa regra para troca da esperanca do quadrado médio de populacăo infinita para populacão finita se aplica.

com dados desbalanceados, a mesma situacão aparece no Método das Constantes Ajustadas CMétodo 3 de 
58.

HENDERSON, 19533, denominacäo motivada pelo fato de que algumas vezes os efeitos fixos em modelos de efeitos fixos săo chamados de constantes. Este mẹtodo não usa soma de quadrados da ANOVA, mas reduçós nas somas de quadrados, devido ao ajustamento de constantes o os componentes de variância são estimados através do ato de i gualar cada reducão calculada ao seu valor esperado sob o modelo completo. SEARLE (1988) mostra que, neste método, sempre existem diferencas entre certos residuos que näo contém os efeitos fixos e assim săo usados para estimar as variâncias näo tendenciosamente. Para essas diferencas $\{35\}$ também se aplica.

o procedimento geral $[35]$ tem, portanto, aplicacão ampla. Pode ser utilizado para dados balanceados e destalanceados em modelos aleatórios ou mistos.

\subsection{Estimação de Máxima Yerossimilhança Restrita Para Componentes de Variáncia em Modelos Mistos}

\subsubsection{Introdução}

Considere-se o modelo misto da análise de variânia representado por um vetor de observaróos y tal que

$$
y=x \mu+U \cdot \beta+e
$$

ande:

$$
\begin{aligned}
& \mu \text { é um vetor dos efeitos fixos; } \\
& \beta \text { é um vetor dos efeitos aleatórios; } \\
& x \text { e u as respectivas matrizes do delineamento e } \\
& \text { e é um vetor de erros tendo variància } o^{2} \text {. }
\end{aligned}
$$


As diferentes variancias dos elementos de $\beta$ e de e säo os componentes de variancia do modelo.

o procedimento de MV de HARTLEY \& RAO (1967) produz a estimacão simultânea dos efeitos fixos e dos componentes de variância pela maximizacăo de $y$ em relacâo a cada elemento de $\mu$ em relacão a cada componente de variância.

Em contraste, CORBEIL \& SEARLE (1976b) desenvolveram estimadores ce suas variancias para amostras grandes) que são livres dos feitos fixos, no sentido de que a verossimilhanca não contém $\mu$; isto é, maximizaram a verossimilhanca sobre um conjunto restrito de parâmetros. Esta é uma generalizacấo do procedimento sugerido por THOMPSON (1902) gue considerou o problema somente para dados balanceados e para modelos completamente casualizados. O procedimento aqui desenvolvido é aplicável para dados năo balanceados gerais cincluindo, é claro, dados balanceados, os quais são, justamente, um caso especiall, e é também aplicável a modelos mistos para qualquer mistura de efeitos fixos e aleatórios. Isto é conseguido pela adaptacăo da transforma६ăo utilizada por PATTERSON \& THOMPSON (1971) que procedeu à particão da função de verosimilhanca em duas partes, sendo wma delas inteiramente livre dos efeitos fixos e sua maximizaçăo resulta no que chamamos de estimadores de máxima verossimilhanca restrita CMVRo para os componentes de variäncia. Foi feita uma adaptacăo da transformaça descrita for HEMMERLE e HARTLEY (1973) que simplifica grandemente o cálculo dos estimadores de HARTLEY e RAO, auxilia o cálculo 
57.

dos estimadores de MVR e também simplifica a deducäo de suas variăncias para amostras grandes. Finalmente, maximizando a parte da verossimilhanca näo utilizada pelos estimadores de MVR, obtém-se a estimacão dos efeitos fixos, baseados nos estimadores de MVR.

Os estimadores de MVR não säo somente invariantes para os efeitos fixos do modelo, mas são também livres das estimativas dos efeitos fixos. Além disso, em muitos casos de dados balanceados Cigual número de observacóes em subclassesj investigados, os estimadores de MVR são identicos aos familiares estimadores de análise de variancia CANOVA para tais dados. Os estimadores de MV de HARTLEY \& RAO não possuem esta propriedade e ela é considerada em razão das propriedades ótimas dos estimadores de ANOVA para componentes de variancia para dados bal anceados.

\subsubsection{O modelo}

$$
\begin{aligned}
& \text { Seja o modelo [3B] caracterizado por } \\
& y=x \mu+U_{1} b_{1}+u_{2} b_{z}+\ldots+U_{c} b_{c}+e
\end{aligned}
$$

onde:

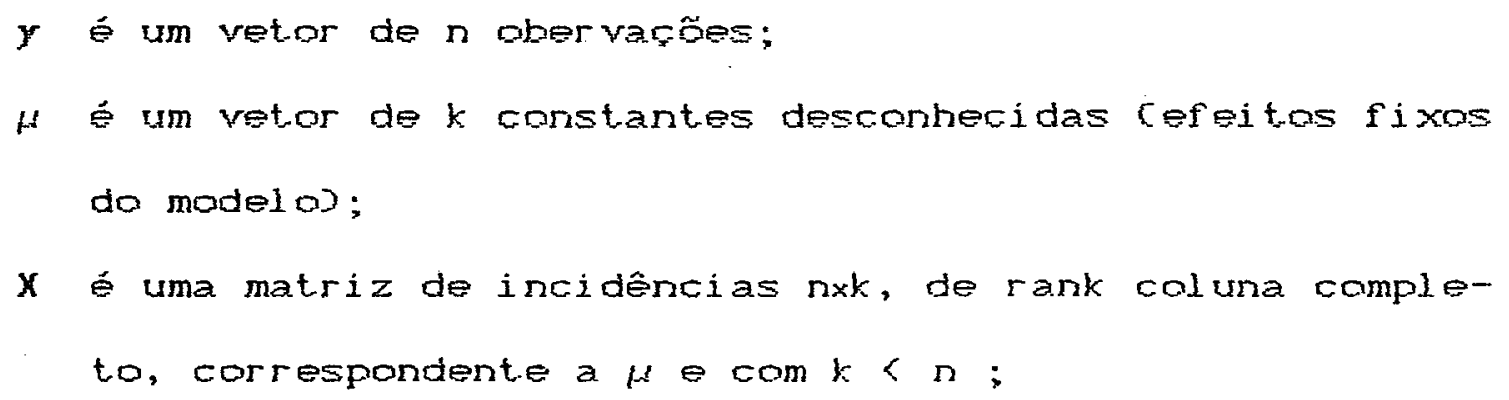


58.

$u_{i}$ é uma matriz do delineamerto $n \times m_{i}$ associada com o i-ésimo fator aleatório, com

$$
\sum_{i=1}^{c} m_{i}+k<n ;
$$

$b_{i}$ é um vetor de $m_{i}$ variáveis aleatórias independentes identicamente distribuidas segundo $N\left(O_{;} \sigma_{i}^{2}\right.$ com os $b_{i}$ 's sendo mutuamente independentes;

- bum vetor de $n$ variáveis aleatórias i.i.d. N(O; $d^{2}$ ) independente dos $b_{i}^{\prime} s$.

Portanto, y tem distribuição Normal multivariada com

$$
\text { média } E(y)=X \mu
$$

e

$$
\text { variancia } \operatorname{Var}(\mathbf{y})=\mathrm{V}=\mathbf{H} \cdot \mathrm{d}^{2}
$$

onde

$$
H=\sum_{i=1} \gamma_{i} u_{i} v_{i}^{\prime}+I_{n}
$$

para

$$
\gamma_{i}=\sigma_{i}^{2}-\sigma^{2}
$$

pois

$$
\begin{aligned}
& V(y)=V\left(x \mu+u_{1} b_{1}+\ldots+u_{c} b_{c}+e\right)= \\
& =u_{1} V\left(b_{1}\right) u_{1}^{\prime}+\ldots+u_{c} V\left(b_{c}\right) u_{c}^{\prime}+V(e)= \\
& =u_{1} \alpha_{1}^{2} u_{1}^{\prime}+\ldots+u_{c} \alpha_{c}^{2} v_{c}^{\prime}+\alpha^{2} I=
\end{aligned}
$$

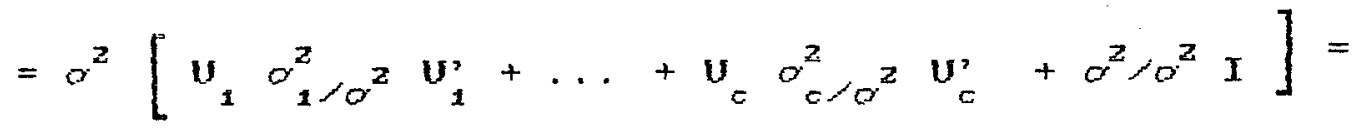

$$
\begin{aligned}
& =\theta^{2}\left[u_{1} \gamma_{1} u_{1}^{s}+\ldots+U_{c} \gamma_{c} U_{c}^{\prime}+I\right]= \\
& =\sigma^{2}\left[\sum_{i=1}^{c} \gamma_{i} u_{i} U_{i}^{\prime}+I\right]=\sigma^{2} H \text {. }
\end{aligned}
$$


s9.

tem-se que $\mu E$ um vetor do número máximo de funcôes estimáveis linearmente independentes dos efeitos fixos. 0 mais simples desses vetores tem como seus elementos as médias populacionais de todas as células de efeitos fixos que contém dados. A correspordente $X$ de $[39]$ assume uma forma simples.

Define-se y como sendo as abservacónes ordenadas tal que todas elas, dentro de cada célula dos fatores de efeitos fixas, seguem sequencialmente um outro. Se existem $k$ dessas células contendo dados, com a t-ésima delas tendo $n_{i}$ o observacões, então

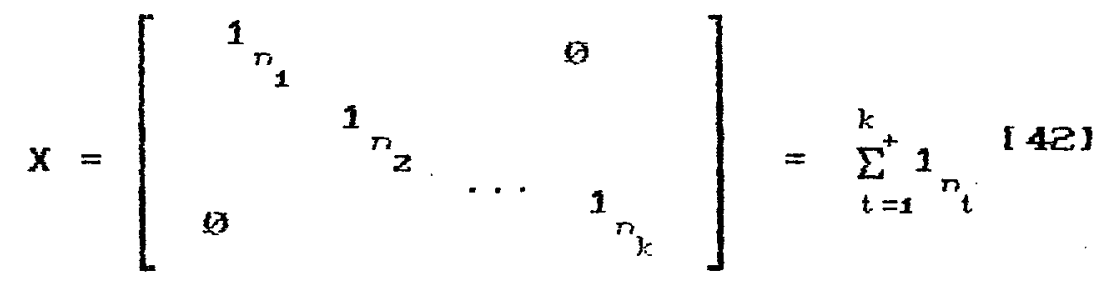

onde ${ }^{1} n_{t}$ é um vetor de $n_{t}$ uns $e \bar{\Sigma}^{*}$ representa uma soma direta de matrizes.

Uma ilustraça é dada a seguir em termos de um exemplo numérico apresentado por BOWKER \& LIEBERMAN (1968), que consiste de três observacões em cada célula de uma classificacão cruzada dupla com três linhas e duas colunas:

Um engenherio de garantia de qualidade ao trabalhar com um componente eletronico industrial percebe, intuitivamente, que existe grande variabilidade entre os fornos utilizados por sua firma para testar a vida dos vários componentes. Para verificar se está ou não correto, ele escolheu um tipo de componente e obteve os dados apresentados na Tabela 6 , para trés temperaturas comumente 
utilizadas para testar a vida destes itens. O componente é acionado no forno até fa- Ihar. Dois fornos aleatoriamente escalhidos for am utilizados no experimento.

Tabel a 6

Tempo dos componentes Cem minutos?

\begin{tabular}{|c|c|c|}
\hline \multirow{2}{*}{ TEMP } & \multicolumn{2}{|c|}{ FOENOS } \\
\hline & $F_{1}$ & $\mathrm{FZ}$ \\
\hline \multirow{3}{*}{$500^{\circ} \mathrm{F}$} & 237 & 178 \\
\hline & 254 & 179 \\
\hline & 246 & $183 *$ \\
\hline \multirow{3}{*}{$550^{\circ} \mathrm{F}$} & 208 & 146 \\
\hline & 178 & 145 \\
\hline & 187 & 141 \\
\hline \multirow{3}{*}{$\operatorname{BOO}^{\circ} F$} & $192 *$ & 142 \\
\hline & 186 & 125 \\
\hline & 183 & 136 \\
\hline
\end{tabular}

O madelo para $y_{\text {pqr }}$ r-ésima obervacâa na p-ésiima linha q-ésima coluna é

$$
y_{\mathrm{pqT}}=\mu+\alpha_{\mathrm{p}}+\beta_{\mathrm{q}}+\operatorname{cop}_{\mathrm{pq}}+e_{\mathrm{pqT}}
$$

para $p=1,2,3 ; q=1,2$ e $r=1,2,3$ onde $\mu$ é a média geral; $\alpha_{p}$ é ofeito devido a pósima linha; $\beta_{q}$ o o efeito devido à q-ésima coluna ; $C \alpha \beta)_{p q}$ é o efeito da interação e e pqr é o termo erro associado à observacão $y_{\text {pgr }}$.

HEMMERLE \& HARTLEY (1973) adaptaram o exempio para ilustrar dados näo balanceados, fom a retirada de duas observacóes Cassinaladas com * na Tabela b), de modo que o número de observaçôes em cada célula aparece na Tabela 7. 
Tabel a 7

\begin{tabular}{ccccc} 
& COLUNA 1 & COLUNA 2 & TOTAL \\
\hline Iinha 1 & 3 & 2 & 5 \\
Iinha 2 & 3 & 3 & 6 \\
Iinha 3 & 2 & 3 & 5 \\
\hline
\end{tabular}

Agora, $r=1,2, \ldots n_{p q}$ para $n_{p q}=2$ ou 3 .

Considerando dados desta natureza como sendo de um modelo misto com efeito de linha fixo, temos $n=16$ observacóes para o modelo [39], com $c=2$ fatores aleatórios nas colunas com $m_{1}=2$ niveis e interacöes com $m_{z}=6$ niveis. A razão dos componentes de variancia para esses fatores säo, respectivamente, $\gamma_{1}=\sigma_{\beta}^{2} \alpha^{2}$ e $\gamma_{2}=\alpha_{\alpha \beta}^{2} \alpha^{2}$ de acordo com [411. As rélulas dos fatores de efeitos fixos estão nas linhas, que são três, e, assim, para $x$ de $[421$, $k=3$ os valores de $n_{k}$ são $n_{1}=5, n_{2}=6$ e $n_{3}=5$.

Matricialmente, o modelo para os dados da Tabela 8 é: 


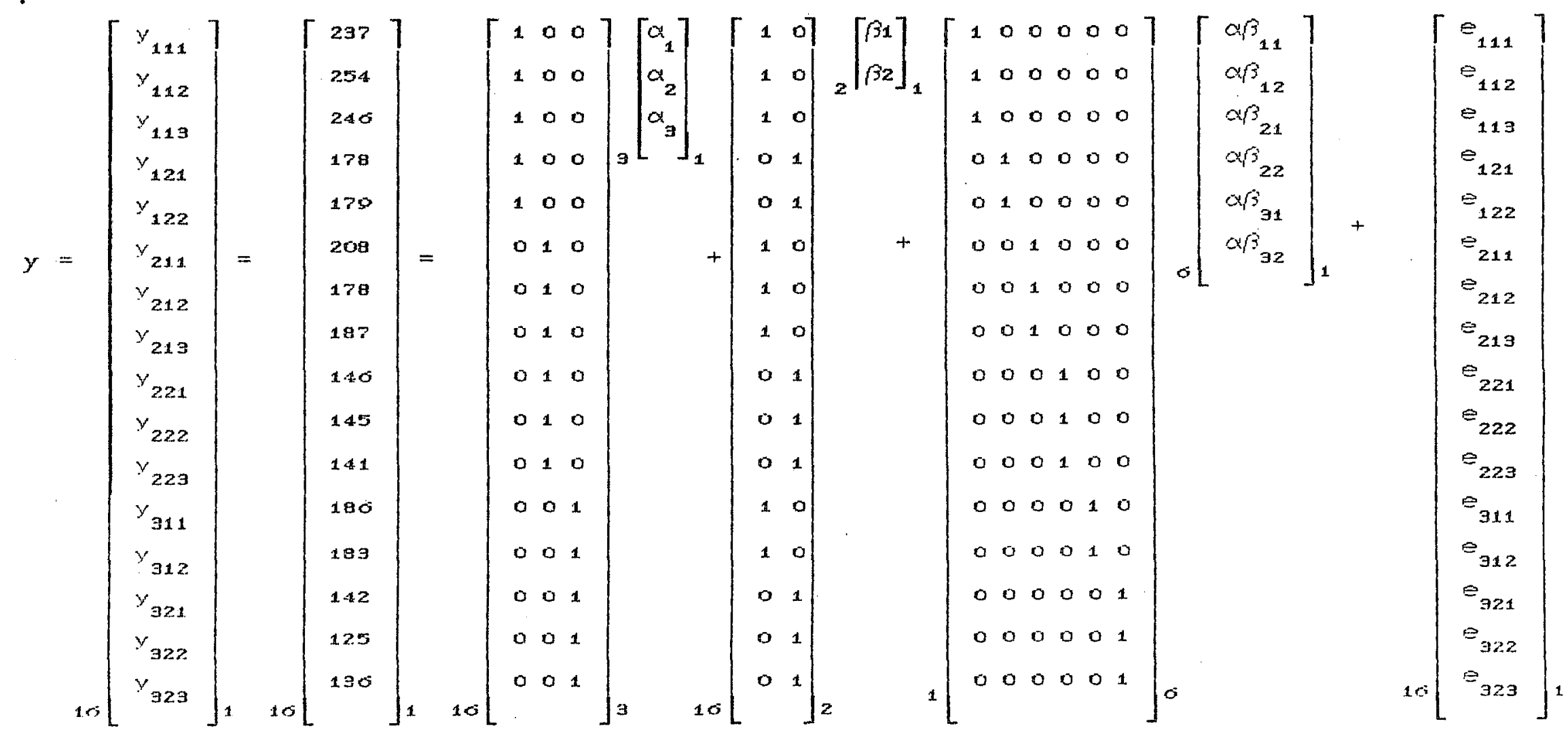

ou seja,

$$
y=x \mu+u_{1} b_{1}+u_{2} b_{2}+e
$$

$$
\begin{array}{ll}
\text { para } & c=2 \quad m_{1}=2 \quad m_{2}=0 \\
e & V(y)=H \sigma^{2}, \quad \text { onde }
\end{array}
$$




$$
H=\sum_{i=1} \gamma_{i} U_{i} U_{i}^{\prime}+I_{n}=\gamma_{1} U_{1} U_{1}^{\prime}+\gamma_{2} U_{2} U_{2}^{3}+I_{10}=
$$

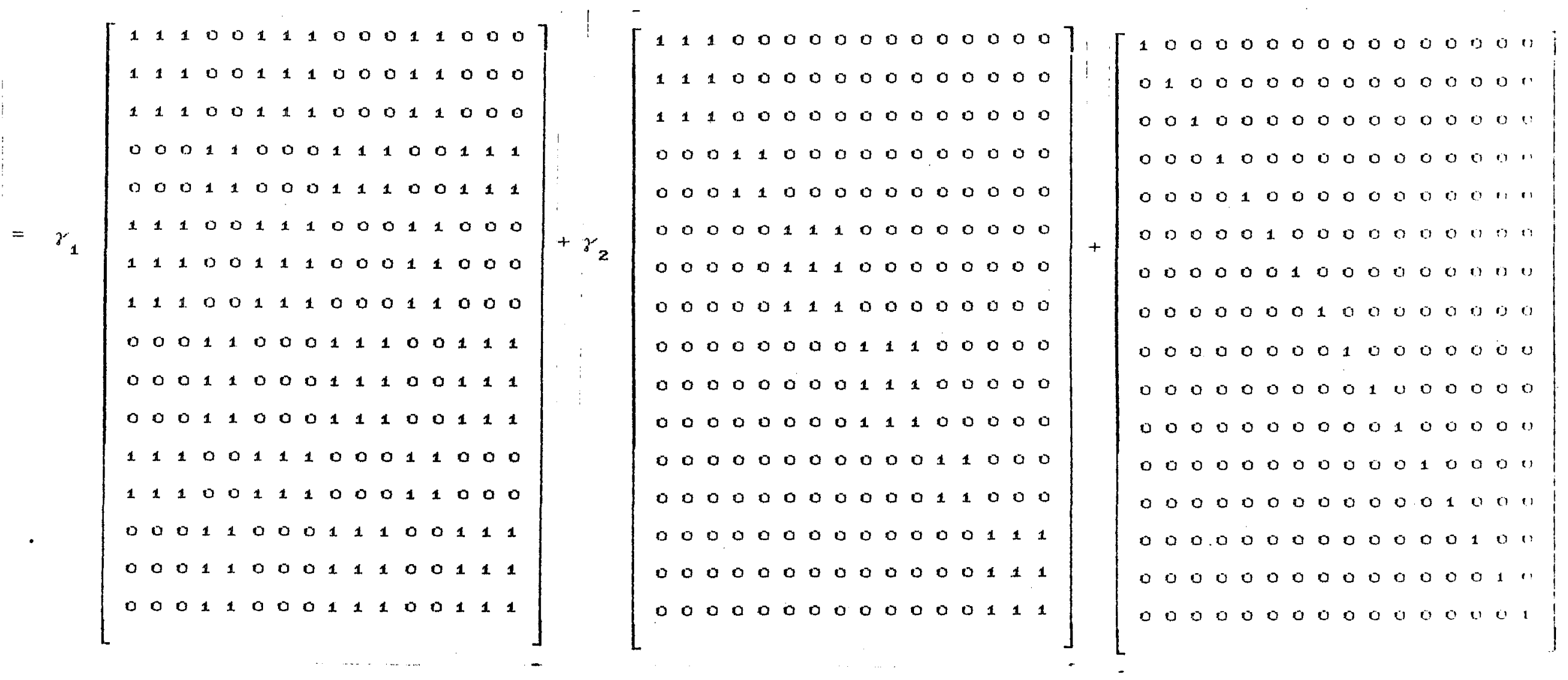




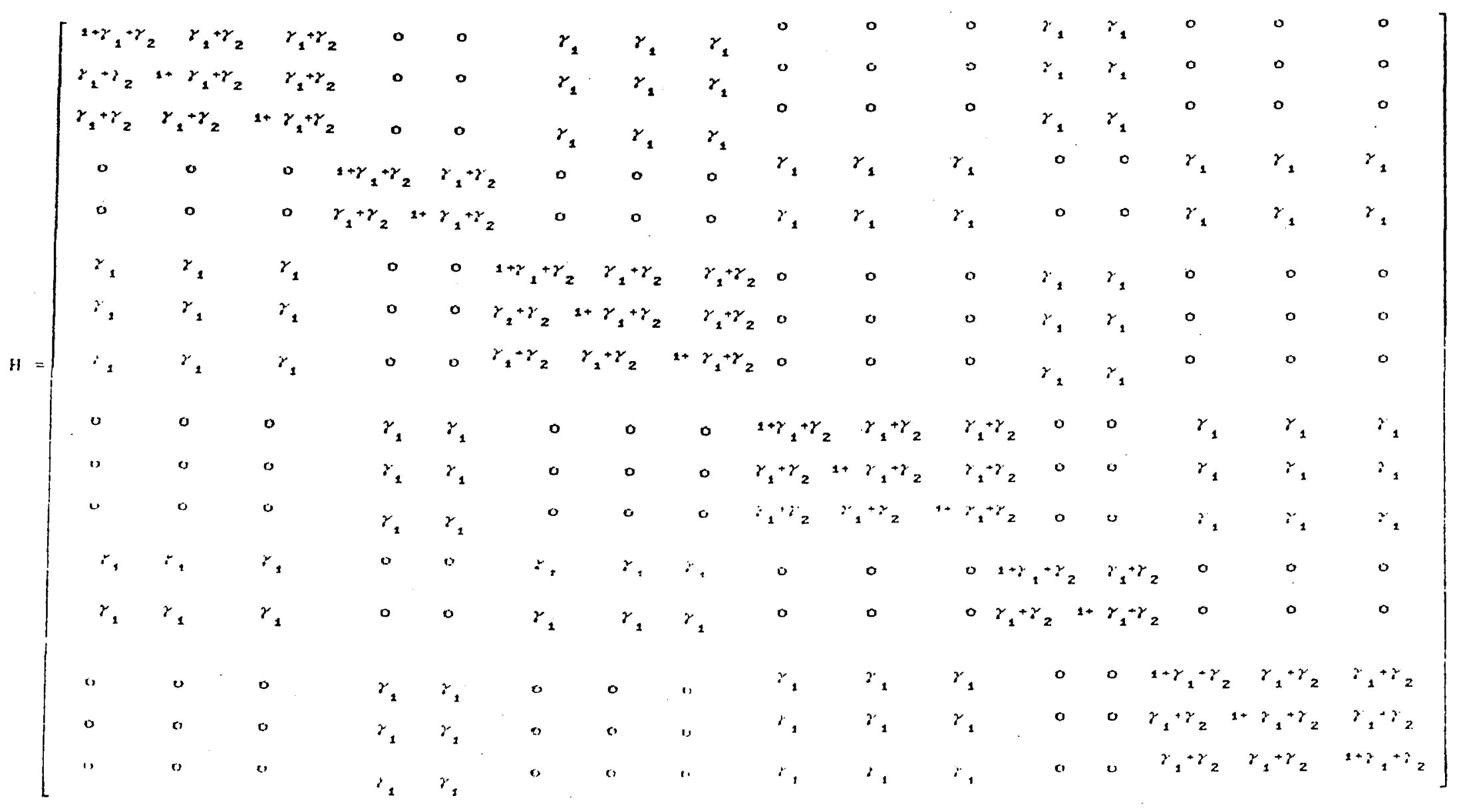


65.

3.2. 3. Os estimadores

Dade a funcão de verossimilhança para

$$
\begin{gathered}
y, N\left(X_{\mu}, H \sigma^{2}\right), \\
L\left(y, \mu, \alpha^{2}, \gamma=\frac{1}{\left.C 2 n \sigma^{2}\right)^{n / 2}|H|^{1 / 2}} \exp \left[\frac{1}{2 \sigma^{2}}(y-x \mu)^{\prime-1}(y-\mu \mu)\right],\right.
\end{gathered}
$$

- logaritmo da funcão de verossimilhanca é

$$
\begin{aligned}
\lambda= & -\frac{1}{2} \Omega \log _{e} 2 \pi-\frac{1}{2} n \log \alpha^{2}-\frac{1}{2} \log _{e}|H|- \\
& \left.-\frac{1}{2 \sigma^{2}} 6 y-x \mu\right)^{\prime} H^{-1}\left(y-x_{\mu}\right.
\end{aligned}
$$

Para reparti-1a om duas partes, uma delas 1 ivTe de $\mu$, PATIERSON \& THOMPSON 41971 s sugerem a transforma६ão singular

ande

$$
\left[\begin{array}{l}
S \\
X^{\prime}
\end{array} H^{-1}\right] y
$$

$$
S=I-X\left(X^{*} x\right)^{-1} X^{*}=\sum_{i=1}^{k}\left(I n_{t}-n_{i}^{-1} J_{n_{i}}\right)
$$

é simétrica e idempotente, sendo $J_{n}$ uma matriz de uns, $n_{t} \times n_{t}$. Desde que SX é nula, pois

$$
\left.\left.S x=\left[I-x C X^{3} x\right]^{-1} x^{\prime}\right] x=x-x c x^{2} x\right)^{-1} x^{\prime} x=x-x I=x-x=0,
$$

Sy tem distribuicăo NCO;SHSO ${ }^{2}$ independentemente de $\mathbf{X}^{\prime} \mathbf{H}^{-1} \mathbf{y}$.

$$
\text { É claro que a distribuicão de Sy é livre dos }
$$

efeitos fixos $\mu$, portanto, sua funçä̊ de verossimilhanç forma a base de nossa deduräo dos estimadores dos componentes de variancia envolvidos en Ho ${ }^{2}$. Entretanto, para evitar a singularidade de SHS surgida da forma de $S$ mostrada em 1441, utilizamos uma alternativa para $S$ dela derivada pela 
BE.

retirada da $n_{1}$-ósima, $c_{n}+n_{2} y$-śsima, $\left.r r_{1}+n_{2}+\ldots n_{k}\right)$ -ésima, ..., $\mathrm{Cn}_{1}+n_{2}+\ldots+n_{k}$ notada por $T$, tem ordem $(n-k) \times n$ é dada por

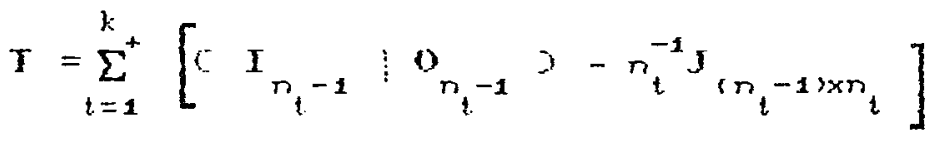

$$
\begin{aligned}
& =\sum_{i=1}^{k} I_{n_{t}}-n_{t}^{-1} J_{n_{t}-1}-n_{t}^{-1} I_{n_{t}-1}
\end{aligned}
$$

[45]

$[46]$

onde $o_{n_{t-1}}$ é um vetor de zeros de ordem $n_{t}^{-1}$ e $J_{\left(n_{t}-1\right)} \dot{e}$ uma matriz de ordem $c_{t}-1$ Jxn aujos elementos são uns.

Para o exemplo que estamos considerando, te-

mos:

$$
n_{1}=5, \quad n_{2}=5 \text { entâs }
$$




$$
\begin{aligned}
& X=\left[\begin{array}{lll}
1 & 0 & 0 \\
1 & 0 & 0 \\
1 & 0 & 0 \\
1 & 0 & 0 \\
1 & 0 & 0 \\
0 & 1 & 0 \\
0 & 1 & 0 \\
0 & 1 & 0 \\
0 & 1 & 0 \\
0 & 1 & 0 \\
0 & 1 & 0 \\
0 & 0 & 1 \\
0 & 0 & 1 \\
0 & 0 & 1 \\
0 & 0 & 1 \\
0 & 0 & 1 \\
0 &
\end{array}\right] ; \quad\left[X^{*} X^{-1}=\left[\begin{array}{lll}
5 & 0 & 0 \\
0 & 0 & 0 \\
0 & 0 & 5
\end{array}\right]\right.
\end{aligned}
$$

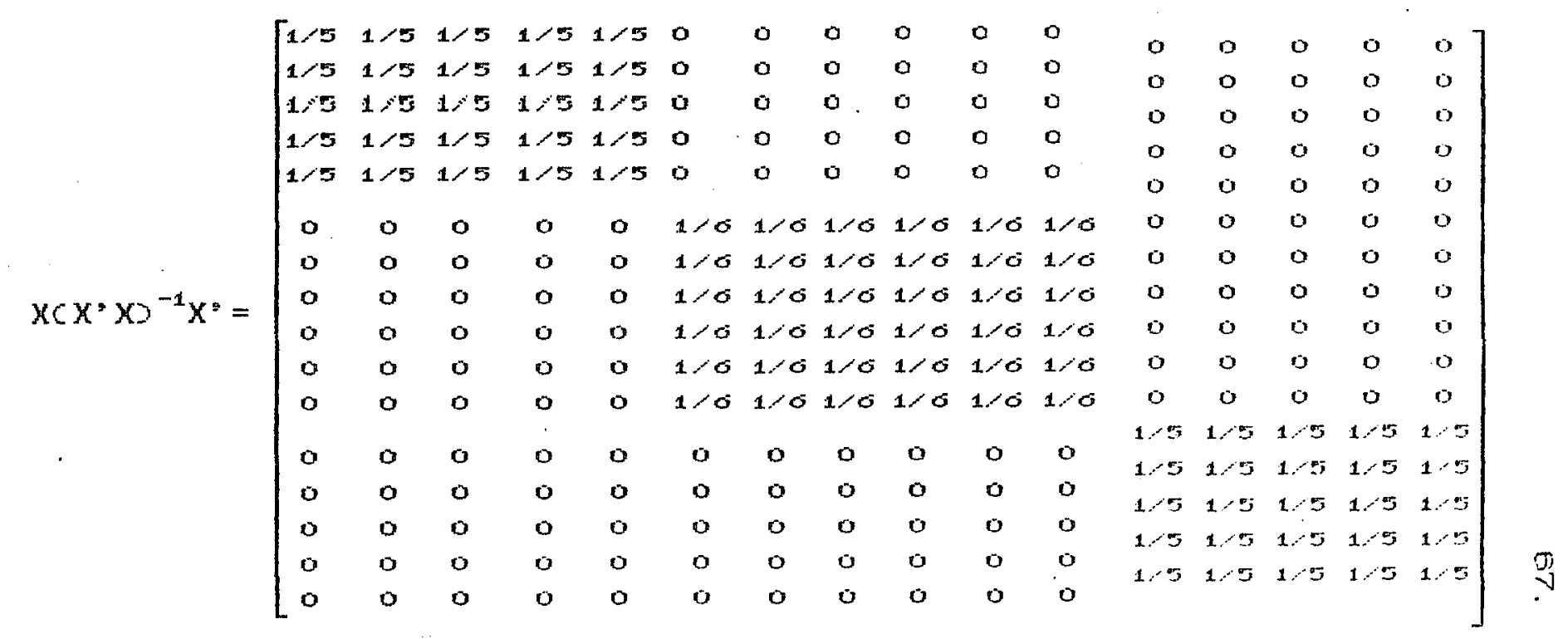




$$
S=\left[\begin{array}{cccccccccccccccc}
4 / 5 & -1 / 5 & -1 / 5 & -1 / 5 & -1 / 5 & 0 & 0 & 0 & 0 & 0 & 0 & 0 & 0 & 0 & 0 & 0 \\
-1 / 5 & 4 / 5 & -1 / 5 & -1 / 5 & -1 / 5 & 0 & 0 & 0 & 0 & 0 & 0 & 0 & 0 & 0 & 0 & 0 \\
-1 / 5 & -1 / 5 & 4 / 5 & -1 / 5 & -1 / 5 & 0 & 0 & 0 & 0 & 0 & 0 & 0 & 0 & 0 & 0 & 0 \\
-1 / 5 & -1 / 5 & -1 / 5 & 4 / 5 & -1 / 5 & 0 & 0 & 0 & 0 & 0 & 0 & 0 & 0 & 0 & 0 & 0 \\
-1 / 5 & -1 / 5 & -1 / 5 & -1 / 5 & 4 / 5 & 0 & 0 & 0 & 0 & 0 & 0 & 0 & 0 & 0 & 0 & 0 \\
0 & 0 & 0 & 0 & 0 & 5 / 0 & -1 / 0 & -1 / 0 & -1 / 0 & -1 / 0 & -1 / 0 & 0 & 0 & 0 & 0 & 0 \\
0 & 0 & 0 & 0 & 0 & -1 / 0 & 5 / 0 & -1 / 0 & -1 / 0 & -1 / 0 & -1 / 0 & 0 & 0 & 0 & 0 & 0 \\
0 & 0 & 0 & 0 & 0 & -1 / 0 & -1 / 0 & 5 / 0 & -1 / 0 & -1 / 0 & -1 / 0 & 0 & 0 & 0 & 0 & 0 \\
0 & 0 & 0 & 0 & 0 & -1 / 0 & -1 / 0 & -1 / 0 & 5 / 0 & -1 / 0 & -1 / 0 & 0 & 0 & 0 & 0 & 0 \\
0 & 0 & 0 & 0 & 0 & -1 / 0 & -1 / 0 & -1 / 0 & -1 / 0 & 5 / 0 & -1 / 0 & 0 & 0 & 0 & 0 & 0 \\
0 & 0 & 0 & 0 & 0 & -1 / 0 & -1 / 0 & -1 / 0 & -1 / 0 & -1 / 0 & 5 / 0 & 0 & 0 & 0 & 0 & 0 \\
0 & 0 & 0 & 0 & 0 & 0 & 0 & 0 & 0 & 0 & 0 & 4 / 5 & -1 / 5 & -1 / 5 & -1 / 5 & -1 / 5 \\
0 & 0 & 0 & 0 & 0 & 0 & 0 & 0 & 0 & 0 & 0 & -1 / 5 & 4 / 5 & -1 / 5 & -1 / 5 & -1 / 5 \\
0 & 0 & 0 & 0 & 0 & 0 & 0 & 0 & 0 & 0 & 0 & -1 / 5 & -1 / 5 & 4 / 5 & -1 / 5 & -1 / 5 \\
0 & 0 & 0 & 0 & 0 & 0 & 0 & 0 & 0 & 0 & 0 & -1 / 5 & -1 / 5 & -1 / 5 & 4 / 5 & -1 / 5 \\
0 & 0 & 0 & 0 & 0 & 0 & 0 & 0 & 0 & 0 & 0 & -1 / 5 & -1 / 5 & -1 / 5 & -1 / 5 & 4 / 5
\end{array}\right]
$$




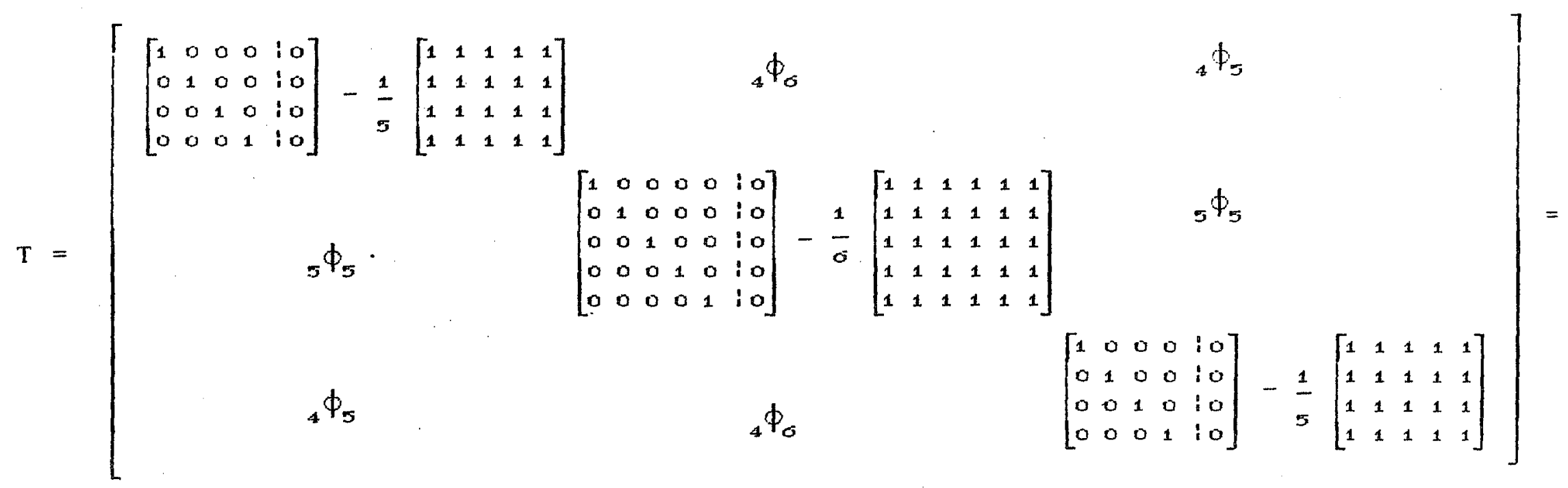

$=\left[\begin{array}{rrrrrrrrrrrrrrrrr}1 / 5 & -1 / 5 & -1 / 5 & -1 / 5 & -1 / 5 & 0 & 0 & 0 & 0 & 0 & 0 & 0 & 0 & 0 & 0 & 0 \\ -1 / 5 & 4 / 5 & -1 / 5 & -1 / 5 & -1 / 5 & 0 & 0 & 0 & 0 & 0 & 0 & 0 & 0 & 0 & 0 & 0 \\ -1 / 5 & -1 / 5 & 1 / 5 & -1 / 5 & -1 / 5 & 0 & 0 & 0 & 0 & 0 & 0 & 0 & 0 & 0 & 0 & 0 \\ -1 / 5 & -1 / 5 & -1 / 5 & 4 / 5 & -1 / 5 & 0 & 0 & 0 & 0 & 0 & 0 & 0 & 0 & 0 & 0 & 0 \\ 0 & 0 & 0 & 0 & 0 & 5 / 0 & -1 / 0 & -1 / 0 & -1 / 0 & -1 / 0 & -1 / 0 & 0 & 0 & 0 & 0 & 0 \\ 0 & 0 & 0 & 0 & 0 & -1 / 0 & 5 / 0 & -1 / 0 & -1 / 0 & -1 / 0 & -1 / 0 & 0 & 0 & 0 & 0 & 0 \\ 0 & 0 & 0 & 0 & 0 & -1 / 6 & -1 / 0 & 5 / 0 & -1 / 0 & -1 / 0 & -1 / 0 & 0 & 0 & 0 & 0 & 0 \\ 0 & 0 & 0 & 0 & 0 & -1 / 0 & -1 / 6 & -1 / 0 & 5 / 0 & -1 / 6 & -1 / 0 & 0 & 0 & 0 & 0 & 0 \\ 0 & 0 & 0 & 0 & 0 & -1 / 0 & -1 / 6 & -1 / 0 & -1 / 0 & 5 / 0 & -1 / 0 & 0 & 0 & 0 & 0 & 0 \\ 0 & 0 & 0 & 0 & 0 & 0 & 0 & 0 & 0 & 0 & 0 & 4 / 5 & -1 / 5 & -1 / 5 & -1 / 5 & -1 / 5 \\ 0 & 0 & 0 & 0 & 0 & 0 & 0 & 0 & 0 & 0 & 0 & -1 / 5 & 4 / 5 & -1 / 5 & -1 / 5 & -1 / 5 \\ 0 & 0 & 0 & 0 & 0 & 0 & 0 & 0 & 0 & 0 & 0 & -1 / 5 & -1 / 5 & 4 / 5 & -1 / 5 & -1 / 5 \\ 0 & 0 & 0 & 0 & 0 & 0 & 0 & 0 & 0 & 0 & 0 & -1 / 5 & -1 / 5 & -1 / 5 & 4 / 5 & -1 / 5\end{array}\right]$


70.

Como pode-se observar, retirande as ultimas I inhas de cada sub-matriz de 5 , reproduz-se $T$.

Para $\mathbf{X}$ de [42] prontamente visto que

$$
I X=\varnothing
$$

e pela própria natureza de $T$, é fácil mostrar que

$$
T^{*}\left(T T^{3}\right)^{-1} T=S
$$

como verificamos numericamente através dos dados.

A transformacăo agora utilizada

$$
z=\left[\begin{array}{c}
T \\
X^{\prime} H^{-1}
\end{array}\right] y=\left[\begin{array}{c}
T Y \\
X^{\prime} H^{-1} y
\end{array}\right]
$$

e com vistas em [47], sua distribuicão é

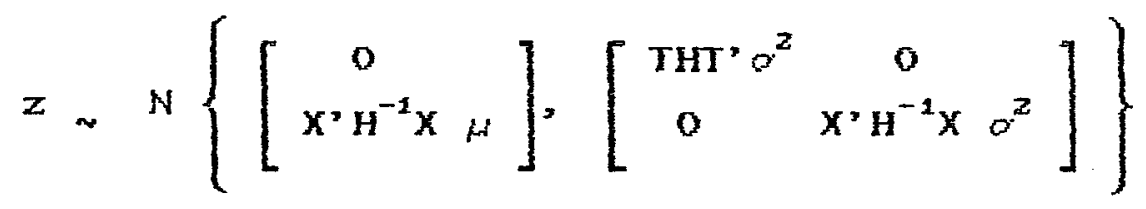

Esta transformacão é não singular porque $X^{\prime}$ e $T$ de $\{42\}$ e [45] têm, cada uma, "rank" Iinha completo e, de [471, as linhas de $T$ são linearmente independentes das linhas de $X^{\prime}$.

Considere-se agora o logaritmo da verossimiIhanca de $z$. Isto é, de $\{49]$ [50\}, o logaritmo da verossimilhanca de TY $\mathrm{T}$ de $\mathbf{X}^{\prime} \mathbf{H}^{-1} \mathbf{Y}$, denotados por $\lambda_{2}$ e $\lambda_{2}$, respectivamente:

$$
\begin{aligned}
& \left.\lambda_{1}=-\frac{1}{2} \ln -k\right\rangle \log _{\theta} 2 \pi-\frac{1}{2} \operatorname{cn}-k \rho 10 g \sigma^{2} \\
& -\frac{1}{2} \log _{e}|\mathrm{THT}|-\frac{1}{2 \sigma^{2}} y^{\prime} \mathrm{T}^{\prime} \mathrm{CTHT} \mathrm{T}^{-1} \mathrm{~T} y
\end{aligned}
$$




$$
\begin{aligned}
& \lambda_{2}=-\frac{1}{2} k \log 2 \pi-\frac{1}{2} k \log _{\theta} \sigma^{2}-\frac{1}{2} \log \left|X_{0} H^{-1} X\right| \\
& -\frac{1}{2 \rho^{2}}\left(X^{\prime} H^{-1} y-X^{\prime} H^{-1} X \omega\right)\left(X^{\prime} H^{-1} X\right)^{-1}\left(X^{\prime} H^{-1} y-X^{\prime} H^{-1} X H\right. \\
& =-\frac{1}{2} k 1 \log _{\theta} 2 \pi-\frac{1}{2} k \log _{\theta} \sigma^{2}-\frac{1}{2} \log _{\theta}\left|X^{\prime} H^{-1} x\right|
\end{aligned}
$$

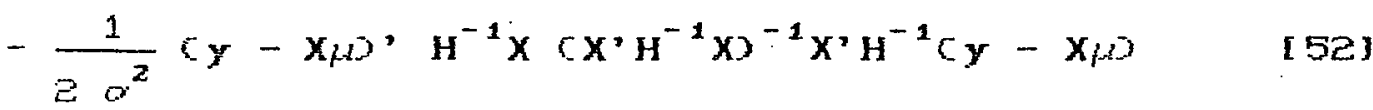

Como $\lambda_{1}$ näo enval ve $\mu$, os estimadores de $\alpha^{2} e$ dos $\gamma_{i}$ 's, chamados estimadores de máxima verossimilhanca restrita (MVR) são, seguindo o mótodo de PATIERSON \& THOMPSON (1971), os valores de $\sigma^{2} e \gamma_{i}$ 's que maximizam $\lambda_{1}$.

Derivando [51] vem:

$$
\begin{aligned}
\frac{\partial \lambda_{1}}{\partial \sigma^{2}}= & -\frac{1}{2 \sigma^{2}}(n-k)+\frac{1}{2 \sigma^{4}} y^{\prime} T^{\prime}\left(T H T T^{\prime-1} T y\right. \\
\frac{\partial \lambda_{1}}{\partial \gamma_{i}}= & -\frac{1}{2} \operatorname{tr}\left[U_{i}^{\prime} T^{\prime}\left(T H T^{\prime}\right)^{-1} T U_{i}\right]+ \\
& +\frac{1}{2 \sigma^{2}} y^{\prime} T^{\prime}\left(T H T^{\prime}\right)^{-1} T U_{i} U_{i}^{\prime} T^{\prime}\left(T H T^{\prime}\right)^{-1} T y
\end{aligned}
$$

para $i=1,2, \ldots, c$, onde troQ é o traco da matriz 0 .

Igual ando [53] e [54] a zero, obtemos os est.imadores de MVR. É claro que as equacões resultantes rão têm solucăo analítica e devem ser resolvidas numericamente. Un frocedimento iterativo é atribuir valores iniciais para

$$
\gamma,=\left\{\gamma_{1}, \ldots, \gamma_{e}\right\}^{\prime}
$$

e entäo:

$$
\begin{aligned}
& \text { (i) resolver } \\
& \qquad \partial^{2}=y^{\prime} T^{\prime}\left(T_{H T}\right)^{-1} \text { Ty }(n-k)
\end{aligned}
$$


7己.

(ii) utilizar os r valores $E c^{2}$ de [55] para calcular os novos o valores que fazem I54] aproximar-se de zero. A repeticäo de (i) e (ii), terminando em (i), é continuada até que o grau de acurácia desejado seja obtido.

Para ilustrar o processo, facamos $\gamma_{1}=20,000$ $r_{2}=0,30$ no nosso exemplo. Entäo: 


$H=\left[\begin{array}{cccccccccccccccc}21,3 & 20,3 & 20,3 & 0 & 0 & 20 & 20 & 20 & 0 & 0 & 0 & 20 & 20 & 0 & 0 & 0 \\ 20,3 & 21,3 & 20,3 & 0 & 0 & 20 & 20 & 20 & 0 & 0 & 0 & 20 & 20 & 0 & 0 & 0 \\ 20,3 & 20,3 & 21,3 & 0 & 0 & 20 & 20 & 20 & 0 & 0 & 0 & 20 & 20 & 0 & 0 & 0 \\ 0 & 0 & 0 & 21,3 & 20,3 & 0 & 0 & 0 & 20 & 20 & 20 & 0 & 0 & 20 & 20 & 20 \\ 0 & 0 & 0 & 20,3 & 21,3 & 0 & 0 & 0 & 20 & 20 & 20 & 0 & 0 & 20 & 20 & 20 \\ 20 & 20 & 20 & 0 & 0 & 21,3 & 20,3 & 20,3 & 0 & 0 & 0 & 20 & 20 & 0 & 0 & 0 \\ 20 & 20 & 20 & 0 & 0 & 20,3 & 21,3 & 20,3 & 0 & 0 & 0 & 20 & 20 & 0 & 0 & 0 \\ 20 & 20 & 20 & 0 & 0 & 20,3 & 20,3 & 21,9 & 0 & 0 & 0 & 20 & 20 & 0 & 0 & 0 \\ 0 & 0 & 0 & 20 & 20 & 0 & 0 & 0 & 21,3 & 20,3 & 20,3 & 0 & 0 & 20 & 20 & 20 \\ 0 & 0 & 0 & 20 & 20 & 0 & 0 & 0 & 20,3 & 21,3 & 20,3 & 0 & 0 & 20 & 20 & 20 \\ 0 & 0 & 0 & 20 & 20 & 0 & 0 & 0 & 20,3 & 20,3 & 21,3 & 0 & 0 & 20 & 20 & 20 \\ 20 & 20 & 20 & 0 & 0 & 20 & 20 & 20 & 0 & 0 & 0 & 21,3 & 20,3 & 0 & 0 & 0 \\ 20 & 20 & 20 & 0 & 0 & 20 & 20 & 20 & 0 & 0 & 0 & 20,3 & 21,3 & 0 & 0 & 0 \\ 0 & 0 & 0 & 20 & 20 & 0 & 0 & 0 & 20 & 20 & 20 & 0 & 0 & 21,3 & 20,3 & 20,3 \\ 0 & 0 & 0 & 20 & 20 & 0 & 0 & 0 & 20 & 20 & 20 & 0 & 0 & 20,3 & 21,3 & 20,3 \\ 0 & 0 & 0 & 20 & 20 & 0 & 0 & 0 & 20 & 20 & 20 & 0 & 0 & 20,3 & 20,3 & 21,3\end{array}\right]$




$$
\begin{aligned}
& \text { Com as matrizes } y, T \text { e } H \text {, obtemas, por } 1551 \\
& \left.\hat{\sigma}^{2}=y^{\prime} \mathrm{TCTHT}^{\prime}\right)^{-1} \text { T } y / 10-30=\frac{1009,0589}{13}=79,1584
\end{aligned}
$$

e calculamos os novos $\gamma_{1} \in \gamma_{2}$ através de

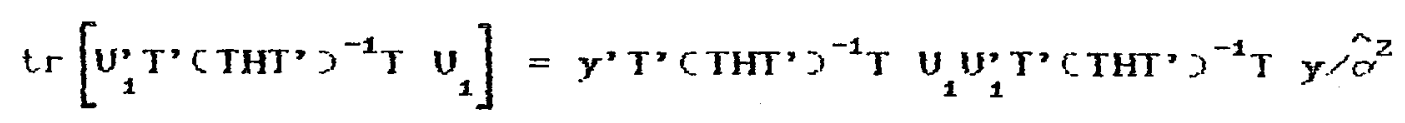

onde $\mathbf{H}$ contém $\gamma_{1}$ como incógnita $=0$ valor iricial para

$\theta$

$$
r_{2}=0,30
$$

$$
\left.\operatorname{tr}\left[U_{2}^{2} T^{\prime} C T H T^{\prime}\right)^{-1} T U_{z}\right]=y^{\prime} T^{\prime} C T H T^{\prime} S^{-1} T U_{z} U_{z}^{\prime} T^{\prime} C T H T^{*} S^{-1} T y r^{2}
$$

onde $\mathrm{H}$ contém $\gamma_{2}$ como incógnita $e \gamma_{1}$ encontrado na expressão anterior.

o processo é repetido até chegar na precisão desejada. No caso, obteremos

$$
\hat{y}_{1}=18,57 ; \quad \hat{y}_{2}=0,32 \quad \hat{c}^{2}=78,84 \text {. }
$$

\subsection{Procedimento de cálculo}

Embor a PATTERSON O THOMPSON (1971) tenham proposto um procedimento baseado no método dos escores de Fisher para $c=1$ sugerido como utilizá-1o para c > 1, a técnica de Newton-Raphson é melhor adaptada a problemas de encontrar sucessivos valores para y que zerem [54] e foi efetivamente aplicada por HEMMERLE \& HARTLEY (1973) para equacöes similares ao método da máxima verassimilhanca de HARTLEY \& RAO (1967). Utiliza-se sua aplicacão aqui, o que simplifica a notacão e procedimento de cálculo. 
75.

\subsubsection{A transformaçäo $V$}

A técnica de Newton-Raphson, que é um procedimento iterativo numérico, para encontrar valores dos elementos de 7 que zeram I54], utiliza a derivada parcial de segunda ordem para $\lambda_{1}$, em relaçăc aos $\gamma_{i}^{\prime} s$, ou seja:

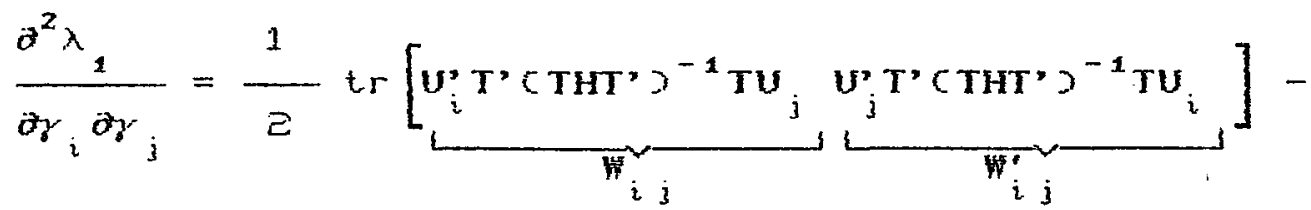

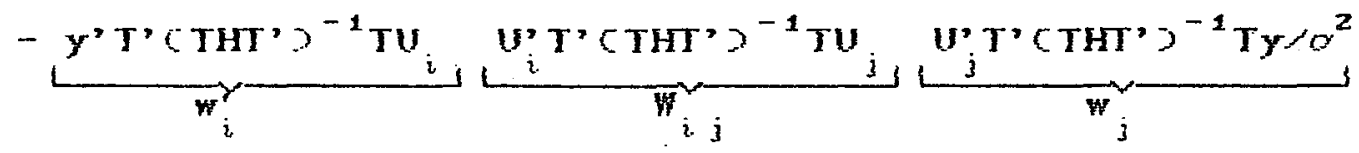

para $i, j=1,2, \ldots, c$

os produtas das matrizes em [54] e [56] săo submatrizes da seguinte transformacão Cmatriz w sugerida por HEMMERLE \& HARTLEY (1973), cujo interesse se baseia no fato de que os cálculos iterativos podem ser efetuados utilizando quantidades que não dependem de $n$ em nenhum passo:

$$
W=\left\{\begin{array}{l}
W_{i j} \\
W
\end{array}\right\}=\left[\begin{array}{l}
U^{2} \\
y^{\prime}
\end{array}\right] T^{\prime}\left(T H T^{\prime}\right)^{-1} T \quad\left[\begin{array}{ll}
u & y
\end{array}\right]
$$

$[57$ ]

para $i, j=1,2, \ldots, c+1$

$$
\begin{aligned}
& \text { Entaăo para } w_{i, c+1} \equiv w_{i} \quad[54] \text { [56] ficam } \\
& \frac{\partial \lambda_{i}}{\partial \gamma_{i}}=-\frac{1}{2} \operatorname{trc} w_{i i}^{2}+\frac{1}{2 \alpha^{2}} w_{i}^{\prime} w_{i} \\
& \frac{\partial^{2} \lambda_{1}}{\partial \gamma_{i} \partial \gamma_{j}}=\frac{1}{2} \operatorname{trc} w_{i j} w_{i j}^{j}-w_{i}^{2} w_{i j} w_{i r o^{2}} \\
& \text { para } i, j=1, z, \ldots, c,=[54\rfloor \text { fica } \\
& \hat{d}^{2}=w_{e+1, c+1}(n-k)
\end{aligned}
$$


76.

A transformaräc w para o exempla que estamos consider ando é:

$$
\begin{aligned}
& W=\left[\begin{array}{lll}
w_{11} & w_{12} & w_{13} \\
w_{21} & w_{22} & w_{23} \\
w_{31} & w_{32} & w_{33}
\end{array}\right]=\left[\begin{array}{lll}
w_{12} & w_{12} & w_{1} \\
w_{21} & w_{22} & w_{2} \\
w_{31} & w_{32} & w_{3}
\end{array}\right]=
\end{aligned}
$$

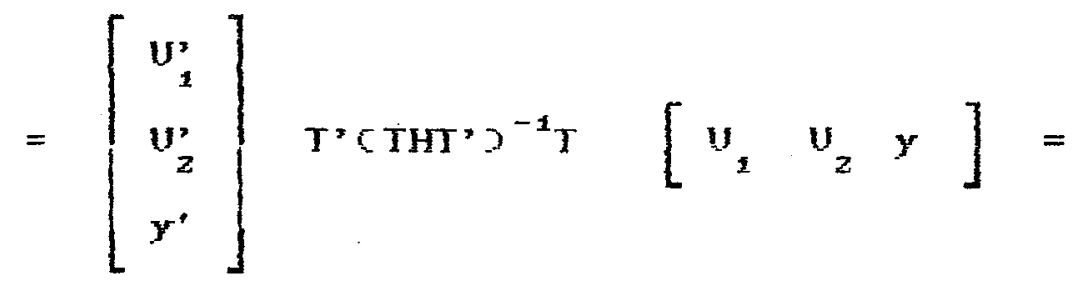

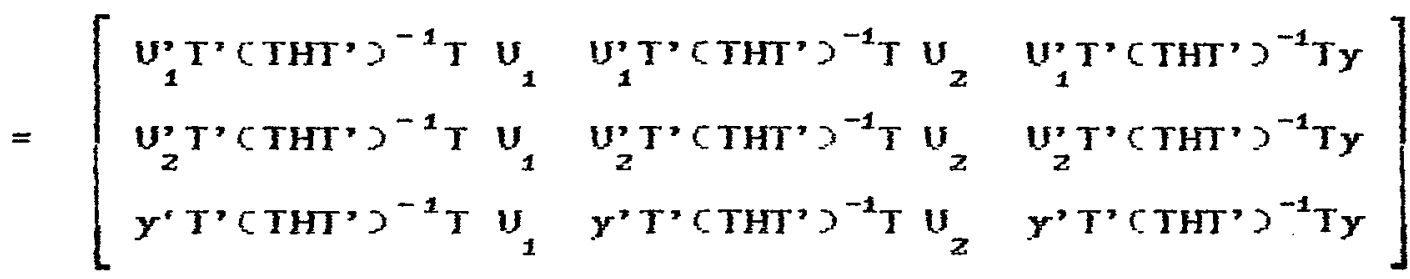

\section{Então:}

$\frac{\partial \lambda_{i}}{\partial y_{1}}=-\frac{1}{2} \operatorname{tr}\left(w_{11}^{2}+\frac{1}{2 \sigma^{2}} w_{1}^{w_{1}}\right.$

$\frac{\partial \lambda}{\partial \gamma_{2}}=-\frac{1}{2} \operatorname{tr} w_{z 2}^{2}+\frac{1}{2 \sigma^{2}} w_{z}^{2} w_{2}$

$\frac{\partial^{2} \lambda_{1}}{\partial y_{1} \partial_{2}}=\frac{1}{2}$ tr $w_{12} w_{12}^{2}-w_{1}^{\prime} w_{12} w_{z}, \partial^{2}$

$\hat{\sigma}^{2}=w_{33}, C_{10}-3$

Numericamente, para $\gamma_{1}=18,57$ e $\gamma_{2}=0,34$ temos: 
$\psi=\left[\begin{array}{rrrrrrrrr}0,027 & -0,027 & 0,008 & -0,008 & 0,000 & -0,000 & 0,009 & -0,008 & 1,448 \\ -0,027 & 0,027 & -0,008 & 0,008 & -0,000 & 0,000 & -0,000 & 0,008 & -1,448 \\ \hdashline 0,008 & -0,008 & 0,452 & -0,452 & -0,235 & -0,235 & -0,200 & 0,200 & 8,854 \\ -0,008 & 0,000 & -0,452 & 0,452 & 0,235 & -0,235 & 0,200 & -0,200 & -8,854 \\ 0,000 & -0,000 & -0,235 & 0,235 & 0,470 & -0,470 & -0,235 & 0,235 & -5,026 \\ -0,000 & 0,000 & 0,235 & -0,235 & -0,470 & 0,470 & 0,232 & -0,235 & 5,025 \\ 0,008 & -0,008 & -0,200 & 0,200 & -0,235 & 0,235 & 0,452 & -0,452 & -2,370 \\ -0,008 & 0,008 & 0,200 & -0,200 & 0,235 & -0,235 & -0,452 & 0,452 & 2,370 \\ \hdashline 1,448 & -1,448 & 8,854 & -0,854 & -5,020 & 5,020 & -2,375 & 2,375 & 1025,37\end{array}\right]$

- portanto,

$$
\begin{gathered}
\operatorname{trc} w_{11}^{j}=0,053 ; w_{1}^{\prime} w_{1}=4,192 ; \operatorname{trc} w_{22}=2,766 ; \\
w_{2}^{\prime}=218,019 ; \operatorname{trc} w_{12} w_{12}=0,001 ; w_{12}^{\prime} w_{2}=0,041 ; \\
w_{33}=1025,387 ; a^{2}=1025,387,13=78,87
\end{gathered}
$$

Os elementos de $W$ de [58] a [60] exigem, de [571, calcular $\left(T H T^{\prime}\right)^{-1}$, de orden $n-k$ que $e$ menor que $n$, ordem da matriz a ser invertida para máxima verossimilhanca $\left(H^{-1}\right)$. Para muitos conjuntos de dados, isto será exageradamente trabalhoso de calcular, mas a inversa pode ser reduzida a uma matriz de ordem $m_{*}=\sum_{i=1}^{c} m_{i}$, número total de niveis dos efeitos aleatórios do modelo. Embora para muitos casos esta matriz seja também muito grande, será sempre menor do que $n-k$, frequentemente muito menor, e em muitos casos será tal gue a inversa pode ser calculada. Para conseguir esta reducäo, note de [41] que

$$
H=I_{n}+U D U
$$

para

$$
u=\left[\begin{array}{llll}
u_{1} & u_{2} & \ldots & u_{e}
\end{array}\right]
$$


78.

$\varrho$

$$
D=\sum_{i=1}^{c}+I_{i}
$$

Então,

$$
T^{\prime} C T H T \cdot T^{-1} T=S-S U M^{-1} U^{\prime} S
$$

para

$$
M=D^{-1}+U^{\prime} S U \text {, de ordem } m_{*}=\sum_{i=1} m_{i}
$$

[65]

Para os dados do exemplo, como

$$
m_{0}=\sum_{i=1}^{z} m_{i}=m_{1}+m_{2}=2+b=8
$$

niveis de efeitos aletórios:

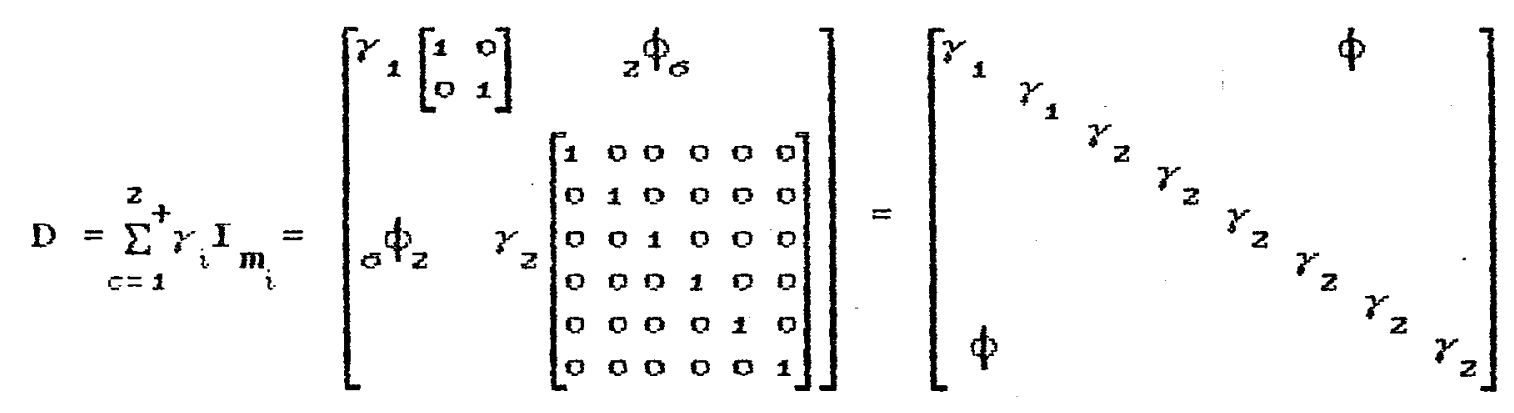

$$
M=\left[\begin{array}{cccccccc}
1, \gamma_{1}+3,0 & -3,0 & 1,2 & -1,2 & 1,5 & -1,5 & 1,2 & -1,2 \\
-3,0 & 1 / \gamma_{1}+3,0 & -1,2 & 1,2 & -1,5 & 1,5 & -1,2 & 1,2 \\
1,2 & -1,2 & 1 \gamma_{2}+1,2 & -1,2 & 0 & 0 & 0 & 0 \\
-1,2 & 1,2 & -1,2 & 1 / \gamma_{2}+1,2 & 0 & 0 & 0 & 0 \\
1,5 & -1,5 & 0 & 0 & 1, \gamma_{2}+1,5 & -1,5 & 0 & 0 \\
-1,5 & 1,5 & 0 & 0 & -1,5 & 1 / \gamma_{2}+1,5 & 0 & 0 \\
1,2 & -1,2 & 0 & 0 & 0 & 0 & 1 / \gamma_{2}+1,2 & -1,2 \\
-1,2 & 1,2 & 0 & 0 & 0 & 0 & -1,2 & 1 / \gamma_{2}+1,2
\end{array}\right]
$$

Agora, definimos

$$
\left.W_{0}=\left[\begin{array}{l}
U^{\prime} \\
y^{\prime}
\end{array}\right] \text { SIU } \quad y\right]=\left[\begin{array}{ll}
U^{2} S U & U^{\prime} S y \\
y^{\prime} S U & y^{2} S y
\end{array}\right]=\left[\begin{array}{cc}
w_{00} & w_{0} \\
w_{0}^{*} & w_{0}
\end{array}\right]
$$


79

que, conforme [57] é W com H substituido por I. Entäo, ao utilizar [64]-[66] em [57], W fica

$$
\begin{aligned}
& W=\left[\begin{array}{l}
U^{\prime} \\
y^{\prime}
\end{array}\right] T^{\prime}\left(\mathrm{THT}^{\prime}\right)^{-1} \mathrm{~T} \quad\left[\begin{array}{ll}
u & y
\end{array}\right]= \\
& =\left[\begin{array}{l}
u^{\prime} \\
y^{\prime}
\end{array}\right]\left[S-S u M^{-1} u^{\prime} S\right]\left[\begin{array}{ll}
u & y
\end{array}\right]= \\
& =\left[\begin{array}{l}
u^{\prime} \\
y^{\prime}
\end{array}\right] S\left[\begin{array}{ll}
u & y
\end{array}\right]-\left[\begin{array}{l}
u^{\prime} \\
y^{\prime}
\end{array}\right] \text { S } u \text { M }^{-1} u^{\prime} S\left[\begin{array}{ll}
u & y
\end{array}\right]= \\
& =w_{0}-\left[\begin{array}{l}
u^{\prime} \\
y^{\prime}
\end{array}\right] \text { Su } M^{-1} v^{\prime} s \quad\left[\begin{array}{ll}
v & y
\end{array}\right]=\quad[67\}
\end{aligned}
$$

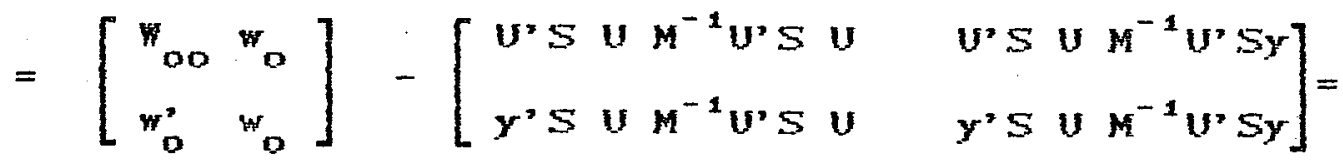

$$
\begin{aligned}
& =\left[\begin{array}{cc}
w_{00} & w_{0} \\
w_{0}^{\prime} & w_{0}
\end{array}\right]-\left[\begin{array}{cc}
w_{00} M^{-1} w_{00} & w_{00} w_{0}^{-1} w_{0} \\
w_{0}^{M} M_{00}^{-1} w_{0} & w_{0}^{M^{-1}} w_{0}
\end{array}\right]= \\
& =\left[\begin{array}{ccc}
w_{00}-w_{00}^{M} & w_{00} & w_{0}-w_{00}^{M} w_{0} \\
w_{0}^{*}-w_{0}^{M} w_{00} & w_{0}-w_{0}^{M} w_{0}
\end{array}\right]
\end{aligned}
$$

No nosso exemplo:

$$
W_{0}=\left[\begin{array}{rrrrrrrr|r}
3,0 & -3,0 & 1,2 & -1,2 & 1,5 & -1,5 & 1,2 & -1,2 & 211,3 \\
-3,0 & 3,5 & -1,2 & 1,2 & -1,5 & 1,5 & -1,2 & 1,2 & -211,3 \\
1,2 & -1,2 & 1,2 & -1,2 & 0 & 0 & 0 & 0 & 00,6 \\
-1,2 & 1,2 & -1,2 & 1,2 & 0 & 0 & 0 & 0 & -80,0 \\
1,5 & -1,5 & 0 & 0 & 1,5 & -1,5 & 0 & 0 & 70,5 \\
-1,5 & 1,5 & 0 & 0 & -1,5 & 1,5 & 0 & 0 & -70,5 \\
1,2 & -1,2 & 0 & 0 & 0 & 0 & 1,2 & -1,2 & 50,2 \\
-1,2 & -1,2 & 0 & 0 & 0 & 0 & -1,2 & 1,2 & -60,2 \\
211,3 & -211,3 & 00,6 & -80,0 & 70,5 & -70,5 & 00,2 & -00,2 & 12533,5
\end{array}\right]
$$

e considerando $\gamma_{1}=18,57$ e $\gamma_{2}=0,34$, temos: 
80.

$$
M=\left[\begin{array}{rrrrcccc}
3,054 & -3,0 & 1,2 & -1,2 & 1,5 & -1,5 & 1,2 & -1,2 \\
-3,0 & 3,054 & -1,2 & 1,2 & -1,5 & 1,5 & -1,2 & 1,2 \\
1,2 & -1,2 & 4,141 & -1,2 & 0 & 0 & 0 & 0 \\
-1,2 & 1,2 & -1,2 & 4,141 & 0 & 0 & 0 & 0 \\
1,5 & -1,5 & 0 & 0 & 4,441 & -1,5 & 0 & 0 \\
-1,5 & 1,5 & 0 & 0 & -1,5 & 4,441 & 0 & 0 \\
1,2 & -1,2 & 0 & 0 & 0 & 0 & 4,141 & -1,2 \\
-1,2 & 1,2 & 0 & 0 & 0 & 0 & -1,2 & 4,141
\end{array}\right]
$$

\subsection{2. Algori tmos}

o.cálculo de $\{68\}$ exige calcular \{65] e [66].

Em [66]: para $S$ do [44], o termo principal de

[66]

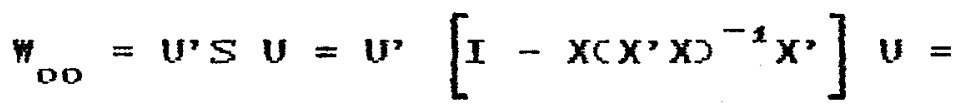

$$
\begin{aligned}
& =u^{\prime} u-u^{2} x\left(x^{2} \times\right)^{-1} x^{\prime} u= \\
& =v^{\prime} v-v^{\prime} x \operatorname{diag}\left\{1 / n_{1}, \ldots, 1 / n_{k}\right\} \times x
\end{aligned}
$$

onde v'U a familiar "matriz dos coeficientes" para os efeitos aleatórios. Para o nosso exemplo:

$$
U^{\prime} U=\left[\begin{array}{llllllll}
0 & 0 & 3 & 0 & 3 & 0 & 2 & 0 \\
0 & 8 & 0 & 2 & 0 & 3 & 0 & 3 \\
3 & 0 & 3 & 0 & 0 & 0 & 0 & 0 \\
0 & 2 & 0 & 0 & 0 & 0 & 0 & 0 \\
3 & 0 & 0 & 0 & 3 & 0 & 0 & 0 \\
0 & 3 & 0 & 0 & 0 & 3 & 0 & 0 \\
2 & 0 & 0 & 0 & 0 & 0 & 2 & 0 \\
0 & 3 & 0 & 0 & 0 & 0 & 0 & 3
\end{array}\right]
$$

Em [69], uma tipica sub-matriz de $v^{\prime} X \dot{E}$

$$
u_{i} x=\left\{n_{i(j), i}\right\}
$$

$[70]$

para $j=1, \ldots, m_{i} ; t=1, \ldots, k ; m_{i} \times k$ matriz cujos elementos tipicos $n_{i(j, t}$ representa . número de observacóes 
81.

no j-ésimo rível do i-ésimo fator de efeito aleatório e no l-ésimo sub-total das células dos fatores de efeitos fixos.

Para os dados da Tabela 6 , temos que as lirhas säo consideradas fixas, com $k=3$ niveis. O primeiro fator aleatório, que corresponde às colunas, tem $m_{1}=2$ níveis e, por [70]:

$$
\begin{aligned}
& U_{1}^{\prime} X=\left[\begin{array}{llllllllllllllll}
1 & 1 & 1 & 0 & 0 & 1 & 1 & 1 & 0 & 0 & 0 & 1 & 1 & 0 & 0 & 0 \\
0 & 0 & 0 & 1 & 1 & 0 & 0 & 0 & 1 & 1 & 1 & 0 & 0 & 1 & 1 & 1
\end{array}\right]\left[\begin{array}{lll}
1 & 0 & 0 \\
1 & 0 & 0 \\
1 & 0 & 0 \\
1 & 0 & 0 \\
1 & 0 & 0 \\
0 & 1 & 0 \\
0 & 1 & 0 \\
0 & 1 & 0 \\
0 & 1 & 0 \\
0 & 1 & 0 \\
0 & 1 & 0 \\
0 & 0 & 1 \\
0 & 0 & 1 \\
0 & 0 & 1 \\
0 & 0 & 1 \\
0 & 0 & 1
\end{array}\right]= \\
& =\left[\begin{array}{lll}
3 & 3 & 2 \\
2 & 3 & 3
\end{array}\right]=\left[\begin{array}{lll}
n_{1(1), 1} & n_{1(1), 2} & n_{1(1), 3} \\
n_{1(2), 1} & n_{1(2), 2} & n_{1(2), 3}
\end{array}\right]= \\
& =\left\{n_{1(j), t}\right\} \text { para } j=1,2 \in t=1,2,3
\end{aligned}
$$

0 segundo fator aleatório são as interacóos, com $m_{2}=\theta$ níveis e em $[70]$ 


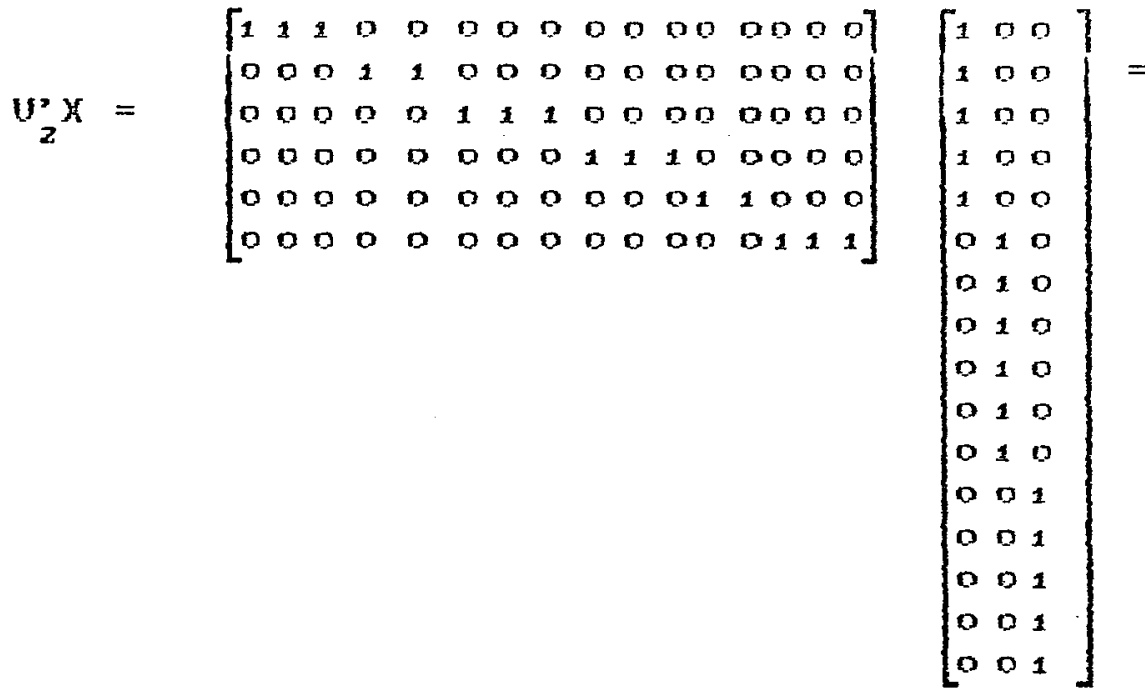

$$
\begin{aligned}
& =\left[\begin{array}{lll}
3 & 0 & 0 \\
z & 0 & 0 \\
0 & 3 & 0 \\
0 & 3 & 0 \\
0 & 0 & 2 \\
0 & 0 & 3
\end{array}\right]=\left[\begin{array}{lll}
n_{z(1), 1} & n_{z(1), z} & n_{z(1), 3} \\
n_{z(z), 1} & n_{z(z), z} & n_{z(z), 3} \\
n_{z(3), 1} & n_{z(3), z} & n_{z(3), 3} \\
n_{z(4), 1} & n_{z(4), z} & n_{z(4), 3} \\
n_{z(5), 1} & n_{z(3), z} & n_{z(5), 3} \\
n_{z(5), 1} & n_{z(5), z} & n_{z(5), 3}
\end{array}\right]= \\
& =\left\{n_{2(j), i}\right\} \quad \text { para } j=1,2, \ldots, \sigma \theta i=1,2,3 .
\end{aligned}
$$

O segundo termo de $\{66\rfloor$ é

$$
w_{0}=u^{\prime} S y=\left\{w_{i} S y\right\}, \quad m_{i} \times 1,
$$

para $i=1, \ldots, c$.

Do [44], $S y=x$ o vetor $y$ com cada observacão substituida por seus desvios da média dos níveis dos fatores de efeitos fixos nos quais ele ocorre:

$$
\begin{aligned}
x & =s y=y-\left[\sum_{t=1}^{k} n_{t}^{-1} J_{n_{t}}\right] y= \\
& =y-\left\{\bar{y}_{t} 1_{n_{t}}\right\} \text { para } t=1, \ldots, k .
\end{aligned}
$$


83.

Portanto,

$$
w_{0}=\left\{y_{i} x\right\}, \text { para } i=1, \ldots, c
$$

é um vetor $m_{i} \times 1$ de totais dos $x^{\prime} s$, referente a cada nível do i-ésimo fator aleatório.

Para ilustrar $x$, utilizamos a notacăo familiar ponto e barra para totais e médias, isto é,

$$
\begin{aligned}
& y_{1}=\sum_{r=1}^{3} y_{11 r} \quad \bar{y}_{11}=\frac{y_{11}}{3} \text {. Entä̀ } \\
& x=\left\{y_{p q r}-\bar{y}_{p} .\right\} \text { para } p=1,2,3 ; q=1,2 \otimes r=1,2, \ldots, n p q \\
& \text { e de } w_{0} \text { de }
\end{aligned}
$$

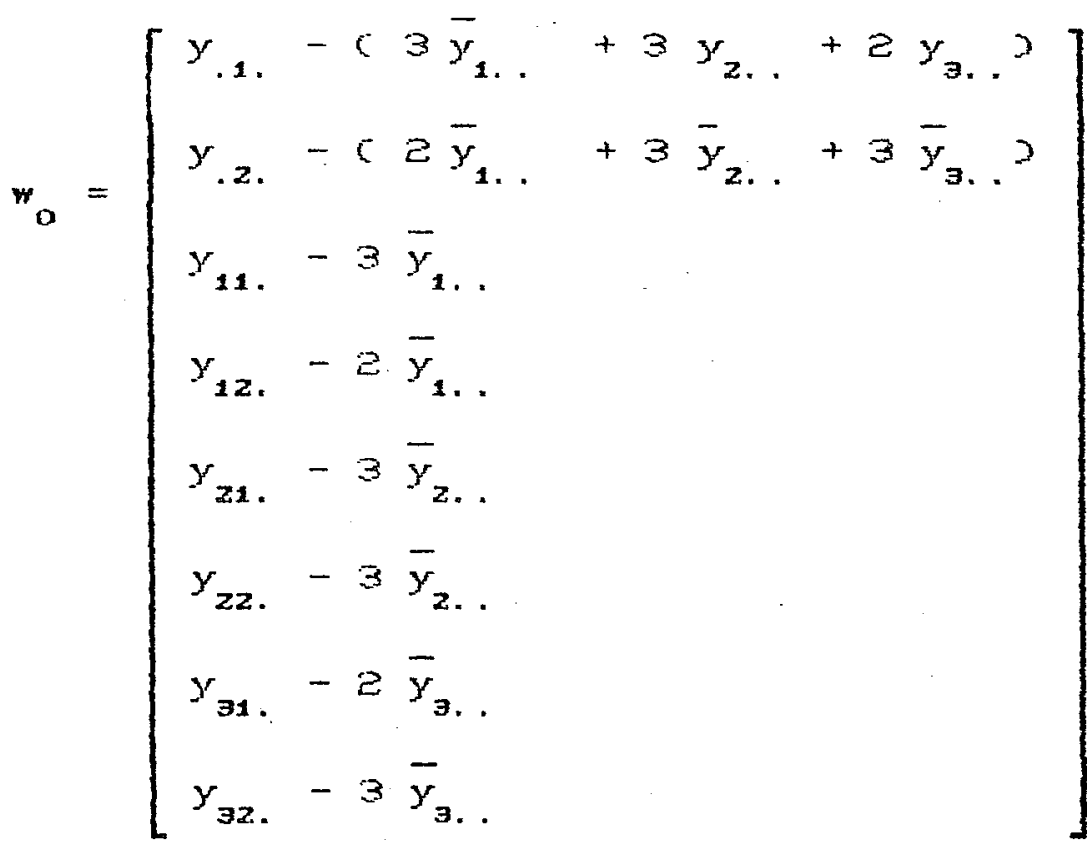

$$
\begin{aligned}
& \text { O termo final para [66] } \\
& { }_{10}^{19} \quad=y^{\prime} S y=x^{\prime} x
\end{aligned}
$$

é a soma de quadrados total dos $x^{\prime} s$, isto é, soma de quadrados dentro das células dos $y^{\prime} s$ para as $k$ células dos fatores itixos,

e, no exemploé $w_{0}=\sum_{p=1}^{3} \sum_{q=1}^{2} \sum_{r=1}^{n}\left(y_{p q r}-\bar{y}_{p} j^{2}\right.$. 
84.

Tendo calculado $w_{00}, w_{0}$ e wara $w_{0}$ de 1661, $M^{-1}$ exigida fara $\$$ em [68] vem de [65] [68 [66] como

$$
M=D^{-1}+W_{D D}
$$

Entäo, a matriz e termos dos vetores de w são

$$
W_{0 D}-\psi_{O O} M^{-1} \psi_{0 O}=D^{-1}-D^{-1} M^{-1} D^{-1}
$$

$\theta$

$$
w_{0}-w_{00} M^{-1} w_{0}=D^{-1} M^{-1} w_{0}
$$

o termo escalar $w_{0}-w_{0}^{\prime} M^{-1} w_{0}$ permanece como está.

Como THOMPSON apontou, as vantagens do lado direito de [74] sobre o esquerdo, consistem na multiflicacão de $\mathrm{M}^{-1}$ pela diagonal, em vez de matrizes simétricas. Com essas expressöes, a implementacão da técnica iterativa pode ser executada exatamente como HEMMERLE \& HARTLEY (1973) sugerisam.

$$
\text { Primeiro, calcula-se } \text { po }_{\text {para }} \text { os dados, }
$$
utilizando [Bg]-[72]. Entäo, atribuimos um conjunto inicial de valores aos $\gamma_{i}^{\prime} s, i=1, \ldots, c$, e utilizando-as em $\mathbf{p}$ de [63], obtém-se $M$ de $[73]$ e calcula-se $M^{-1}$. Então, utiliza-se $M^{-1}$ em $[74]$ e [68] para obter W. os elementos de $W$ säo então utilizados em [58I, [59] [60] para obter, pelo procedimento de Newton-Raphson, salucöes das equacöes formadas igualando [53] e [54] a zero. Para cada iteracão, D de [63] altera e, portanto, $M$ de $[731$ também troca; consequentemente, por [74] mudam os termos de $W$.

Para o exemplo utilizado em 3.2.2, foi desenvolvida uma rotina para o módulo CM CCáloulo de Matrizess do 
85.

programa soc (Software cientifico), cujos resultados, após 5 iteracôes, coincidiram com aqueles obtidos através dos pacotes BMDP (Biomedical Package) e SAS CStatistical Analysis System, conforme podemos verificar nos Apêndices $1,2 e 3$.

\subsection{3. Esti macâo dos Efeitos fixos}

No modelo descrito em $[39]$ e [40], os estimadores de máxima verossimilhanca para $\mu$, assumindo $H$ conhecida é

onde de [61]

$$
\hat{\mu}=\left(X^{*} H^{-1} X\right)^{-1} X^{\prime} H^{-1} y
$$

$$
\begin{aligned}
H^{-1}= & C I+U D U^{\prime} J^{-1}=I-U C D^{-1}+U^{\prime} U^{-1} U^{2} \\
& \text { Ao substituir os } \gamma_{i} \text { em } D^{-1} \text { por seus estimadores }
\end{aligned}
$$

de MVR e notando o valor correspondnente de $H$ por $\tilde{H}$, um estimador de $\mu$ sugerido por [75] é

$$
\mu=\left(X \cdot \tilde{H}^{-1} X\right)^{-1} X \cdot \tilde{H}^{-1} y
$$

o desenvol vimento do estimador da matriz de covariâncias envolve o reconhecimento de que estimador de H. I gnorando esta complexidade vem:

$$
\operatorname{Var}(\mu)=\left(X \cdot \tilde{H}^{-1} \mathrm{X}\right)^{-1} \mathrm{X} \cdot \tilde{\mathrm{H}}^{-1} H \tilde{H}^{-1} \mathrm{X}\left(\mathrm{X}, \tilde{H}^{-1} \mathrm{X}\right)^{-1} \sigma^{2}
$$

e ao utilizar novamente $\tilde{H}$ e $\tilde{o}^{2}$ em lugar de $H$ e $\sigma^{2}$ temos um estimador para sua variância dado por

$$
\operatorname{Varr}(\omega)=c x \cdot \tilde{H}^{-1} X^{-1} \tilde{o}^{2}
$$

Não são conhecidas propriedades ótimas para este estimador ou para sua matriz de covariância, mas sabe-se, como pode ser prontamente observado, que $\hat{\mu}$ maximiza $\lambda_{2}$ de 1521 , para $H$ conhecida. 
Q6.

\section{A. ILUSTRACAO DOS METODOS E DISCUSSAO}

Para complementar e ilustrar as métodos, sâo apresentados três exemplas numéricos.

O Exemplo 1 é uma aplicacão do procedimento de MVR descrito em 3.2.

Os Exemplos Z e 3 têm problema de estimativas negativas para componentes de variancia e, aqui, discute-se alternativas de solucão, através dos métodos apresentados no presente trabalho.

\subsection{Exemplo 1}

A Tabela 8 mostra as estimativas dos componentes de variância para o modelo de classificacão cruzada dupla gue ilustrou 3.2. para dados não balanceados. Considera- se também os resultados para dados balanceados. Os programas e resultados abtidos pela SAS para MVR o MV encontram-se nos Apèndices 3 a 6 .

E conveniente notar que neste exemplo não existe problema de est.imativa negativa para os componentes de variancia e, portanto, os resultados da Tabela 8 para a Análise de Variància dizem respeito ao mótodo tradicional, isto é, não se referem a modelo com populacăo finita. 
87.

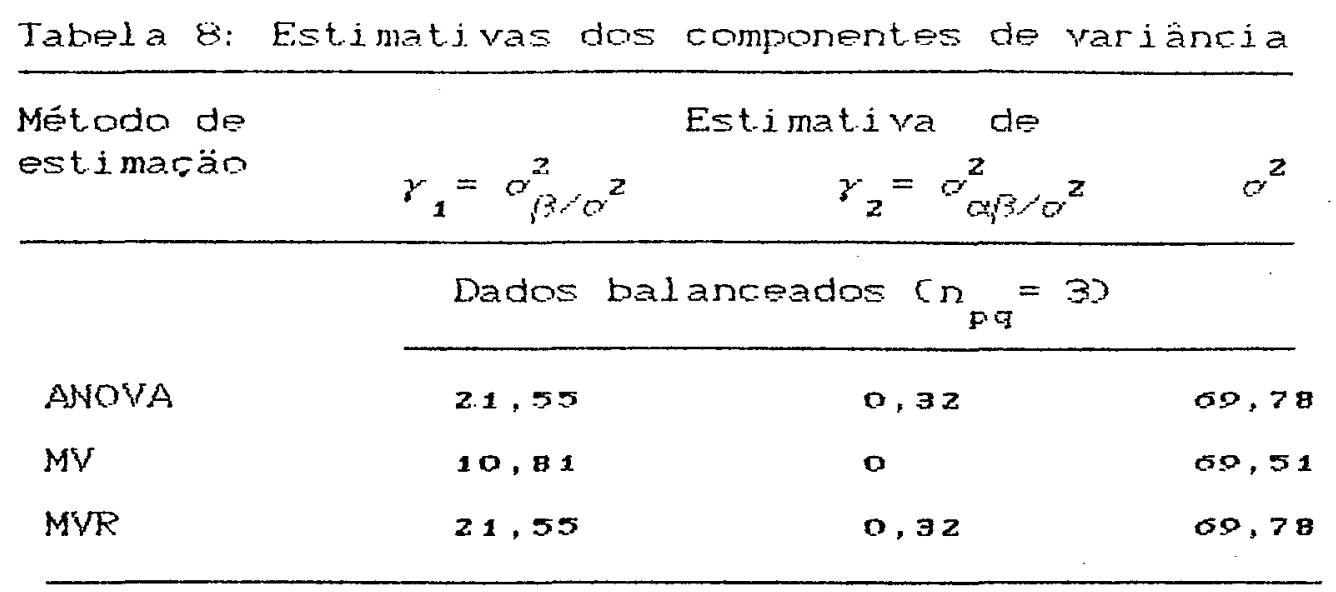

Dados näo bal anceados

\begin{tabular}{lrll} 
& & 0.95 & 78,63 \\
MV & 18,42 & 0,35 & 77,53 \\
MVR & 9,33 & 0 & 78,64 \\
\hline
\end{tabular}

os resultados sugerem tres somentários.

Primeiro, para dados balanceados os estimadores de MVR e ANOVA säo identicos, sugerindo que isto geralmente coorra para dados desta natureza, desde que nấo exista problema de estimativa negativa para os componentes de variância, CORBEIL \& SEARLE (1976b) que estudaram quatro casos de dados balanceados cesquema de classificacão simples, hierắrquico duplo e cruzada dupla com um fator tratado como fator de efeitos fixos, ambos com e sem iteracăol encontraram - mesmo resultado.

Segundo, o estimador de MV para $\gamma_{2}$ é zero, significando que o estimador para o componente de variância da interacăo $\alpha_{\alpha \beta}^{2}$ é também zero. Isto é uma conseguencia do algoritmo de cálculo; quando o valor calculado do estimador de MV é negativo, elé tomado igual a zero. A consequência 
88.

disso é importante: implica năb exatamente que o componente de variancia está sendo estimado por zero, mas que o fator correspondente a esse componente cneste caso, o fator interacăo não deve pertencer ao modelo e assim o modelo deve ser trocado para excluílo. Com a troca de modelo os outros componentes de variância säo entäp estimados. Isto justifica o estimadar $\alpha^{2}$ de $M V$ ser diferente do obtido por ANOVA, no caso de dados balanceados, o diferente do estimador de constantes ajustadas no caso de dados näo balanceados. Tendo em vista o fato de que, para dados balanceados os estimadores de ANOVA são conhecidos por terem desejáveis propriedades de minima variância, e desde que, nesses dados, o estimador de ANOva de $\alpha_{\alpha \beta}^{2}=$ (0. $32 \times 60.783=$ 22,3z está longe de ser zero, a solução apresentada na estimacão de MV de eliminar o fator interacăo do modelo parece radical. A mesma situacăo ocorre em dados nấo balanceados, embora os estimadores de constantes ajustadas nâo têm propriedades de variância mínima como os estimadores de ANOVA em dados balanceados. Todavia, a estimacäo de MV para essos dados tambóm elimina o fator interacão. Em nenhum caso, a estimacăo de MVR faz isto.

Uma terceira característica desses resultados é que a est.imativa de $M V$ de $r_{i}=\alpha_{\beta}^{2} / \alpha^{2}$ em ambos as dados, balanceados e não balanceados, está muito próxima da metade daguela obtida pelos estimadores de MVR e ANOVA ou estimador das constantes ajustadas. Isto nào é propriamente uma consequència da troca de modelo surgida da estimativa 
89.

negativa de $\gamma_{z}$, já referida; isto tambén acorre no próprio modelo com interaräo. Em ambos os casos, para dados balanceados, as divisores das solucöes das equacöes de MV săo os graus de liberdade, ista é, b Cnúmero de colunass, enquanto que para MVR é b-1. O efeito disto é a troca do estimador aproximadamente na razầ $(\mathrm{b}-1)$ b que ${ }^{-}$igual a $1 / 2$ neste caso, pois b=e. Um efeito similar ocorre com dados não bal anceados.

\subsection{Exemplo 2}

Para comparar o método apresentado em 3.1 e método da MVR, foi criada uma situação de classificacâo cruzada dupla en que surge o problema de estimativa negativa. A partir dos dados de MoHUGH \& MIELKE (1968) que ilustraram 2.3, construiu-se a Tabela 9 , onde constam as observaç̃es.

Tabela 9: Dados referentes a uma classificação dupla com duas observacốes por célula

\begin{tabular}{cccc}
\hline & \multicolumn{3}{c}{ FATOR B } \\
\cline { 2 - 4 } FATOR A & 1 & 2 & 3 \\
\hline 1 & 1059 & 1237 & 949 \\
& 980 & 1040 & 780 \\
2 & 1245 & 1341 & 1332 \\
3 & 1480 & 1580 & 1490 \\
& 1283 & 1078 & 1129 \\
4 & $950 *$ & 980 & 975 \\
& 1101 & 988 & 1262 \\
\hline
\end{tabular}


90.

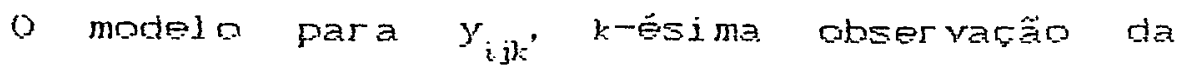
i-ésimo nível de $A$ e j-ésimo nível de $B$ é

$$
y_{i j k}=H+\alpha_{i}+\beta_{j}+(\alpha \beta)_{i j}+e_{i j k}
$$

Para

$$
i=1,2,3,4 ; j=1,2,3 \quad \theta \quad k=1,2 ;
$$

onde

A média geral;

$\alpha_{i}$ é o éfeito aleatório devido ao i-ésimo nivel do fator A;

$\beta_{j}$ é o efeito aleatório devido ao j-ésimo nível do fator $B$;

$C \alpha \beta)_{i j}$ é ofeito aleatório da interarão

$e_{i j k}$ é o erro associado à observacấo $y_{i j k}$.

As estimativas dos componentes de variània foram realizadas através do Método da Análise de Variància, do método descrito em 3.1 da MVR, para dados balanceados também para dados não balanceados, a partir da retirada das observacôes assinaladas com $*$.

Os resultados da Análise de Variância, obtidos pelo SAS, se encontram na Tabela 10 das estimativas dos componentes de variáncia na Tabela 11. 
Tabela 10. Análise de Variàcia.

DADOS BALANCEALOS

\begin{tabular}{|c|c|c|c|}
\hline$C . V$. & g. 1 . & Q.M. & ECQ.M. \\
\hline$A$ & 3 & 219767,49 & $\sigma_{\theta}^{2}+2 \sigma_{\alpha \beta}^{2}+\theta \sigma_{\theta}^{2}$ \\
\hline$E$ & 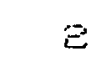 & 200,54 & $\sigma_{\sigma}^{2}+2 \sigma_{\alpha \beta}^{2}+\varepsilon \alpha_{\beta}^{2}$ \\
\hline$A * B$ & 6 & $2.7600,99$ & $\alpha_{\sigma}^{2}+2 \sigma^{2} \theta$ \\
\hline Resíduo & 12 & 19765,79 & $\alpha_{\theta}^{2}$ \\
\hline Total & 23 & & \\
\hline
\end{tabular}

DADOS NAO BALANCEADOS

C. . g.1. Q.M. ECQ.M.S

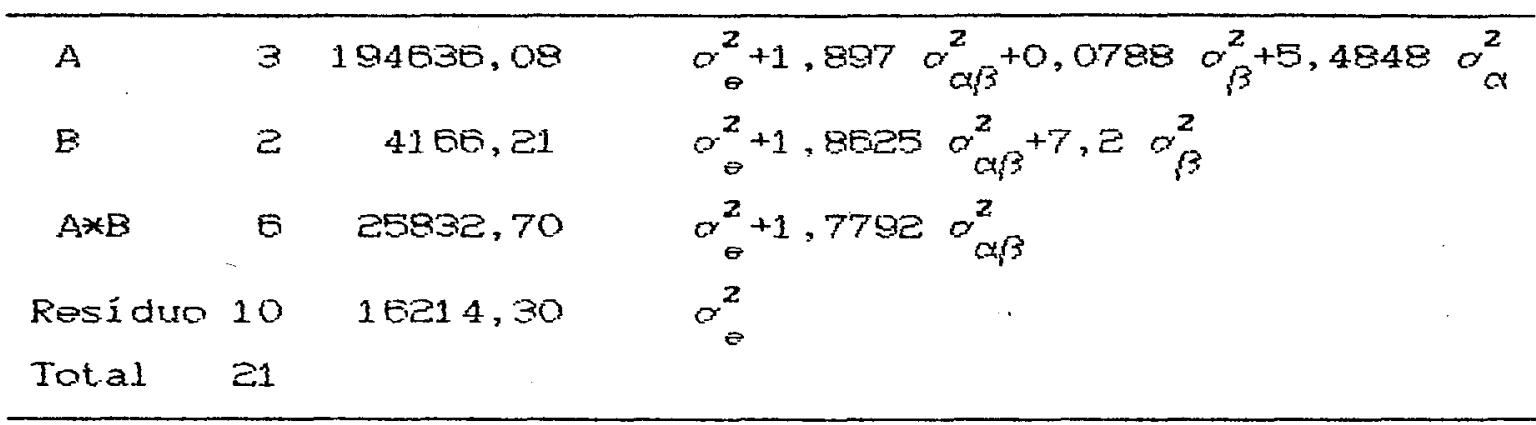

Tabela 11: Estimativas dos componentes de variância.

MËTODO

\begin{tabular}{|c|c|c|c|c|}
\hline $\begin{array}{l}\text { Análise de } \\
\text { Variància }\end{array}$ & $\begin{array}{c}\alpha_{\alpha}^{2} \\
32027,75\end{array}$ & $\begin{array}{c}\alpha_{\beta}^{2} \\
-3417,56\end{array}$ & $\begin{array}{l}\sigma_{\alpha / 3}^{2} \\
3917,00\end{array}$ & $\begin{array}{c}\alpha^{2} \\
19765,79\end{array}$ \\
\hline $\begin{array}{l}\text { Populacão } \\
\text { Finita }\end{array}$ & 39694,69 & 32,57 & 13800,49 & 19765,79 \\
\hline \multirow[t]{2}{*}{ MVR } & $33167, \mathrm{ZZ}$ & 0 & 500,21 & 19765,64 \\
\hline & & DADOS NAO & ALANCEADOS & \\
\hline $\begin{array}{l}\text { Análise de } \\
\text { Variância }\end{array}$ & $\begin{array}{c}\alpha_{\alpha}^{2} \\
30704,31\end{array}$ & $\begin{array}{c}d^{2} \\
-3071,85\end{array}$ & $\begin{array}{c}\sigma_{\alpha \beta 3}^{2} \\
5400,17\end{array}$ & $\begin{array}{c}d^{2} \\
16214,30\end{array}$ \\
\hline $\begin{array}{l}\text { Populacăo } \\
\text { Finita }\end{array}$ & 35208,90 & 300,51 & 13513,18 & 16214,30 \\
\hline$M V R$ & 29755.68 & 0 & 1746,48 & 16674,23 \\
\hline
\end{tabular}

\section{DADOS BALANCEADOS}


E importante ressaltar que os resultados para MVR foram obtidos através do procedimento VARCOMP do programa SAS, visto que o procedimento descrito em 3.2 exige que o modelo seja misto. O SAS utiliza as estimativas iniciais obtidas pelo MIVOUEO e um procedimento iterativo até a convergencia é alcancado através da funcăo abjetivo de log-verossimilhanca da parte da verossimilhanca que não contém os efeitos fixos. Como valores iniciais do processo iterativo o programa utiliza $\hat{o}_{\theta}^{2}=1$ e os demais primeiros valores iguais a zero, o que simplifica as expressöes do M VQUE e então os cálculos exigidos.

$$
\text { Observou-se que a estimativa de } \alpha_{\beta}^{2} \text { resultou }
$$
negativa em ambos os dados cbalanceados e näo balanceados. No entanto, a estimativa supondo populacão finita corrigiu este problema, admitindo-se $N_{A}=4, N_{B}=3$ e $N_{e}=2$, enquanto que a estimativa de MVR apresentou valor zero para o parametro em discussão. SWALlow \& MONAHAN $(1984)$ ressaltam que os estimadores de MVR são por definicăo năo negativos. Entretanto, valores negativos podem surgir no processo iterativo e, se utilizados, podem ocasionar matrizes singulares ou próximas da singularidade que afetam os călculos, fazendo com que as estimativas sejam zeradas. Para este caso, é mais aconselhável efetuar a troca de modelo de populacão infinita para população finita. 
93.

4.3. Exemplo 3

Reportando-se, novamente, ao exemplo de McHuGH \& MTELKE (1968) apresentado em 2.3 e, considere-se, além do modelo froposto naquela sefão $c y_{i j}=\mu+\alpha_{i}+e_{i j}{ }, 0$ seguinte:

onde

$$
\gamma_{i j}=\mu+\alpha_{i}+\beta_{j}+e_{i j}
$$

$\alpha_{i}$ é ofeito fixo devido ao i-ésimo nivel do fator A;

Bé o efeito aleatório devido ao j-ésimo nível do fator $B$

$e_{i j}$ é orro associado à $C_{i j}$-ésima observacão.

A Análise de Variancia obtida pelo SAS, para o modelo misto está na Tabela 12 e as estimativas dos componentes de variância, para ambos os modelos, na Tabela 13.

Tabela 12: ANÄLISE DE VARIANCIA

\begin{tabular}{|c|c|c|c|}
\hline G. V. & 9.1. & Q. M. & ECQ.M. \\
\hline A & 3 & $29116,2 ?$ & $\sigma_{\theta}^{2}+\Sigma \alpha_{i}^{2}$ \\
\hline$B$ & 2 & 124,00 & $\alpha_{\theta}^{2}+4 \alpha_{\beta}^{2}$ \\
\hline Residuo & 6 & $18053, \mathrm{ez}$ & $a^{2}$ \\
\hline Total & 11 & & \\
\hline
\end{tabular}

Tabela 13: Estimativas dos componentes de variancia

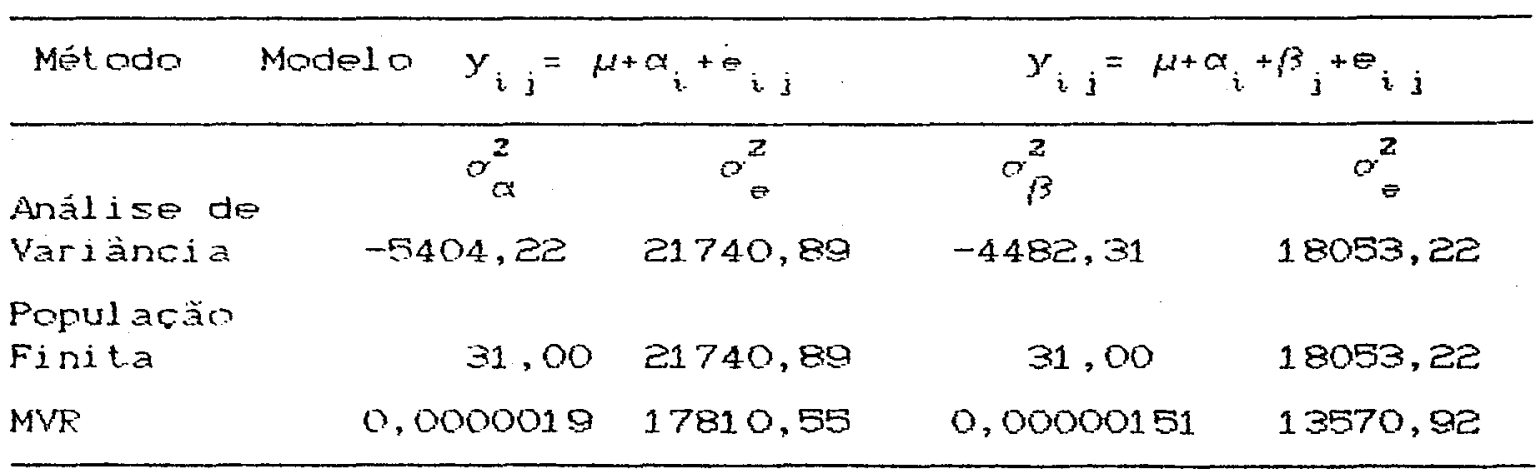


Par a os dadns analisados, em ambos os modelos, pode-se constatar que as estimativas para os componentes de variância resultaram em valores positivos, tanto no método da Populacáo Finita como da MVR.

Observou-se que as estimativas de $\alpha_{0}^{2}$ obtidas através do método da MVR diferiram consideravelmente das estimativas obtidas pelo método da Análise de Variáncia, o que causa certa estranheza já que isto não se verifica de forma täo acentuada nos demais exemplos. HENDERSON (1986) constatou que estimativas por MVR dependem da matriz de incidências, dos valores básicos dos parámetros e dos algoritmos utilizados, e a convergencia pode ou não ocorrer no espaco dos parâmetros. De modo que não se pode estar certo se a solucăo é um máximo global ou meramente um máximo local. Consequentemente, năo se pode ter certeza de que a estimativa seja na verdade MVR.

A rotina para o módulo CM do SOC CApêndice 73 foi adaptada para estes dados, considerando o modelo misto, para estimar $\gamma$. Verificou-se que as estimativas năo convergem, independentemente do valor inicial utilizado para $r$, pois à medida em que aumenta o número de iteracóes, o determinante da matriz $W$ se aproxima de zero.

Segundo HEMERLE \& HARTLEY (1973), embora rão esteja associado a um método numérico particular, a transformacâo $W$ está implementada em conjunto com o método modificado de Newton-Raphson no qual os componentes de variancia 
95.

tem a restricäo de näo serem negativos e, portanto, o procedimento descrito em 3.2 nầ é adequado para essa situacão.

\section{4. Discussão}

o método para Populacão finita em modelos aleatórios, que săo de maior interesse para estimativas de componentes de variáncia, fornece estimativas positivas para esses componentes, no caso de dados balanceados e não balanceados, deste que as condicües para suposicão de populacăo finita sejam satisfeitas.

No caso de modelos mistos, o procedimento se aplica apenas ao quadrado médio que não contém termos de efeitos fixos. Para dados balanceados, o procedimento é similar ao caso de modelos aleatórios. Para dados não balanceados, os componentes de variância säo estimados igualando cada reducăo nas somas de quadrados calculadas pelo Método 3 de Henderson ao seu valor esperado sob o modelo completo, efetuando as respectivas substituicồes dos termos de populacão infinita para população finita.

No caso do procedimento de MVR adotado no presente trabalho, sabe-se que não foi desenvolvido tendo como objetivo específico resolver o problema de estimativas negativas para componentes de variància, já que nestas situacóes a matriz de transformacäo W tende a ser singular, o que implica na näo convergència dos estimadores. 
90.

Além disso, este procedimento năo se aplica a modelas aleatórias, pois a matriz $x$, que se refere aos efeitos fixos do modelo, desaparece, mas é adequado para modelos mistos, com ou sem interacöes. No entanto, o método da MVR pode também ser utilizado em modelos aleatórios, desde que o procedimento de cálculo o permita, como é o caminho utilizado pelo SAS.

O procedimento VARCOMP do SAS, que utiliza as estimativas iniciais do MIVouEo, força a nâo negatividade para a estimarâo dos componentes de variancia, o que significa que qualquer estimativa negativa para $\alpha_{a}^{2}$ é tomada como zero las estimativas de $\alpha^{2}$ săo sempre näo negativas.. Impor a năo negatividade transgride a teoria da estimacão do MI VOUE, desde que as estimativas negativas devem ser permitidas a fim de manter a năo tendenciosidade, mas isto está de acordo com a prática comum, na qual o uso virtual sempre toma as estimativas negativas como zero, pelo menos quando se estimam componentes de variância individualmente. Ao forvar a não negatividade, perde-se a não tendenciosidade dos esti imadores de MI VQUEA.

Como as resultados obtidos pelo SAS também podem conduzir a estimativas näo satisfatórias para os componentes de variancia, sugere-se que para uma vasta utilizacão do método da MYR sejam desenvolvidos novos procedimentos e algoritmos de cáloulo.

Observou-se que, mesmo se tratando de dados balanceados, em situacöes em que ocorrem estimativas negati- 
97.

vas para os componentes de variancias, pelo método da Análise de Variância, as estimativas da MVR näo coincidem, pois podem näo convergir ou serem assumidas como zero, o que contraria CORBEIL \& SEARLE ( 1976$).$

Para solucionar o problema, sugere-se supor a populacäo finita e calcular as estimativas dos componentes de variância pelo método da populacão finita, com os devidos cuidados. 
98.

\section{CONCLUSOES}

o método para Popularäo Finita soluciona o problema de estimativas negativas para componentes de variância em modelos aleatórios ou mistos, no caso de dados balanceados e năo balanceados, desde que as condicốes para suposicào de populacão finita sejam satisfeitas.

o método da MVR, neste trabalho, foi utilizado como uma tentativa para solucionar o problema de estimativas negativas para componentes de variancia, já que, estruturalmente, apresenta propriedades desejáveis. No entanto, constatou-se que o método pode não funcionar adequadamente em algumas situacöes e, consequentemente, deve ser aplicado com certa cautela.

Convém ressaltar que em situacóos em que ocorrem estimati vas negativas dos componentes de variância através do Método de Análise de Variància, as estimativas e MVR podem näo convergir ou serem zeradas, dependendo do procedimento adotado para calculo. Isto acontece por falha dos algoritmos de cálculo que conduzem a matrizes näo singulares ou próximas da singularidade, prejudicando a convergencia dos estimadores. Em vista disso, conclui-se que uma utilizacăo mais ampla do método da MVR depende basicamente do de- 
90.

senvalvimento de procedimentos algoritmos mais eficientes.

Neste caso, sugere-se supor a populacăo finita e aplicar o métado descrito em 3.1 com as respectivos cuidados. 
100.

\section{REFERENCI AS BIBLIOGRAFICAS}

ANDEFSON, C.R. \& EAMCEOFT, T.A. Statistical Theory in Fesearch, MoGraw-Hill Book Go., Ney York, 1962 . 3ggp.

ANDERSON, T.W. Asymptotically efficient estimation of covariance matrices with 1 inear structure. Annals of Mathematical statistics, Baltimore, 1: 135, 1973.

BASSON, R.P. A comparison of variances of some estimators in the balanced incomplete block (BIB) variance components model. Biometrics, Richmond, 26: 657-669,1970.

BENNET, C. A. \& FRANKLIN, N.L. Statistical analysis in chemistry and the chemical industry. Wiley, N.Y., 1954 , $724 p$.

EEZERRA, R.C.F. O problema de estimativas negativas. São Paulo, 1976. CMestrado - Instituto de Matemática e Estatistica八sP. BBp.

BOWKER, A.H. \& LIEBERMAN, G. J. Engineering Statistics. Prentice-Hal1, Englewood Cliffs, N.J., 1963, 585 p.

Gíl, M. A. Métouos de estimaräo de componentes de variancia em modelos mistos. Campinas, 1982 . CMestrado - UNICAMPS. $1 \mathrm{ZSp}$.

CORBEIL, R.R. \& SEARLE, S.R. A comparison of variance components estimators. Biometrics, Raleigh, 32: 779-791, 1976 . 
COREEIL, F.R. \& SEARLE, S.R. Restricted maximum likelihood (REML) estimation of variance components in the mixed model. Technometrics, Richmond, 18: 31-38, $1976 \mathrm{~b}$.

CORNFIELD, J. \& TUKEY, J. W. Average values of mean squares in factorials. Annals of Mathematical Statistics, Baltimore, 27: 907-49, 1956.

DEMPSTER, A.P.; LAIRD, N.M. ; RUEIN, D. E. Maximum likelihood from incomplete data via the EM algorithm. Journal of the Royal Statistical Society. Series B. London, 39: 1,1977 .

GAYLOR, D. W. \& HARTWELL, T.D. Expected mean squares for nested classifications. Eiometrics, Raleigh, 25: 427-30, 1909.

GI ANOLA, D. \& FERNANDO, R.L. Bayesian methods in animal breeding theory. Journal of Animal Science, 63: 217,1986.

CONCALVES, N.M. Comparacăo de diversas metodologias para a análise de um delineamento aumentado com tratamentos fixos e aleatórios. Brasilia, 1984. (Mestrado - UnB).

GRAYBLL, F.A. Introduction to Matrices with Applications in Statistics. California, Wadsworth Publishing Co., 1969. $37 \mathrm{ep}$.

HARVILLE, D. A. Maximum likelihood approaches to variance components estimation and to related problems. Journal of the American Statistical Association, Washington, $320-340,1977 a$.

HARVILLE, D. A. Maximum likelihood variance component estimation and related problems. Journal of the American Statistical Association, Hashington, 72: $320,1977 \mathrm{~b}$. 
HARTLEY, H.O. \& RSO, I.W.K Maximum-1ikelihood estimation for the mixed analysis of variance model. Biometrika, London, 54: 93-108, 1957 .

HAYMAN, B.I. Maximum likelihood estimation of genetic components of variation. Biometrics, Raleigh, september, 1900. p. $369-381$.

HEMMERLE, W.J. B HARTLEY, H. O. Computing Maximum Likelihood estimates for the mixed A.O.V. model using the $W$ Transformation. Technometrics, vol. 15, 4: 819-831, 1973 .

HENDERSON, G.R. Estimation of variance and covariance componentes. Biometrics, Raleigh, 9: 2e6-25e, 1953.

HENDERSON, C.R. Applications of linear models in animal breeding. Guelph, ont, $1984 a$.

HENDERSON, G.R. Estimation of variances and covariances under multiple trait models. Journal of Dairy Science, 67: $1581,1984 \mathrm{~b}$.

HENDERSON, C.R. Recent developments in variance and covariance estimation. Journal of Animal Science, 63: 208, 1986.

HERBACH,L.H. Properties of model II type analysis of analysis of variance tests, A: optimum nature of the F-test for model II, in the balanced case. Annals of Mathematical Statisctics. Ann Arbor, 30: 939-959, 1959.

HILL, B.M. Inference about variance components in the one-way model. Journal of the American Statistical Association, Baltimore, 60: 806-25, 1965.

HILL, W. G. \& THOMPSON, R. Probabilities of nonpositive definite between group or genetic covariance matrices. Biometrics, Raleigh, 34: 429, 1978. 
HOCKING, R.R. The analysis of Linear Models. Cole Publishing Company, California, 1985.

HOCHING, R.R. \& HUTNER, M.H. Some analytical and numerical comparisons of estimators for the mixed A.O.V. madel. Bimetrics, Raleigh, 31: 19-27, 1975.

IENNRICH, R.I. \& SAMPSON, P.F. Newton-Raphson and related algoritms for maximum 1 ikelihood variance component estimation. Technometrics, vol. 18, 1: 11-17, 1976.

KLOTZ, J.H.; MILTON, R. C.; ZACKS, S. Mean square efficiency of estimators of variance components. Journal of the American Statistical Association, Boston, 64: $1383-1402$, 1969.

KLOTZ, J. \& PUTTER, J. Maximum likelihood estimation of multivariate covariance components for the balanced one-way layout. The Annals of Mathematical Statistics, vol. 40, 3: $1100-1105,1909$.

LAMOTIE, L.R. On non-negative quadratic unbiased estimation of variance components. Journal of the American Statistical Association, Washington, 68: 728-30, 1973.

LoH, L.Y. Estimators of variance components in the balanced incomplete block design. Journal of the American Statistical Association, Boston, 64: $1014-1030,1969$.

MATHER, K. Biometrical Genetics. London, Methuen and Co. Lt.d. , 1949. 162p.

MCHUGH, R.B. \& MIELKE, P. H. Jr. Negative variance estimates and statistical dependence in nested sampling. Journal of the American Statistical Association, Washington, 63: $1000-3,1958$. 
MEYER, K. Maximum likelihood procedures for estimating genetic parameters for later lactations of dairy cattle. Journal of Dairy Science, 66: $1988,1983$.

MEYER, K. Maximum likelihood estimation of variance components for a multivariate mixed model with equal design matrices. Biometrics, Raleigh, 41: 151, 1985.

MEYER, K. Eetween algoritms: A "short cut" restricted maximum likelihood procedure to estimate variance components. Journal of Dairy Science, 69: $1904,1988$.

MILLER, J.J. Asymptotic properties and computation of maximum likelihood estimates in the mixed model of the analysis of variance. Technical Report, Stanford Uni versity, 12, 1973 .

NELDER, I.A. Statistical methods in biometrical genetics. Heredity, $7: 111-19,1953$.

OLSEN, A.; SEELY, J.; BIRKES, D. Invariant ouadratic Unbiased estimation for two variance components. Annals of Statistics, 4: $878-90,1970$.

PATTERSON, H.D. \& THOMPSON, R. Recovery of interblock information when block sizes are unequal. Biometrika, Cambridge, 58: 545-554, 1971 .

PEREIRA, C. Método para contornar o problema de estimativas negativass em componentes de variância. Piracicaba, 1983. CMestrado - Escola Superior de Agricultura "Luiz de Queiroz" USPS. SPp.

PERES, C. A. \& SALDIVA, C.D. Planejamento de Experimentos. $5^{\circ}$ SINAPE, SF., 1982. 
105.

FRESS, S.J. Applied Multivariate Analysis: using Bayesian and frequentist methods of inference. 2.ed., Flórida, Robert E. Krieger Publishing Co., 1982. GoOp.

RAO, C.R. Estimation of heteroscedastic variances in 1 inear models. Journal of the American Statistical Association, Boston, 65: 101-172, 1970.

RAO, C.R. Estimation of variance and covariance components MINQUE theory. Journal of Multivariate Analysis, New York, 1 : $257-275,1971 \mathrm{a}$.

RAO, C.R. Minimum variance quadratic unbiased estimation of variance components. Journal of Multivariate Analysis, New York, 1: 4445-456, $1971 \mathrm{~b}$.

RAO, C.R. Estimation of variance and covariance components in Iinear models. Journal of the American Statistical Association, Boston, 67: 112-115, 1972.

RUSSEL, T.S. \& BRADLEY, R. A. One-way variances in a two-way classification. Biometrika, Cambridge, 45: 111-129, 1958.

SAHAI, H. 8E THOMPSON, H. O. Non-negative maximum likelihood estimators of variance components in a simplelinear model. The American Statistical, 27: 112-113, 1973.

SCHAEFFER, L.R.; WILTON, J.W.; THOMPSON, R. Simul taneous estimation of variance and covariance components from multitrait mixed model equations. Biometrics, Raleigh, 34: $199,1978$.

SEARLE, S.R. \& FAmCETI, R.F. Expected mean square in variance components models having finite populations. Biometrics, Raleigh, 26: 243-54, 1970. 
106.

SEARLE, S.R. Another laok at Henderson's methods of estimating variance components. Biometrics, Richmond, 24: $749-787,1968$.

SEARLE,S.R. ' Large sample variances of maximum likelihood estimators of variance components using unbalanced data. Biometrics, Raleigh, september 1970: 505-524, 1970.

SEARLE, S.R. Linear Models. John Willey \& Sons, New York, 1971 a. $531 \mathrm{p}$.

SEARLE, S.R. Topics in variance component estimation Cinvited papers. Biometrics, Raleigh, 27: 1-76, 1971b.

SERAPHIN, J.C. Compararão numérica de trôs estimadores de componentes de variância em alguns modelos genéticoestatisticos de cruzamento. CMestrado - Escola Superior de Agricultura "Luiz de Queiroz"/USPS. 74p. 1984.

SILVA, J.C. \& HALLAUER, A.R. Estimation of epistatic variance in Iowa Stiff Stalk Synthetic Maize. Journal of Heredity, Washington, 66: 290-290, 1975.

SWALLOW, W.H. \& MONAHAN, J.F. Monte Carlo comparison of ANOVA, MNQUE, REML and ML estimators of variance components. Technometrics, vol.26, 1: 47-57, 1984.

THOMPSON, W. A., Ir. The froblem of negative estimates of variance components. The Annals of Mathematical Statistics, Baltimore, 33: 273, 1962.

THOMPSON, R. The estimation of variance and covariance components with an application when rocords are subject. to culling. Biometrics, Raleigh, 29: 257, 1973. 


$$
107 .
$$

TIAO, G.C. TAN, W.Y. Bayesian analysis of random-effect models in the analysis of variance I. Posterior distribution of variance components. Biometrika, London, 52: $37-53,1965$.

VALENTE, I. Multiple trait variance-covariance component estimation procedures with missing information for some traits. Ames, Iowa, 1988 . CDoutorado - Iowa State Universit.y. $143 p$.

VALERIO FILHO, W. V. Métodos de Henderson para componentes de variância de dados não balanceados. Piracicaba,1983. CMestrado - Escola Superior de Agricultura "Luiz de Queiroz"

WILK, M. B. \& KEMPTHORNE, O. Some aspects of the analysis of factorial experiments in a completely randomized design. Annals of Mathematical Statistics, Baltimore, 27: 950-85, 1956. 
108.

$A P \hat{E} N D I C E S$ 


\section{APENDICE 1}

Rotina para o módulo CM do programa SOC:

Co:

Exemplos com $n=16$.

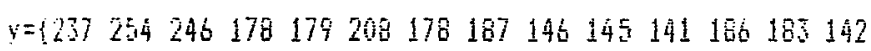

125156 ; imprime y?

$\mathrm{b}=\{1111122222233333$ migrime t;

$y=$ delinibis

ifiprige $n$

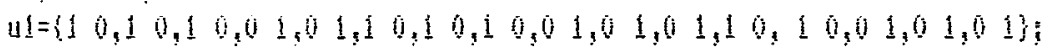

itiprite ul:

$u i=\{100000,100000,100000,010000,0100000$,

$001000,001000,001000,000100,000100,000100$.

$000010,000010,000001,000001,0000013$

igprine 42 ;

teta $0=\{22,0,35\}$; i jupige teta 0 ;

tetal=tetan[1, ]isiprige tetail

teta2=teta0[2, ] i imprine tetaz;

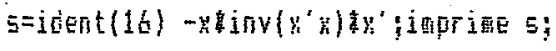

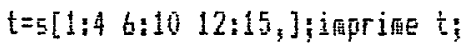

inter=1 inprige inter:

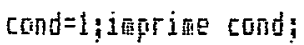

eniquanto (inter $(=20$ of cond $>.0001)$

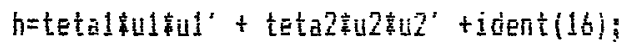

$a=t$ '

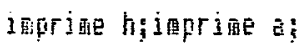

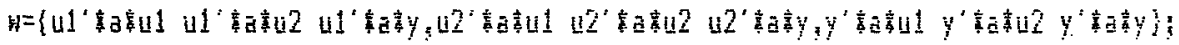

inprime $\mathrm{W}$;

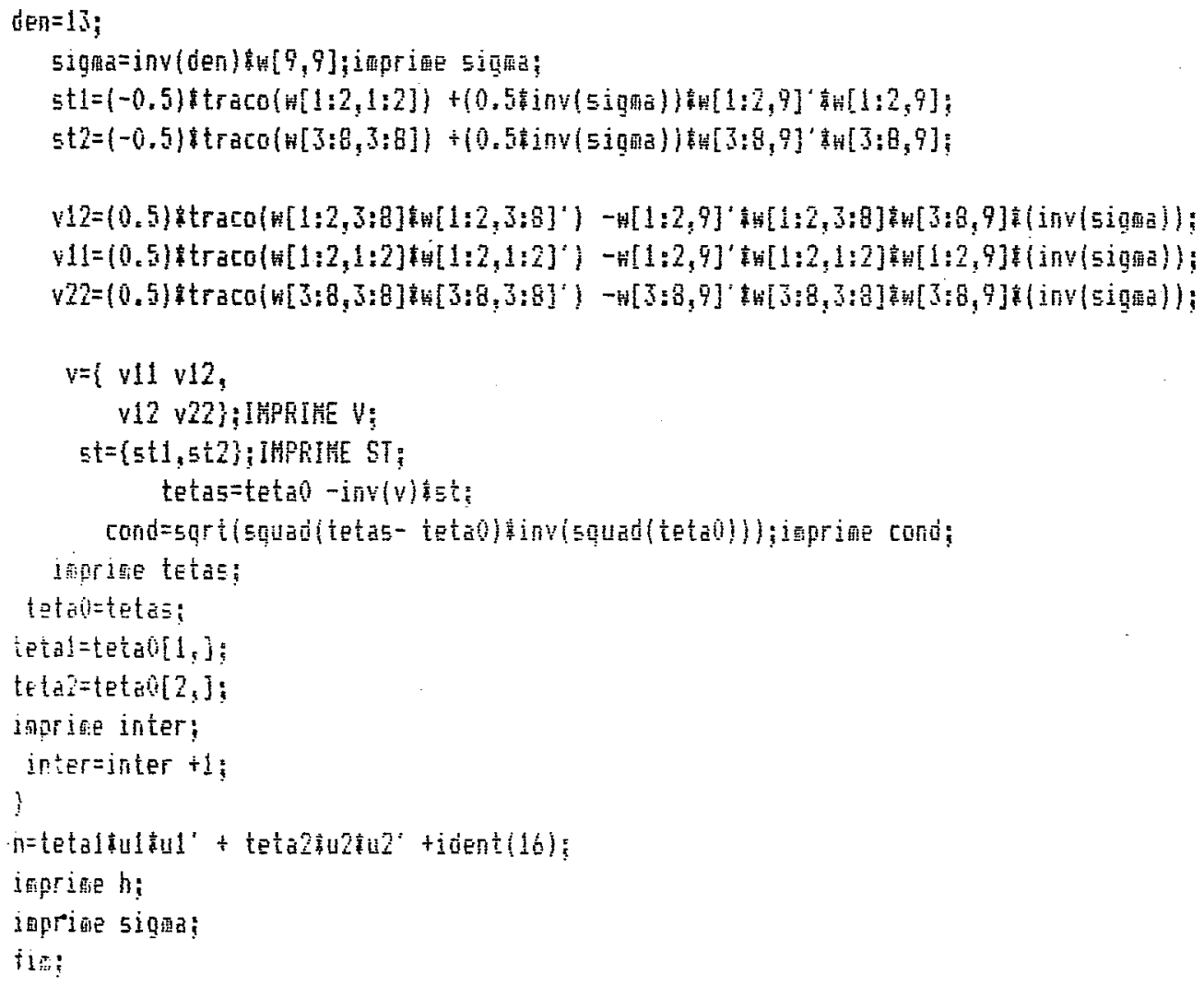


110.

Resul tados:

ESTIMATI VAS

\begin{tabular}{cccc}
\hline ITERACOES & $\alpha_{\theta}^{2}$ & $y_{a}^{2}$ & $\gamma_{t}^{2}$ \\
\hline 1 & 77,7747 & 17,5693 & 0,3520 \\
2 & 78,9207 & 18,5533 & 0,3412 \\
3 & 78,8613 & 18,5688 & 0,3417 \\
4 & 78,8468 & 18,5723 & 0,3419 \\
5 & 78,8434 & & \\
\hline
\end{tabular}




\section{APENDICE ?}

Progr ama BMDP par a MVR.

PAGE 1. BMIIFOU

BMIFSU GENEFAL HIXEN MUIEL ANALYSIS OF VAFTANCE

DMTF STATTSTICAL SOFTWAE, TNC.

1.964 WESTWOOI BLUII. SUTTE $20 \mathrm{E}$

LOS ANGELES, CA 90025

(213) $475-5700$

PROGRAM REUISER FOK FC UERSION MAY $198 A$

MAINUAL FEUISED - 1983

COFYFIGHT (C) 1983 REGENTS OF UNIUEFSITY OF CALIFORNIA

TO SEE FEHARKS AND A SUMKAFY OF NEW FEATURES FOK

THTS FROGFAH, STATE NEWS. IN THE FFINT FAFAGFAFH.

$01 / 01 / 80$

AT $06: 2 \mathrm{E}: 2 \%$

FROGFAM CONTROL INFOFMATION

/problem title is fornoins.

linput variables are 5.

format is free.

/variable names are temp, forn, $t, r$ rep, $y$.

/group codes (1) are $1,2,3$.

codes (e) are 1,2 .

codes (3) are $1,2,3,4,5,6$.

ldesign dependent is $y$.

fixed is temin.

frame $1 s$ temp.

random is forn.

rname is forn.

random is $t f$.

rname is $t f$.

lend

method=reml.

TEFENUENT WAEIABLE y

PAFAMETEK $\quad$ ESTTHATE

STAHDARI

YEUTATTON

EST/ST IIEU.

ERR VARI

CONSTANT

temp

temp

forn
78.8403890183

179.9779124668

32.8412865017

$-12.4779124687$

1464,367275420
35.35408056

27. 2342934660

4.4142006045

4. 2890998948

2090.0233913160
6. 6095009648

7. 4399399757

$-2.9092147350$ 
APENDICE 3

Procedimento VARCOMP para MVR

Exemplo 1 com $n=16$.

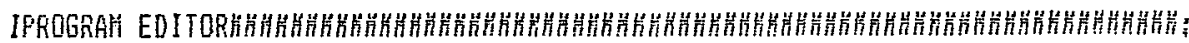

:Cufinzand $===>$

:

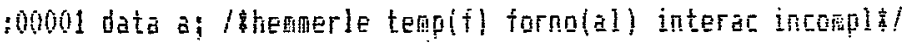

$: 00002$ input a b y ae?

$: 00003$ cards:

$: 000041125711.25411246$

$: 000051217812179$

$: 00006212082117821187$

$: 0000722146222145222141$

:00000 31 18ó 31183

50009321423212532136

$: 00010$ :

:00011 proc varcomp method=renil;

$: 00012$ class a b:

:00013 model $y=a ! b /$ fined $=1$;

:00014 run:

$: 00015$

$: 00016$

$: 00017$

300019

$: 00019$

$: 00020$

$: 00021$

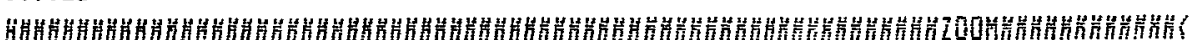

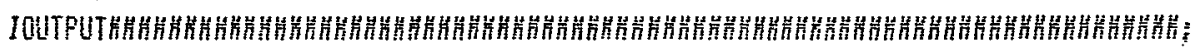

: Compand $===$ >

$\xi$

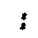

SAS 0:05 Thurstay, Septerber 29, 1980:

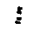

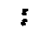

; Restricted hayimum Likelihoud Variance Components Estimation Procedure

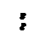

inependent Variable: Y

:

;

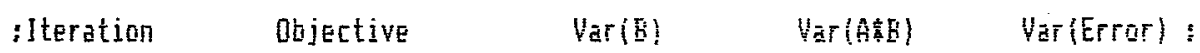

;

0

: 1

$63 . \div 1341449$

1269.52701231

0.00000001

$91.5501173:$

$: 2$

33.41205906

1274.06210053

0.0000000

91. 5697150 :

: 3

63. 41253042

1278.46760635

0.60600059

$71.49690490:$

: 4

63.41194803

1222.71474020

0.60000245

$71.45214787=$

$: 5$

$63.4113872 \mathrm{x}$

1784.84427407

0.00001527

91.44037695 :

$: 6$

63.41095072

1290.85797978

0.00009504

91.41.55099:

$: 7$

63.41052359

1294.76232525

0.00050136

$91.39727724:$

$: 9$

63.41003186

1293.5360905

$0.003 \operatorname{son} a 1$

$71.3602476=$

$: 9$

63.40900595

1302.06417710

0.02292164

$91.32 \times 67959$ :

63.40454952

1304.59434764

0.1433559

$91.2232027 \%$ :

$: 10$

63.37851777

1301.30706353

0.91933326

$70.71312399 ;$

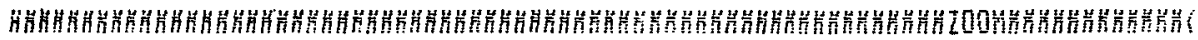




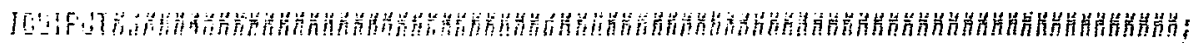

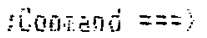

;

$: 11$

6.21813200

1257.57386968

7.12220390

$97.31202831:$

63.13163622

1248.18873174

48.32754577

$76.11587489:$

$: 13$

63.03332748

1494.12602156

24.36570376

$79.37616680:$

63.03118016

1456.21221616

26.57922509

78.97727508 :

63.03113001

1462.37517647

26.86895447

70.87443012 :

$63.03112671 \quad 1463.90213561$

26.73755220

$72.84793342:$

63.03112652

1464.25825754

26.95324207

$78.84416193:$

63.03112651

1464.34169199

26.95767589

78.84280590 :

63.03112651

1464.36126968

26.95857643

$78.94248750:$

Convergence criterion at. 


\section{APËNDI CE 4}

Procedimento VARCOMP para MV:

Exemplo 1 com $n=16$.

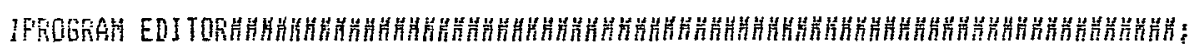

:Cughand $==$ ?

$;$

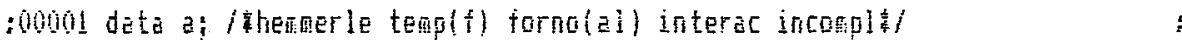

:00002 input a b y $\mathrm{As}^{\mathrm{a}} \mathrm{a}$;

30000 cards; :

, 00004112371125411246

:000051217812179:

:00006 212082117821187

$: 00007221462214522141$

900083118631183

50000321423212532136

:00010:

:00011 proc varcomp apthod=nl!

:00012 class a b;

:00013 model $y=a$ ib / fixed=1; :

:00014 run;

300015

$: 00016$

$: 00017$

50018

500019

, 00020

.00021

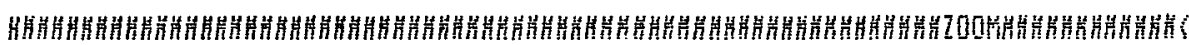

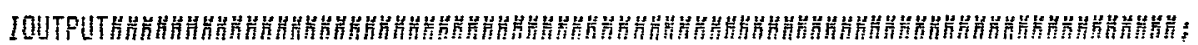

; Comfind $===>$

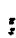

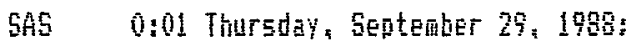

: Marirug Likelihood Variance Components Estindtion Procedure

:

:Dependent Variable: Y

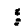

:

IIteretion Ohjective Var(B) Var(AsB) Ver(error):

:

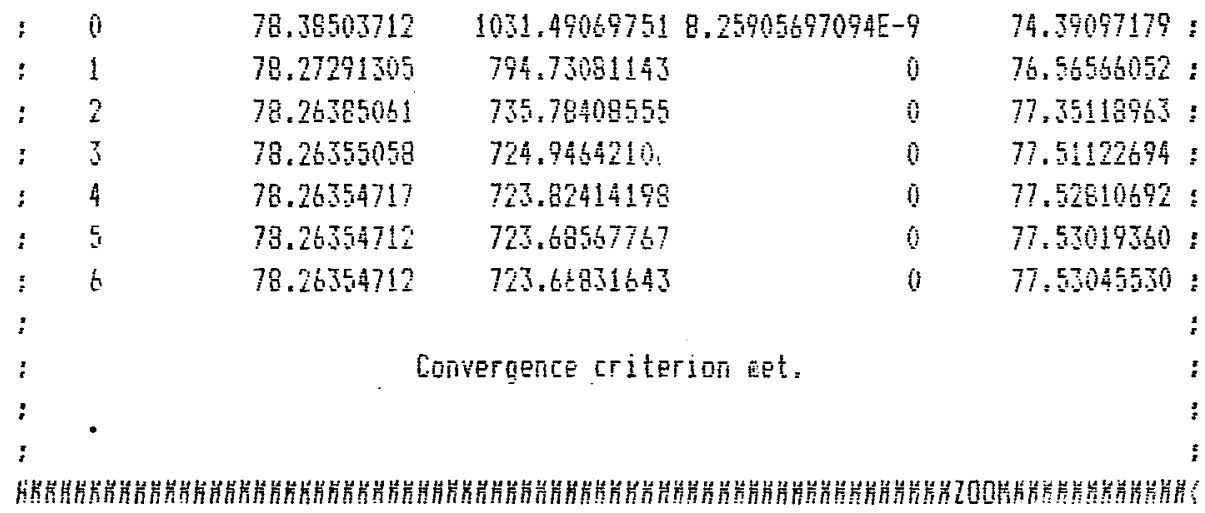




\section{APENDI CE 5}

Frocedimento VARCOMP para MVR

Exemplo $1 \mathrm{com} n=18$

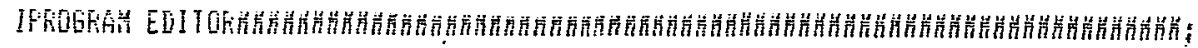
:Comint $==3$

;

:00001 data à / homerlel templfi forndal) complin

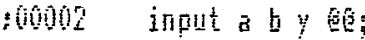

.0000 cards:

500004112371125411246

500005121781217912183

00006212002117821187

00007221462214522141

900003311863118331192

$: 00009321423212532136$

$: 00010$ :

s0o011 proc varcoan aethod=real?

$\$ 00012$ class a b;

s00013 wodel $y=a$ ib / tixed=i:

:00014 run?

s00015

100016

$\div 00017$

$: 60018$

$: 00019$

000020

$\div 00021$

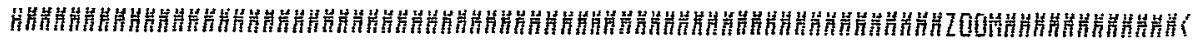

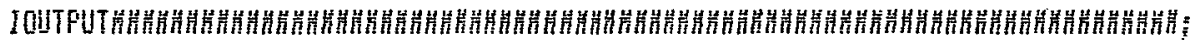

:Cominad $===$ ?

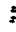

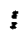

Thursoly, September 28,19

F Restricted Heximuni Likelihood Variance Components Estiration Procedure

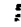

:Dependent Variable: Y

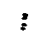

$\overline{5}$

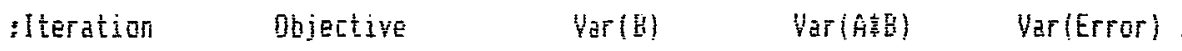

$\frac{2}{\tau}$

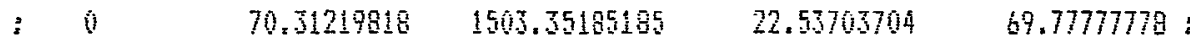

: $1 \quad 70.31219516 \quad 1503.35185105 \quad 22.53703704 \quad 69.7777779:$

;

: Converoerce criterion at. 
116.

APENDICE 6

\section{Procedimento VARCOMP para MV \\ Exemplo 1 com $n=18$.}

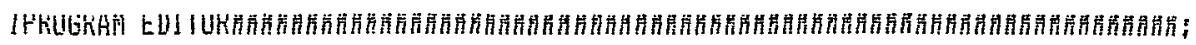

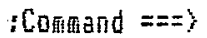

:

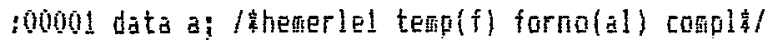

:00002 input a b y equ

$: 00003$ [ärds:

90004112371125411246

300005121701217912183

$: 00006212082117821187$

5000072214622214522141

:00006 3118631183 31192

.00009321423212532136

$500010 ;$

:00011 proc varcưp method=en!

:00012 class a ba

;00013 codel $y=a$; / fixed $=1$;

500014 run:

:00015

100016

$\$ 00017$

500018

$\$ 00019$

$: 00020$

500021

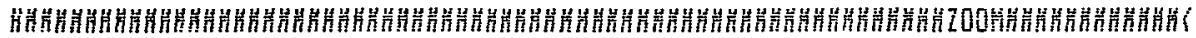

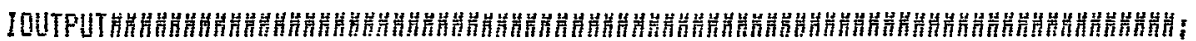

rCominand $==3$

:

;

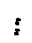

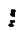

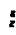

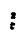

: Dependent Variable: y

Hayiqun Likelihood Variance Coaponente Estimation Procedure

SAS 0,05 Thurcday, Sententer 27, 1998:

:

$:$

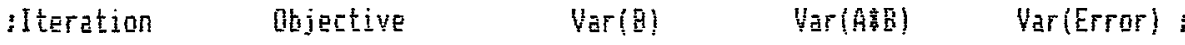$$
\text { ; }
$$

;

$\because 0$

$86.39892129 \quad 1252.79320939$

19.78086420

[0. 18497395

5.48908224

$59.14814815:$

85.90957421

932.29251167

812. 82521775

85.61152703

694.71471224

85.52250789

737.13884221

85.5209984

749.64814623

85.52207261

751.36437297

85.52207251

751.56098376

85.52209251

751.52290569

$62.34295079:$

65.43127701 :

0) $70.3549326 b^{\prime}:$

$0 \quad 89.67564538:$

$0 \quad 69.52914969$ :

:

?

0

59.50947399 :

0 $\quad 69.50722632$;

$: 8$

Convergence criterion ret.

$0 \quad 6950597577$ :

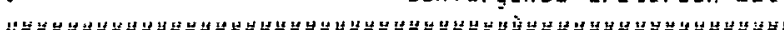


Rotina para o módulo CM do programa Soc:

Exemplo 3

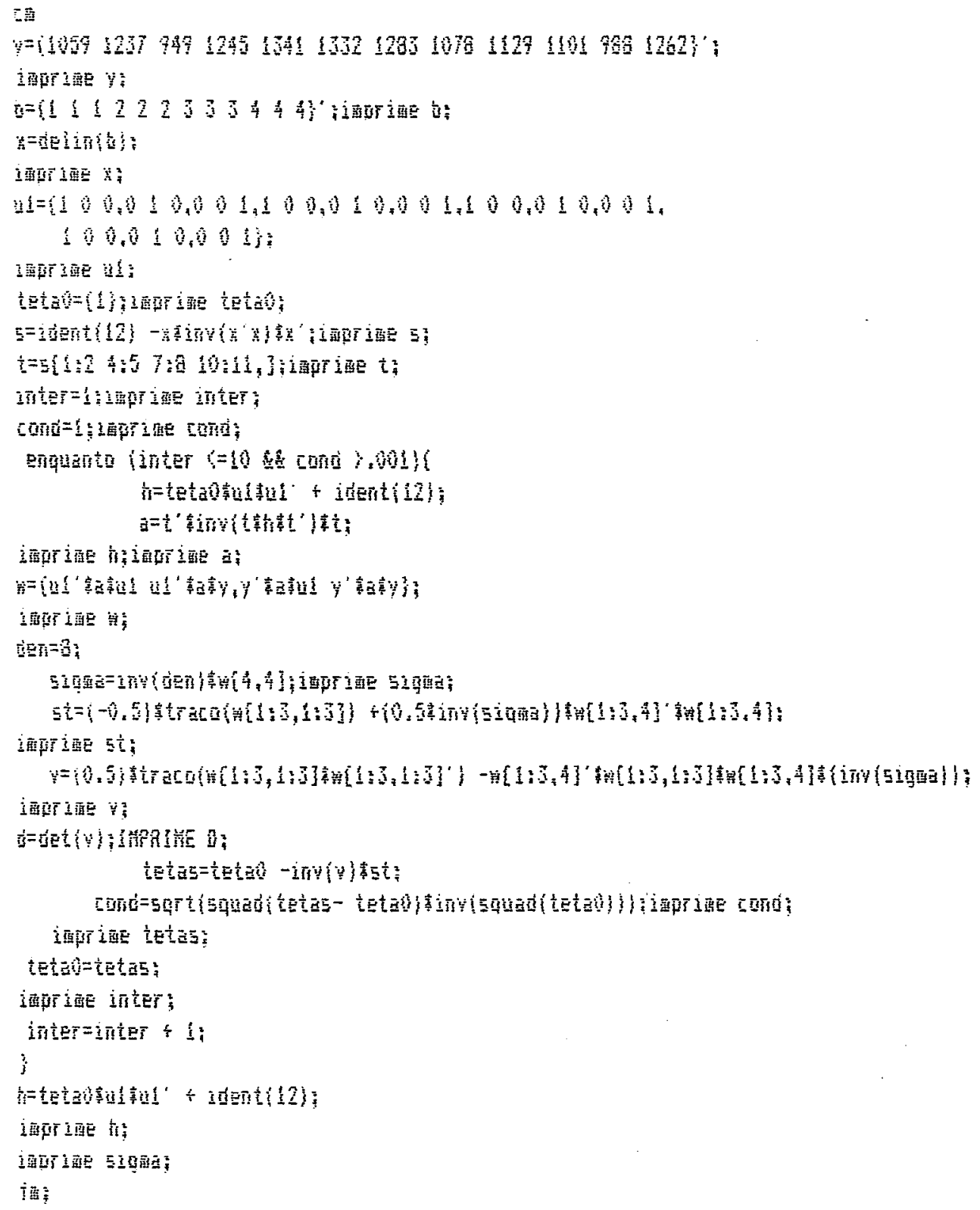


118.

Resul tados:

\begin{tabular}{ccc}
\hline \multicolumn{2}{c}{ ESTIMATIVAS } \\
\hline ITERACOES & $\sigma^{2}$ & $\gamma$ \\
\hline 1 & 13694,916667 & $-0,147511$ \\
2 & 13615,534555 & $-0,042539$ \\
3 & 13577,291168 & 0,167058 \\
4 & 13588,499308 & 0,586424 \\
5 & 13549,182308 & 1,425148 \\
6 & 13544,543125 & 3,102590 \\
7 & 13542,228312 & 6,457473 \\
8 & 13541,072094 & 13,167236 \\
9 & 13540,494282 & 26,586763 \\
10 & 13540,205450 & 53,000000 \\
\hline
\end{tabular}

